\title{
AN EVALUATION OF THE RELATIONSHIP BETWEEN SELF-ESTEEM AND PET BONDING IN CHILDREN
}

A Dissertation presented to the Faculty of the Graduate School

University of Missouri

In Partial Fulfillment

of the Requirements for the Degree

Doctorate of Philosophy

\author{
By \\ PAMELA L. EVANS-SMITH \\ Dr. Rebecca Johnson, Dissertation Supervisor
}

DECEMBER 2014 


\section{Copyright}

(C) Copyright by Pamela L. Evans-Smith 2014

All Rights Reserved 
The undersigned, appointed by the Dean of the Graduate School, have examined the dissertation entitled

\section{AN EVALUATION OF THE RELATIONSHIP BETWEEN SELF-ESTEEM AND PET BONDING IN CHILDREN}

Presented by Pamela L. Evans-Smith

A candidate for the degree of Doctor of Philosophy

And hereby certify that in their opinion it is worthy of acceptance.

Rebecca A. Johnson

Tina L. Bloom

Sara E. Gable

Larry H. Ganong

Debra A. Gayer 


\section{DEDICATION}

I would like to dedicate this work to my husband, Kevin Smith and to my children, Jonah, Erika, Cooper, and Benton. Without their support I could not have completed this endeavor. Thank you for understanding the many times I stayed in the dog kennel to make a deadline and when I worked on revisions at the soccer field, football field, and swimming pool while cheering you on.

I would like to thank my parents, Jack and Mary Evans. Your encouragement and challenges (well if that's the best you can do) have kept me from giving up. Thank you for always being supportive and instilling in me the value of an education. I know that you will be with me as I accept my diploma.

I would like to thank Dr. Cheryl Bausler and Dr. Roxanne McDaniel. You both have served many roles while I have completed this journey- cheerleader, sounding board, and motivator to name a few. Did I mention that I was on the lifetime plan?

I would like to thank my colleagues and students at the school of nursing. Colleagues, thank you for your words of encouragement and for taking a heavier load so that I could finish my journey. Students, thank you for helping me keep everything in perspective and for reinforcing that education is where I belong.

Finally I would like to thank Mr. Fred Graham for always seeing my true potential. You are one of the reasons that I entered into the field of education. I hope that I have the same impact on my students. 


\section{ACKNOWLEDGEMENTS}

I would like to thank my dissertation committee for all of their support and encouragement. I feel very fortunate to have been the recipient of their guidance and knowledge. My dissertation advisor, Dr. Rebecca Johnson, has been a steadfast mentor during this process. She has pushed me to complete the journey. Her sense of humor and calm manner has kept me going. Dr. Larry Ganong showed me the influence that family dynamics have on children. Dr. Deb Gayer shared her passion for the health of children. Dr. Sara Gable helped me to think outside of the box when looking at the problems associated with childhood obesity. Dr. Tina

Bloom has showed me that nutrition education needs to start early. Dr. Kay Libbus showed me that there are numerous ways to reach your goals. 


\section{TABLE OF CONTENTS}

ACKNOWLEDGEMENTS............................................. ii

LIST OF FIGURES.................................................. vii

LIST OF TABLES .................................................... viii

ABSTRACT ............................................................. ix

Chapter

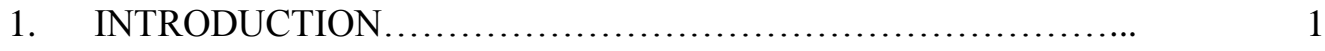

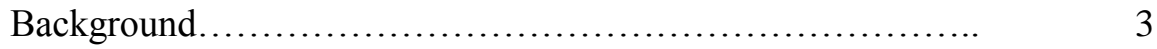

Childhood Obesity................................... 3

Self-Esteem and Obesity............................ 4

Human-Animal Interaction......................... $\quad 5$

Significance of the Study................................. 8

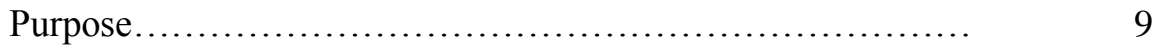

Research Questions..................................... 9

Definition of Terms....................................... $\quad 10$

Conclusion............................................. 11

2. REVIEW OF RELATED LITERATURE...................... 12

Childhood Obesity..................................... 12

Body Mass Index................................. 13

Health Problems of Obesity.......................... 17

Self-Esteem............................................ 17

Unidimensional Versus Multidimensional Model.......... 20

Domains......................................... 22

State or Trait Self-Esteem........................... $\quad 23$

Influences on Self-Esteem.............................. 26 
Media Influence...................................... 28

Peers' Influence........................................ 31

Parental and Family Influence......................... 33

Human Animal Interaction History $\ldots \ldots \ldots \ldots \ldots \ldots \ldots \ldots \ldots \ldots . . \ldots \ldots$

Obesity and HAI........................................ 37

Physiological Effects of HAI............................... 37

Cardiovascular Effects................................. $\quad 37$

General Health Complaints........................... $\quad 40$

Activity Levels..................................... 41

Psychological Effects of HAI................................ 43

Loneliness............................................ 43

Depression............................................... 43

Animals as Members of the Family............................ 44

Human-Pet Relationship.................................. 46

Empathy and Prosocial Behavior............................ 47

Animals and Social Support................................. 48

Theoretical Framework......................................................... 49

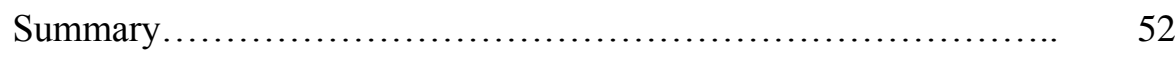

3. DESIGN AND METHODS ......................................... 53

Design, Setting and Participants............................. 53

Study Design ....................................... 53

Research Questions................................. 53

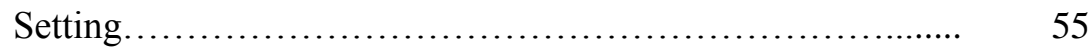

Participants........................................ 57 
Recruitment............................................. $\quad 60$

Measures.................................................... 63

Self-Perception Profile for Children...................... 64

Pet Bonding Scale ..................................... 67

Demographic Questionnaire............................... $\quad 69$

Data Collection............................................ $\quad 69$

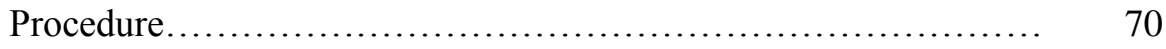

Human Participant Protection................................ $\quad 71$

Data Management........................................ $\quad 72$

Data Analysis.............................................. $\quad 73$

4. $\quad$ RESULTS .................................................... 75

Demographic Characteristics of the Sample.................... 78

Pet Ownership Characteristics.............................. 81

Hypotheses Testing........................................ 86

Other Findings......................................... 89

Performance of the Study Instruments........................ 91

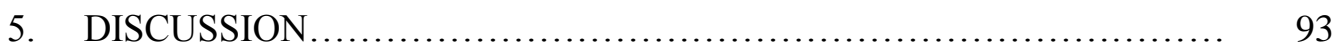

Discussion of Dependent Variables in Current Literature........... 93

Self-Esteem in Children............................... 93

Pet Bonding....................................... 97

Anthropomorphizing................................. 100

Strengths and Limitations................................ 101

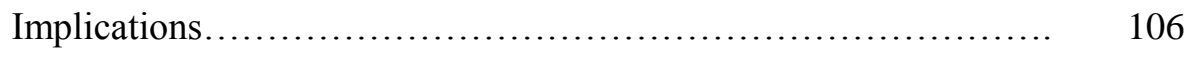

Future Research........................................ 107

REFERENCES....................................................... 109 


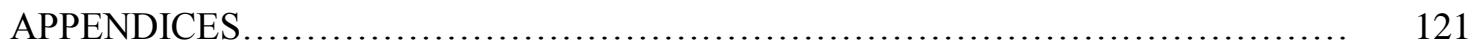

Appendix A Consent Form to Participate in a Research Study................ 121

Appendix B Assent Form to Participate in a Research Study................. 124

Appendix C Self-Perception Profile for Children........................... 126

Appendix D Pet Bonding Scale........................................ 128

Appendix E Demographic Questionnaire.................................. 132

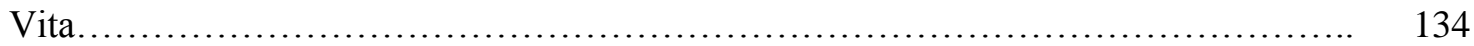




\section{LIST OF FIGURES}

Figure Page

1. Unidimensional Self-Esteem Model...................................... 20

2. Multidimensional Self-Esteem Model................................... 21

3. Sample Question from the Manual for the Self-Perception Profile for Children.. 65

4. Groups of Participants............................................ 76 


\section{LIST OF TABLES}

Table

Page

1. Groups of Participants............................................... 53

2. Descriptive Statistics for SPPC \& PBS ............................... 77

3. Demographic Characteristics of Participants............................. 79

4. Means of BM I, BMI Percentiles and z scores for participants................ 81

5. Characteristics of Pet Ownership ..................................... 82

6. Correlation Coefficients............................................... 85

7. Test of Between-Subjects Effects with Self-Esteem as the Main Effect......... 86

8. Test of Between-Subjects Effects with Pet Bonding Scale Score as the Main Effect...............................................................

9. Test of Between-Subjects Effects with Scores from Selected Items on the PBS as the Main Effect..................................................... 89

10. Test of Between-Subjects Effects with Self-Esteem as the Main Effect and Dog Ownership and BMI Percentile as Interactive Effects......................... 90

11. Univariate ANOVA Physical Appearance and Social Acceptance Scores with Dog Ownership.................................................. 92

12. Comparison of Harter's Sample with the Sample from the Current Study....... 94 
AN EVALUATION OF THE RELATIONSHIP BETWEEN SELF-ESTEEM AND PET

BONDING IN CHILDREN

Pamela L. Evans-Smith

Dr. Rebecca Johnson, Dissertation Supervisor

\section{ABSTRACT}

Obesity has been linked to many physical as well as psychological problems. Many children who are obese suffer from low self-esteem. No studies have been published documenting the effect of owning a dog on the self-esteem of children who are obese. This study used a non-experimental, descriptive, four-group comparison design. One-hundred-twenty participants comprised the four groups: obese children with a dog, obese children without a dog, children of a healthy weight with a dog, and children of a healthy weight without a dog. Participants who were in the $85^{\text {th }}$ percentile or higher for their height and weight were placed in the obese group. All participants completed the Self-Perception Profile for Children (SPPC) and participants who owned a dog that lived in the house at least $50 \%$ of the time also completed the Pet Bonding Scale (PBS). The four groups were similar on most demographic characteristics. Obese children had lower scores in the domains of Physical Appearance, Social Competence, and Self-Worth. Participants in the study who owned a dog, both obese and of a healthy weight, were more likely to have lower Physical Appearance and Behavioral Conduct scores. All 60 participants in this study who owned a dog considered the dog to be a member of their family. The findings of this study can be used as the basis for future studies evaluating the relationships between dog ownership of obese children and effects on self-esteem. 


\section{Chapter 1}

\section{Introduction}

Obesity in childhood is a societal problem that is increasing at an alarming rate. In $1974,5 \%$ of $2-5$ year olds in the United States were considered obese, while by 2004 this had increased to $13.9 \%$; the incidence of obesity in 6-11 year old children increased from $4 \%$ to $18.8 \%$; and the incidence of obesity in $12-19$ year old adolescents increased from $6.1 \%$ to $17.4 \%$ (Centers for Disease Control, 2004). Children who are obese have a greater chance of remaining obese into adulthood (Moran, 1999; Speiser et al., 2005). The longer the duration of obesity, the greater the number and seriousness of comorbidities associated with the obesity. According to the Centers for Disease Control (2010), in 2008, the annual healthcare cost of obesity and associated co-morbidities in the US was estimated to be $\$ 147$ billion per year. The Centers for Disease Control (2010) also reported that the annual costs for medical treatment of obesity and co-morbidities associated with obesity, increased to $9.1 \%$ in 2006 compared with $6.5 \%$ in 1998 . As more children become obese, the annual costs for medical treatment of obesity and comorbidities associated with obesity will continue to rise.

The immediate physical health problems associated with obesity have been well documented in the literature: type 2 diabetes, sleep apnea, hyperlipidemia, hypertension, cardiovascular disease, and stress to joints (Dietz, 1998; Narayan, Boyle, Thompson, Sorenson, \& Williamson, 2003). These health concerns not only affect adults but also children who are obese. More children than ever before under the age of 16 years, are being diagnosed with type II diabetes, hypertension and joint problems (Copeland et al., 2013; Gortmaker, Must, Perrin, Sobol, \& Dietz, 1993; Kagan, 2010; Moran, 1999; Nolan, 
Damm, \& Prentki, 2011; Speiser et al., 2005). Children who are obese are not only faced with physical health care problems but also with mental health issues such as low selfesteem, depression, and other mood disorders (Cameron, 1999; Israel \& Ivanova, 2002; Pierce \& Wardle, 1997; Sjoberg, Nilsson, \& Leppert, 2005; Strauss, 2000; Strauss \& Pollack, 2003). Low self-esteem has been shown to lead to depression (Battle, 1978). Once children become obese, a cycle may begin in which depression develops due to their feelings about their body size, they may then seek comfort in food, thereby compounding the obesity which in turn may worsen the depression (Zeller, Saelens, Roehrig, Kirk, \& Daniels, 2004). Without proper guidance and interventions, obese children will become obese adults (Moran, 1999; Speiser et al., 2005).

In addition to the physical and mental health care issues that people with obesity deal with, they also deal with the stigma of obesity in society (Brownell, Puhl, Schwartz, \& Rudd, 2005; Fouts \& Burggraf, 1999; Fouts \& Burggraf, 2000). While numerous studies have researched ways to increase obese children's weight loss, none have looked at how to increase children's self-esteem in ways other than weight loss. While weight loss is needed, if obese children are depressed, this may inhibit their ability to exercise. If obese children become aware of the stigma that society has associated with obesity, the stigma may cause further low feelings of self-esteem and worsening depression. This may be a continuous cycle throughout the child's life unless interventions occur. While changing society's view of obesity is not impossible, it will take years. Because of the length of time needed to change society's view, many children who are obese will still have to face the stigma associated with obesity while work is being done to change society's view. Something must be done for the children who are obese while they are 
dealing with the stigma placed on obesity. Teaching obese children coping mechanisms in how to deal with this stigma associated may help break the cycle.

\section{Background}

Childhood obesity. Children who are obese are scrutinized and judged by family, peers, and other adults (Crandall, 1995; Davison \& Birch, 2001; Latner \& Schwartz, 2005; Tiggemann \& Anesbury, 2000). Some of these adults have authoritative roles in children's lives, while others are random adults with whom children come into contact. Children who are obese are not immune to the stigma that accompanies obesity. Obese children are less likely to be chosen as a friend or identified by other children as popular (Bell \& Morgan, 2000; Latner \& Stunkard, 2003; Phillips \& Hill, 1998), and more likely to be thought of as being "bad" (Cramer \& Steinwert, 1998). Obese children also experience teasing about their weight by both family and friends (Eisenberg, Neumark-Sztainer, \& Story, 2003). The disapproval felt by obese children from their family does not stop after puberty. Parents continue to demonstrate disdain towards obese children in many different ways including differential allocation of financial support. Crandall (1995) found that girls who were overweight experienced feelings of prejudice from their parents by not receiving as much financial assistance to attend college compared with siblings who were not overweight and when compared with other families who had children who were not overweight. If parents are not viewed as supportive to the children, it may be that they turn to other family members for support and positive regard. The question arises, will obese children turn to the family pet instead of peers, the school nurse, their teacher, or their parents if they do not receive appropriate validation from other humans? 
Unfortunately, health care providers (Fabricatore \& Wadden, 2004; Klein, Najman, Kohrman, \& Munro, 1982; Teachman \& Brownell, 2001) and teachers have also been shown to display prejudice toward obese children (Neumark-Sztainer, Story, \& Harris, 1999). To children, a teacher or health care provider represents a person who is a role model and a trusted adult. To be rebuffed by these adults results in another detriment to children's self-esteem (Swann \& Seyle, 2006).

Children who are obese are also more likely to remain obese as adults (Moran, 1999; Speiser et al., 2005). Obese adults find discrimination when applying for jobs (Fikkan \& Rothblum, 2005), seeking promotions (Fikkan \& Rothblum), and they have more problems with romantic interests than thin people (Sobal, 2005). By beginning to address obesity in children we may be able to change the subsequent negative outcomes in adulthood. While we may not be able to immediately change how society views obesity, we may be able to help children who are obese change how they view themselves and ultimately improve their self-esteem.

Self-esteem and obesity. Numerous studies have reported the relationship between childhood obesity and self-esteem levels. Findings demonstrate an inverse relationship between children's body mass index (BMI) and level of self-esteem (French, Perry, Leon, \& Fulkerson, 1996; Kaplan \& Wadden, 1986; O’Dea, 2006; Strauss, 2000; Tiggemann \& Wilson-Barrett, 1998). This inverse relationship begins around the age of five years in girls (Davison \& Birch, 2002) and is similar in boys (Kaplan \& Wadden, 1986; Klesges, Haddock, Stein, Klesges, Eck, Hanson, 1992). One factor that can increase obese male children's self-esteem is their father's view of children's body build and the effect that the body build may have on children's sports capabilities (Felker, 
1968). This may be due to the fact that if a boy is husky, people will often comment on him as a "future" football player, while a boy who is thin is not frequently associated with starring in athletics. While this may help the male child's perception of self from the view point of some adults in his life, it does not prevent other family members such as siblings or peers from making comments that may diminish the child's self-esteem.

There are many factors that may have an effect on obese children's self-esteem. As previously cited, the low self-esteem associated with obesity, may be due to children's feelings of social stigmatization, feelings of not being accepted by family and friends, and feelings of inadequacy. According to Mruk (2006), one way to increase feelings of self-esteem is by providing acceptance. If obese children are not accepted by people in their lives, it may be reasonable to ask whether or not they may find unconditional love and acceptance from a companion animal such as a dog.

Human animal interaction. While obese people may experience intolerance by other people, they do not experience feelings of discrimination from companion animals. Unlike people, companion animals do not judge a person by body size. Many researchers have reported that people who own companion animals state that their pet loves them no matter what (Bryant, 1985; Melson, Schwarz, \& Beck, 1997; Triebenbacher, 1998a; Triebenbacher 1998b).

Anthropomorphism is the assigning of human characteristics to a nonhuman. Triebenbacher (1998b) found that $98 \%$ of the children in her study $(\mathrm{N}=174)$ assigned human feelings to their pets such as happiness, sadness, and feeling scared. This feeling that the pet has humanistic qualities, may be one reason a pet may be beneficial to obese children who are feeling the stigma of being obese. Levinson (1978) and Melson, 
Schwarz and Beck (1997) found that while children should receive unconditional positive regard from a parent, they may not be receiving this from their parent, but may instead; receive this unconditional positive regard from a pet. Veevers (1985) referred to this use of a pet as a surrogate. Veevers hypothesized that this human-pet relationship may supplement children's need for human-human relationships or in some extreme cases, the human-pet interaction may actually be a replacement for human-human relationships.

Researchers reported that children turned to their pets during happy times, but also during times of emotional distress due to the perceived support that the pet offered (Bryant, 1985; Melson et al., 1997; \& Triebenbacher, 1998 a \& 1998b). The relationship with the pet may even be stronger for obese children, because these children may feel negatively judged by humans while the pet always accepts them. The unconditional love offered by a pet, specifically a dog, may not replace the approval or acceptance that the children are looking for from the adults and peers in their life but it may help to supplement their need for approval and acceptance. It may be one source that they can count on for approval during challenging periods of growth, developmental changes, and adjustments associated with school and friendship groups (Triebenbacher, 1998a).

Numerous studies have suggested that human animal interaction may have significant beneficial effects on physical and mental health such as by lowering blood pressure, promoting weight loss, and alleviating feelings of loneliness, depression, and improving self-affection (Allen, Blasovich, \& Mendes, 2002; Anderson, Reid, \& Jennings, 1992; Baun, Bergstrom, Langston, \& Thoma, 1983; Bryant, 1990; Dembicki \& Anderson, 1996; Folse, Minder, Aycock, \& Santana, 1994; Friedmann, Katcher, Thomas, Lynch, \& Messent, 1983; Friedmann \& Thomas, 1995; Havener, Gentes, Thaler, Megel, 
Baun, Driscoll et al., 2001; Serpell, 1991; Zasloff \& Kidd, 1994). These effects have been found not only in cases where participants already had established relationships with a pet; but also in cases where participants derived these benefits through interacting with an animal previously unknown to them.

The literature leads us to believe that in some instances, a bond does not have to have been formed with the animal in order for the person to benefit from the interaction with the animal. This may mean that the mere presence of an animal may have a positive effect on a person's emotional well-being. Oxytocin is a peptide hormone that has been shown to be related to social attachment (Nagasawa, Kikusui, Onaka, \& Ohta; 2009). Nagasawa, Kikusui, Onaka, and Ohta (2009) found that oxytocin levels increased in people just by seeing their dog gazing at them. Odendaal and Meintjes (2003) found that oxytocin levels rose in humans after interacting with dogs. This increase occurred in people who were interacting with their own dogs as well as with unfamiliar dogs.

For instance, having an unfamiliar companion animal present during a physical exam was shown to decrease children's behavioral distress (Hansen, Messinger, Baun, \& Megel, 1999). The simple presence of the dog during the exam was enough to help children relax. Similarly, another study showed that a bond with an animal may be formed over a very short period of time which may be associated with a decrease in depression (Folse, Minder, Aycock, \& Santana, 1994). In this study participants were introduced to an unfamiliar dog and met with the dog weekly for 45 minutes during a seven-week period. At the end of the seven-week period, the participants' depression index scores had decreased. Other studies have shown that bonds formed with pets over longer periods of time have a profound effect on a person's health. Friedmann, Katcher, 
Lynch, and Thomas (1980), found in two large studies that patients who owned pets had a greater chance for survival one year after suffering from an acute myocardial infarction (Friedmann \& Thomas, 1995).

The person does not need to know the animal nor does the person need to be touching the animal in order to derive the benefits from the interaction. In each case, the findings support the notion that either the interaction and/or a bond with an animal have a positive effect on the mental and physical health of the individual.

\section{Significance of the Study}

Animals are known for their ability to accept and love unconditionally (Bryant, 1985; Melson, Schwarz, \& Beck, 1997; Triebenbacher, 1998a; Triebenbacher 1998b). Because children who are obese may feel that they are being discriminated against or scrutinized by others when performing tasks (Foster \& Page, 2006; Latner \& Schwartz, 2005), the study reported here provides useful data describing the relationship that obese children may have with their pet dogs and identifies whether or not there are differences or similarities in this relationship between healthy weight and obese children. The study shows the extent to which children who are obese recognize the unconditional love and acceptance offered by an animal and count it as an unconditionally accepting friend. If children feel that they are being accepted this may increase their level of self-esteem (Mruk, 2006) and help them deal with society's stigma of obesity. While their weight may not change, their self-perception may change in a positive manner thus increasing their self-esteem. The study also describes the relationship between children's selfesteem and the strength of the bond formed between them and their family dog. While numerous studies have been completed in which efficacy of weight loss strategies for 
obese children have been evaluated, no other study has looked at factors that may positively change obese children's self-esteem outside of any weight loss program. Increasing obese children's self-esteem may have a positive effect on children's level of depression. Because poor self-esteem may lead to depression, by increasing children's self-esteem we may be able to directly decrease their depression.

\section{Purpose}

The purpose of this study was to examine the association among the strength of the bond formed between obese children and their dog and the impact that this bond may have on the children's self-esteem.

\section{Research Questions}

The study addressed the following research questions:

1. What is the difference in self-esteem between obese children who have a family dog and obese children who do not?

H1: Obese children who have a family dog will have higher self-esteem than obese children without a family dog.

2. To what extent are obese children more strongly bonded with their family dog than children of a healthy weight?

$\mathrm{H} 2$ : Children who are obese will have a significantly stronger bond with their dog than children who are of a healthy weight.

3. What is the difference in self-esteem levels between children who have a family dog and children who do not have a family dog?

H3: Children who have a family dog will have higher self-esteem than children who do not have a family dog. 
4. To what extent do children anthropomorphize the family dog?

H4: Obese children will anthropomorphize the family dog more frequently than children who are of a healthy weight.

5. To what extent is the strength of the bond with their family dog associated with obese children's self-esteem?

H5: Obese children who have a stronger bond with their family dog will have higher self-esteem than obese children with a weaker bond with their family dog.

\section{Definition of Terms}

For the purpose of this study the following definitions of terms were used:

1. Body Mass Index (BMI): A number calculated from a person's weight and height in order to gain knowledge about a person's extent of body fat; it is also used to screen for weight categories that may lead to health problems $\left(\frac{\text { weight }}{\text { height } 2}\right)(\mathrm{CDC})$.

2. Human Animal Bond: The relationship that is formed between a person and an animal that is well known to the person; for this study the bond will be scored by using Angle's Pet Bonding Scale. The instrument has a possible score range from $25-75$ points. A score of $\geq 70$ will be considered a strong bond.

3. Human Animal Interaction: Contact between an animal and a person; this can be with a known animal or a newly acquainted animal.

4. Healthy weight: A Body Mass Index lower than the $85^{\text {th }}$ percentile (CDC).

5. Obesity: A Body Mass Index at or above the $95^{\text {th }}$ percentile (CDC).

6. Overweight: A Body Mass Index at or above the $85^{\text {th }}$ percentile and lower than the $95^{\text {th }}$ percentile (CDC). 
7. Self-esteem: People's perceptions of themselves which are formed through the experiences in the environment and especially influenced by environmental reinforcements and significant others (Shavelson, Hubner, \& Stanton, 1976); can be used interchangeably with self-perception.

8. State self-esteem: The ordinary fluctuations in people's feelings about themselves; these fluctuations can be influenced by normal every day operations, these fluctuations are seen as a state because they will not change the overall trait self-esteem; a specific situation may decrease or increase a person's self-esteem at that moment in time (Leary, 1999; p. 33).

9. Trait self-esteem: An expression of how people view themselves generally and how they feel others perceive them (Harter, 1999).

\section{Conclusion}

Childhood obesity continues to be a major health care concern in the United States. The impact of obesity is not only on children's physical health but can also be detrimental to their mental health and self-esteem. Children who are obese may experience negative teasing and discrimination throughout their lives. This teasing and discrimination may come from their peers or their family. Dogs do not judge someone by their body size. Due to this unconditional acceptance, some children may turn to their dog for the acceptance that they are not receiving from their social circle.

Few studies have been conducted investigating the relationships formed between children and their dog. This study may contribute to the understanding of the depth and extent of the relationship formed between children and their dogs. 


\section{Chapter II}

\section{Review of Related Literature}

\section{Childhood Obesity}

Childhood obesity is a problem that is no longer isolated to the United States. Cole (2006) reported that the increase in childhood obesity is occurring in numerous industrialized countries. The United States and Canada had been reported to have the largest growth rate in childhood obesity (Cole, 2006); however, while the prevalence of obesity remains high in the United States, it appears to have remained stable between 2003-2004 and 2009-2010 (Ogden, Carroll, Kit, \& Flegal, 2014). Other countries such as England, Scotland, and Australia are still experiencing increasing rates of childhood obesity (Cole, 2006). World-wide, 22 million children under the age of 5 years are overweight (Centers for Disease Control and Prevention, 2006). The only country reported to have a decrease in childhood obesity is Russia and this is thought to be attributed to the declining socioeconomic climate of the country (Cole, 2006). While many countries are experiencing an upsurge in childhood obesity, researchers and healthcare providers are finding controversy when defining and assessing obesity.

The debate over the definition of obesity in childhood has been a topic under scrutiny. Numerous ways of assessing obesity have been proposed. Some of these methods include: anthropometric measurements, such as waist circumference or waist-tohip ratios (Speiser et al., 2005); underwater weighing (Mei et al., 2002; Speiser et al., 2005; Zimmermann, Gubeli, Puntener, \& Molinari, 2004); dual-energy X-ray absorptiometry (DXA) (Mei et al., 2002; Speiser et al., 2005; Zimmermann et al., 2004), skinfold thickness (Speiser et al., 2005), total body electrical conductivity (Mei et al., 
2002), total body potassium (Mei et al., 2002; Zimmermann et al., 2004), bioelectric impedance assay (BIA) (Speiser et al., 2005), and computed tomography (Mei et al., 2002; Speiser et al., 2005). Many of these methods are costly, not feasible to conduct with children, impractical to use in the clinic or school setting, or difficult to replicate (Speiser et al., 2005). One method that is consistently utilized to identify obesity in children is the body mass index (BMI).

Body Mass Index. The BMI is an inexpensive and convenient way of determining whether children are underweight, a healthy weight, overweight, or obese. In order to calculate a BMI, children's weight and height must be known. One potential problem with using the BMI to identify children who are obese or at risk for obesity is the fact that the BMI "cannot distinguish between fat mass and lean mass" (Cole, 2006, p.4). This becomes a major issue with the adolescent population because the ratio of muscle and bone to height and fat percentage changes rapidly during puberty (Sardinha, Going, Teixeira, \& Lohman, 1999) leading to misdiagnosis, many times over diagnosing of obesity. Because male and female bodies physically mature differently, both at different rates and by different deposits of adipose tissue, the BMI also poses another problem in adolescents. During adolescence, ages 13-years to 18 -years of age, females experience an increase in adipose tissue during puberty while most males become more muscular and lose adipose tissue (Burns, Barber, Brady, \& Dunn, 1996). The body mass index for age is a way to attempt to correct the BMI for children and adolescents. The BMI for age is similar to the normal growth and development charts used by pediatric health care providers, which take into account the percentile for age, weight, and height at each age group. However, because adolescents enter puberty at different ages and thus 
have major growth spurts at different ages, the adjustment isn't always correct for the adolescent population. In order to adjust for the fat gain during pre-pubertal growth, some authors recommend measuring waist circumference as well as BMI (Cameron, Jones, Griffiths, Norris, \& Pettifor, 2009).

While waist circumference alone is not as sensitive as BMI in pre-pubertal children, waist circumference does become more sensitive at the onset of puberty "as the centralization of fat primarily takes place only after the onset of puberty" (Cameron et al., 2009, p. 1066). Another issue with the BMI is the lack of supporting evidence of its validity across ethnicities (Reilly, 2002). In the past, the majority of the participants in BMI studies have been American children, the majority Caucasian. Dietz and Bellizzi (1999) found that race had an effect on the results of the BMI calculation of children. This was due to different percentages of body fat in the differing races. In races, such as Asian, where the percentage of body fat differs from Caucasian American children, the BMI would not be as valid in diagnosing overweight or obesity. Some countries have developed BMI growth charts utilizing normal growth data from children in their respective countries (Speiser et al., 2005).

The U.S. Centers for Disease Control (CDC) have developed gender- and agespecific BMI growth charts for children age 2-18 years (Cole, Bellizzi, Flegal, \& Dietz, 2000) to help increase the validity of the BMI across races. This was accomplished by reanalyzing the results of international surveys of six countries: Brazil, Great Britain, Hong Kong, the Netherlands, Singapore, and the United States (Cole et al., 2000). The researchers selected these countries due to their large data sets including health information about citizens of all ages. Widely differing rates for obesity were found 
(Cole et al., 2000). Each database had at least 10,000 representatives of each gender ranging in age from birth to 25 years of age (Cole et al., 2000). The data were plotted and linked to an adult cut-off point of either $25 \mathrm{~kg} / \mathrm{m} 2$ for overweight or $30 \mathrm{~kg} / \mathrm{m} 2$ for obese. While this process is not without flaws, the proposed cut-off points, which vary by age and gender, are less arbitrary and more internationally based than the current use of the original BMI (Cole et al., 2000). There was not a breakdown of different races from the United States data. While this study used a large sample including different races than has been the case in much of the obesity research, some races were not represented such as African, most likely due to the lack of international health surveys completed in the countries of Africa.

In the United States, health care practitioners use charts to assess normal growth and development of American children. Once a child's BMI has been calculated, the health care provider plots the child's BMI on the appropriate chart taking into consideration the child's age and gender. When utilizing the BMI for adults, the accepted cut-off points are $25 \mathrm{~kg} / \mathrm{m} 2$ for overweight and $30 \mathrm{~kg} / \mathrm{m} 2$ for obesity. These cut-off points were identified due to the related health risks that are associated with those BMIs for adults (Cole et al., 2000). These same numbers should not be used with children because during childhood there are growth fluctuations within the same age period (Cole et al.2000).

When determining whether children are under, weight, a healthy weight, overweight, or obese, the health care provider follows standardized cutoffs when using the BMI, however; the cut-off points utilized with children are looking at a percentile not a set number such as is used with the adult BMI. The acceptable cut-offs for establishing 
overweight in children, which place them at a high risk to develop obesity, and children who are obese are $85^{\text {th }}-95^{\text {th }}$ percentile and greater than the $95^{\text {th }}$ percentile respectively (Cole et al., 2000). Healthy weight would be considered less than $85^{\text {th }}$ percentile.

What can be understood from the current literature is that the BMI is not the most accurate way of determining overweight and obesity; however, it is the most convenient and inexpensive way of assessing children's weight status, and the most commonly used mechanism. Although the Centers for Disease Control have incorporated growth charts with BMI in order to enhance validity of the BMI in children, there is little doubt that such systems may fail to take into account growth spurts which may significantly alter children's body composition. Even more problematic is that such growth spurts cannot reliably be predicted within age groups or developmental levels of children.

When considering adolescents, however, there is agreement that the health care provider should assess children's general appearance and muscle mass before diagnosing children as overweight or obese by relying on the calculated BMI. For adolescents a common approach is to assess Tanner Staging, a standardized method to establish where adolescents are in the stages of puberty development, when determining whether adolescents fall into the category of overweight, obese, or a healthy weight. If adolescents have reached an adult level, which would be stage 5, then adolescents may be included in the adult category when using the BMI cut-offs. However, if adolescents are less than a stage 5, adolescents are still developing and may have adipose tissue that is common during pubertal development and not necessarily obesity related. Labeling children overweight or obese does not fix problem with the weight and many times being 
labeled as overweight or obese can have a detrimental effect on children's self-esteem (Cameron, 1999).

Health problems of obesity. As previously stated, there are numerous serious co-morbidities associated with childhood obesity. The longer the duration of obesity, the greater the number and seriousness of associated co-morbidities. Once a child becomes overweight or obese, it is more likely that the child will remain in one of these categories or progress from being overweight to being obese (Cunningham, Kramer, \& Narayan, 2014). Cunningham et al. also found that children who entered kindergarten overweight were "four times as likely as normal weight children to become obese" (p. 403). Because obese children tend to become obese adults, the stress of the illnesses caused by obesity have a longer toll on the person's body. More children under the age of 16 years, than ever before are being diagnosed with type II diabetes, hypertension, and joint problems (Copeland et al., 2013; Gortmaker, Must, Perrin, Sobol, \& Dietz, 1993; Kagan, 2010; Moran, 1999; Nolan, Damm, \& Prentki, 2011; Speiser et al., 2005). Children who develop diabetes and do not control their glucose levels have an increased risk for developing cardiovascular, renal, optical, and neurological problems in the future (Ball, Bindler, \& Cowen, 2014). Not only are obese children faced with physical health care problems, but also mental health issues, such as depression, social isolation, eating disorders, and low self-esteem (Burrows \& Cooper, 2002; Cameron, 1999; Israel, \& Ivanova, 2002; Cornette, 2008; Sjoberg, Nilsson, \& Leppert, 2005; Strauss, 2000; Strauss, \& Pollack, 2003; Wang, Wild, Kipp, Kuhle, \& Veugelers, 2009).

\section{Self-Esteem}


Many scholars see self-esteem as the factor that defines humans both socially and internally. Because self-esteem may be either positive or negative depending on the person's perception of themselves, this may have a positive or negative impact on the person's life and social interactions. While self-esteem may define people, the experts struggle to find a definition of self-esteem. There are several different schools of thought about the definition of self-esteem. Even more complex is the differentiation of this term from the notion of self-concept.

Self-concept is a term that has been used interchangeably with self-esteem in some literature. Carless and Fox (2003) defined self-concept as "The self-description of the abilities, activities, qualities, traits, personal philosophies, morals and values, and roles adopted by the self" (p. 69). Shavelson, Hubner, and Stanton (1976) defined selfconcept as a person's perceptions of himself which are formed through the experiences in the environment and especially influenced by environmental reinforcements and significant others. Harter (2008) defined self-concept as being "primarily reserved for evaluative judgments of attributes in discrete domains, such as cognitive competence, social competence, physical appearance, and so forth, or 'domain specific selfevaluations"' (p. 5). All three definitions vary to some degree, however; they all seem to agree that self-concept is defined by people's feelings of themselves in more than one area or domain whether a physical attribute such as body size or a theoretical concept such as other's perceptions of a person. Self-concept is a combination of how people see themselves in the domains of physical, cognitive, and personal abilities.

There are numerous other constructs that have been used in the literature when referring to people's sense of self such as: self-esteem, self-image, self-worth, self-belief, 
self-awareness, and self-regard (Butler \& Gasson, 2005; Harter, 2008). While Butler and Gasson posited that many of these terms may be used interchangeably, the authors believed that there are subtle differences between the constructs. Butler and Gasson (2005) separated the terms self-concept and self-esteem by defining self-concept as "the global over-arching view of self" and self-esteem as "the evaluative aspect related to worth" (p. 191). Some experts believe that these terms are not the same; however, they are related to each other (Mruk, 2006). While Harter believed that self-concept was an evaluation of people's competence in different domains, she felt that global self-worth or self-esteem was a separate entity that can be affected by the feelings of competence in the domains but does not solely rely on the competence in the domains.

William James (1890) was one of the first scientists to write about self-esteem. He noted that:

If no one turned round when we entered, answered when we spoke, or minded what we did, but if every person we met 'cut us dead' and acted as if we were non-existent things, a kind of rage and impotent despair would ere long well up in us from which the foulest bodily tortures would be a relief; for these would make us feel that, however bad might be our plight, we had not sunk to such a depth as to be unworthy of attention at all. (p. 294)

Self-esteem has been said to be a reflection of one's feelings of self-worth (Mruk, 2006). If people do not feel worthy then they usually report low self-esteem. Brown and Marshall (2006) felt that self-esteem is a personality variable that generally represents the way people feel about themselves. 
Unidimensional versus multidimensional model. There are two main schools of thought when discussing measurement of self-esteem or self-worth. The first school of thought is referred to as the Unidimensional Model (Coopersmith, 1967; Piers \& Harris, 1964) (Figure 1). With the Unidimensional Model, the researchers believe that selfesteem can be measured by combining how people feel their competence level is in the individual domains and the summation of these domains is a measurement of their total self-esteem (Coopersmith, 1967; Piers \& Harris, 1964).

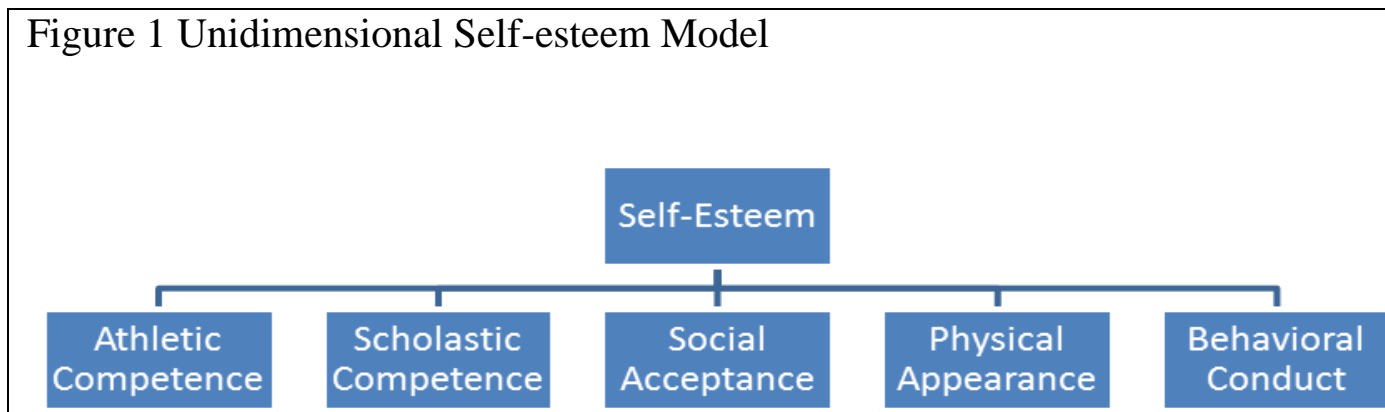

Figure 1. Self-Esteem as a sum of a person's competence levels in their individual domains.

The second school of thought for self-esteem is the Multidimensional Model (Harter, 1999) (Figure 2). Researchers who support the multidimensional model, believe that people, even children as young as 8 years, can separate their feelings of competence in different domains and keep these feelings of competence separate from their feelings of overall self-esteem or what Harter (1982) refers to as general self-worth. 
Figure 2 Multidimensional Self-esteem Model

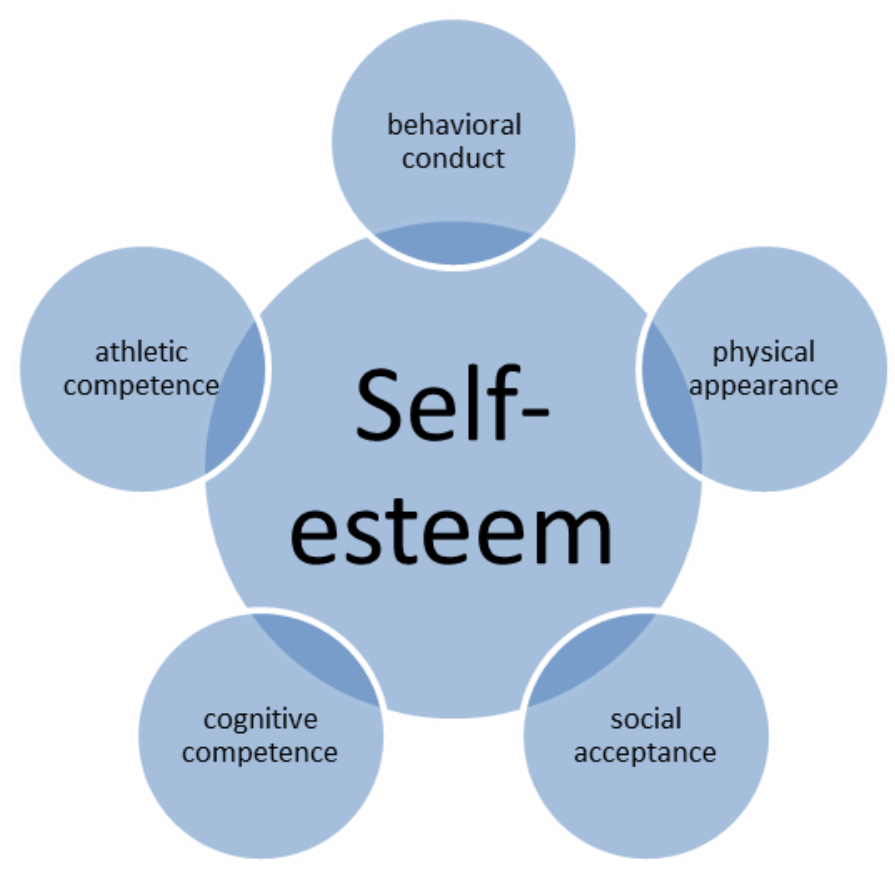

Figure 2. Self-Esteem as a separate entity aside from a person's feelings of competence in the different domains.

Both schools of thought argue that the way people feel that others think of their worth and abilities are factored into self-esteem (Cooley, 1902; Harter 1982). However, the multidimensional model utilizes James' (1890) work which states that people may protect their general self-worth or self-esteem by not placing a high amount of care onto a domain in which they know that they do not excel in. For instance children who are obese may score lower in the physical appearance and athletic competence domain while still having a normal to high general self-worth. This is because children may not value the physical appearance and athletic competence domains but instead value the scholastic and behavioral conduct domains in which they excel. This may help to explain why some obese children have normal to high total self-esteem scores and other obese children have lower total self-esteem scores. 
Domains. James suggested that people derived their self-esteem or worthiness from only those domains that were important to them. If the domain was not important to people then their feelings of self-worth would not be impacted if they were not successful in this domain. If a domain is important to people then their success in that area was crucial to their feelings of self-worth and it would impact their self-esteem. For instance if a 15-year-old male high school student does not value academics but does value athletic competence, then the fact that he may be failing trigonometry most likely does not affect his self-esteem; however, if he drops a crucial pass during an important football game then this may have an impact on his feelings of self-esteem.

James did not expand on whether this holds true for all people. Some of the more recent researchers consider that this ability to overlook areas that are not seemingly important to people may be a way to protect their high self-esteem (Crocker \& Park, 2004). It may be that it does bother the student when he has a failing grade in trigonometry, however in order to protect his feelings of self-esteem he tells himself that trigonometry is not important to him. Why is it then that all people cannot protect their feelings of self-esteem in this manner?

The ability to protect self-worth in this manner may be affected by the person's "heritability" of self-esteem. Neiss, Sedikides, and Stevenson (2002) contend that selfesteem may be a hereditary trait. If the parents have high self-esteem levels then the children will also display high levels of self-esteem.

There are more researchers who argue that self-esteem is impacted more by nurturing than by nature. Arend, Gove, and Sroufe (1979) argue that children who are cared for by parents who are warm and responsive feel that their parents value and 
respect them which allow the children to develop a positive view of themselves.

Coopersmith (1967) also felt that nurturing had a large impact on children's feelings of self-worth. He found that children who reported their mothers as being more involved in their personal lives such as knowing their friends and showing an interest in children's lives displayed higher levels of self-esteem than children who were raised by parents who were not involved in their personal life. These theories of nurturing affecting self-esteem could also offer some insight into Cooley's view of self-esteem.

Cooley (1902) developed the "looking glass self" when discussing self-esteem. Cooley felt that "so in imagination we perceive in another's mind some thought of our appearance, manners, aims, deeds, character, friends, and so on, and are variously affected by it" (p. 180). Cooley thought that we attempt to use people who are significant in our lives as a mirror to view our self-worth as our significant others view it. In this aspect, people's self-worth wasn't determined by whether they felt worthy but whether they felt that the significant others felt that they were worthy. So if children choose an adult who is nurturing as a person to mirror their view of self-worth, they are more likely to have a higher self-esteem. If children choose an adult who is negative towards them, whether the negativity is directed at an outward personal characteristic such as weight or an inward trait such as intelligence, they are more likely to have a lower self-esteem.

State or trait self-esteem. There is considerable debate in the literature as to whether self-esteem can change over time. Harter (2004) reported that there are three main philosophies regarding self-esteem. There are those researchers who found that global self-esteem is relatively stable over time. There are those researchers who found 
that self-esteem fluctuates in a normal developmental pattern over time. And there are those researchers who found that self-esteem has short term changes.

Harter goes on to discuss that each philosophy can be true. She states that most researchers agree that generally people's overall self-esteem is fairly stable. If people are having a bad day then there may be a small drop in their self-esteem for that day but overall their self-esteem stays relatively the same throughout their lifetime. She also goes on to point out that during adolescence the self-esteem levels may fluctuate drastically depending on the context that the adolescent is in. These fluctuations in self-esteem could be considered an expected developmental pattern. For instance, an adolescent's self-esteem may diminish if they are attempting to participate in a sport in which they are not competent conversely their self-esteem may increase if they are participating in a scholar bowl in which they know the answers to all of the questions.

Harter (2004) studied adolescents who were transitioning from high school to college and found that some reported a decrease in their self-esteem, some reported an increase in their self-esteem and some reported no change in their self-esteem. The students who reported a decrease in their general self-esteem, were students who reported transitioning from a school where the domain that they excelled in was valued at their first school but no longer valued at their new school. The adolescents who reported an increase in their general self-esteem were those students who reported excelling in a domain that was not valued at their first school but was valued at their new school. The students who did not report a change in their self-esteem reported that both schools valued the same domain. 
Harter (2004) studied another group of adolescents and found that some reported no day-to-day changes in their self-esteem while others reported minor to major fluctuations in their self-esteem levels. While these results did not establish an answer to the nature versus nurture debate in self-esteem, it did provide examples of how the same situation may affect people's self-esteem in different ways.

Researchers have also established two different forms of self-esteem: state selfesteem and trait self-esteem (Leary, 1999). For some people, self-esteem remains relatively stable over time and is labeled by many researchers as trait self-esteem (Brown \& Marshall, 2006; Granleese \& Joseph, 1994; Harter, 2004; Kernis, 1993; Leary, 1999). Trait self-esteem reflects the person's overall sense of value and acceptance (Leary, 1999). For other people, self-esteem varies either over time or by situation (Harter, 2004) and is labeled by researchers as state self-esteem. State self-esteem changes frequently and reflects how the person is feeling about themselves (Leary, 1999) and may also be affected by the person's perception of how others value them at that moment (Brown \& Marshall, 2006).

While numerous studies have found a relationship between obesity and low selfesteem in children (Cameron, 1999; Crocker \& Garcia, 2005; Dohnt \& Tiggemann, 2006b; Franklin, Denyer, Steinbeck, Caterson, \& Hill, 2006; French, Story, \& Perry, 1995; Hill, 2006; Israel \& Ivanova, 2002; O’Dea, 2006), some studies have found that children who are obese have a high or normal level of self-esteem (Cameron, 1999; French et al., 1995; Hill, 2006). Phillips and Hill (1998) stated that while girls who were overweight rated lower self-esteem in the domains of athletic competence and physical appearance, the domains of scholastic competence, social competence, behavioral 
conduct, and global self-worth were not considered statistically lower than their healthy and underweight counterparts. Franklin et al. (2006) reported that obese boys and girls were "two and four times more likely than their normal weight counterparts to report low competence in athletics, physical appearance, and global self-worth" (p. 2484) and obese girls were also "two times more likely to have low perceived social competence" (p. 2484). If obese children have low self-esteem why isn't it always in the same domains and why do some obese children have lower global self-worth scores while other obese children's global self-worth scores are normal? This could be in part a coping mechanism for obese children. If children feel that people perceive their athletic competence and physical appearance lacking because of their weight, their ego may increase their feelings of competence in the other domains to compensate for the decreased feelings in the other domains.

\section{Influences on Self-Esteem}

Why do some children who are obese suffer from lower self-esteem while other obese children do not have a self-esteem issue? Russell-Mayhew, McVey, Bardick, and Ireland (2012) found that two mediating factors determined how obesity affected the child's psychosocial health: 1) weight-based stigmatization and teasing 2) weight and shape concerns (body dissatisfaction).

Warschburger (2005) reported that $50 \%$ of overweight boys and $58 \%$ of overweight girls who were hospitalized for inpatient care of their obesity were reported by their parents to have been teased by peers regarding their weight. While many children report weight based teasing by their peers, Bang et al. (2012) found that many children are affected psychologically by teasing from their parents. 
Allen, Byrne, Blair and Davis (2006) discovered that children who reported a high concern for their weight and shape also reported a low self-esteem while children who reported a low concern for their weight and shape had higher self-esteems regardless of the child's actual weight. Allen et al. (2006) also reported that in some obese children there was a normal global self-esteem but they still had a low esteem in the domain of their physical appearance. It was also noted that weight concern had an inverted relationship with body satisfaction; this held true whether the child was overweight or not (Allen et al., 2006).

Three main influences are repeatedly referred to in the literature as influencing obese children's self-esteem. These are media influence (Borzekowski, Robinson, \& Killen, 2000; Cusumano \& Thompson, 2001; Dohnt \& Tiggemann, 2006a; Dohnt \& Tiggemann, 2006b; Fouts \& Burggraf, 2000; Gapinski, Schwartz, \& Brownell, 2006; Greenberg, Eastin, Hofschire, Lachlan, \& Brownell, 2003; Greenberg \& Worrell, 2005; Harrison, 2000), peer influence (Bell \& Morgan, 2000; Dohnt \& Tiggemann, 2005; Dohnt \& Tiggemann, 2006a; Dohnt \& Tiggemann, 2006b; Eisenberg, Neumark-Sztainer, \& Story, 2003; Foster \& Page, 2006; Gable, Krull, \& Srikanta, 2008; Gapinski, Brownell, LaFrance, 2003; Harrison, 2000; Latner \& Schwartz, 2005; Latner \& Stunkard, 2003; Neumark-Sztainer \& Eisenberg, 2005; Phillips \& Hill, 1998; Puhl \& Latner, 2007; Sobal, 2005), and parental influence (Crandall, 1991; Keery, Boutelle, van den Berg, \& Thompson, 2005; Lowes \& Tiggemann, 2003; Mendelson, White, \& Mendelson, 1996; Puhl \& Latner, 2007; Stradmeijer, Bosch, Koops, \& Seidell, 2000; Zeller, Saelens, Roehrig, Kirk, \& Daniels, 2004). As discussed in Chapter 1, self-esteem is affected by how people believe that others perceive them. If the children choose to watch media in 
which they are bombarded by models and actors who are all thin then the literature suggests that obese children may realize that they are not the same as the models and actors which may impact the child's self-esteem (Borzekowski, Robinson, \& Killen, 2000; Cusumano \& Thompson, 2001; Dohnt \& Tiggemann, 2006a; Dohnt \& Tiggemann, 2006b; Greenberg, Eastin, Hofschire, Lachlan, \& Brownell, 2003; Greenberg \& Worrell, 2005). If parents and peers are making derogatory comments regarding children's weight then the literature suggests that this too may have an impact on children's self-esteem (Dohnt \& Tiggemann, 2005; Dohnt \& Tiggemann, 2006a; Dohnt \& Tiggemann, 2006b; Eisenberg, Neumark-Sztainer, \& Story, 2003; Gapinski, Brownell, LaFrance, 2003; Latner \& Schwartz, 2005; Latner \& Stunkard, 2003; Lowes \& Tiggeman, 2003; Neumark-Sztainer \& Eisenberg, 2005). One can glean from the literature that because children spend the majority of their time either with a friend, a parent, or watching television, this constant exposure may have a detrimental effect on their self-esteem.

Media influence. The media, both television and print, is constantly bombarding us with characters who are average or below average in weight. Several studies have assessed the number of underweight individuals as compared with the number of overweight individuals shown on prime time television shows (Fouts \& Burggraf, 2000; Greenberg, Eastin, Hoffschire, Lachlan, \& Brownell, 2003). Greenberg et al. (2003) found that television on the average presents 3 out of every 100 women as obese while in everyday life, 1 in 4 women are obese. Greenberg et al. (2003) also reported that in everyday life only $5 \%$ of the women are considered underweight while on television 1 out of 3 women appear underweight. By not representing the average body sizes, the media may be sending a message to children that the norm is for everyone to be thin, that 
being thin or underweight is the norm instead of average weight to overweight being the norm.

Not only are women who are overweight under represented on television but the majority of the overweight women who are presented are viewed in a negative manner (Fouts \& Burggraf, 2000; Greenberg et al. 2003). Greenberg et al. (2003) established that the overweight characters had fewer romantic relationships, interactions with friends on the show, and were less likely to interact with other characters in a positive way. Overweight female characters were more likely to receive a negative comment from the male characters and these negative comments were followed by a negative reaction from the audience such as laughter (Fouts \& Burggraf, 2000). Dohnt and Tiggemann (2006b) also noted that girls who watched television programs that highlighted beautiful characters were less satisfied with their own appearance. As television viewing time is steadily increasing across the nation these problems may be associated with more feelings of negativity directed at people who are obese.

Print media have also been shown to have an effect on the self-esteem of children. Not only do print media present ultrathin models, but the number of articles and advertisements targeting diets or diet aids increased by $56 \%$ over a period of time from 1959 to 1980 (Garner, Garfinkel, Schwartz, \& Thompson, 1980). In the period of time between 1980 to 1990, the amount of exercise articles also increased, surpassing the amount of diet articles (Wiseman, Gray, Mosimann, \& Ahrens, 1992). While this increase in exercise articles may be seen by some as a healthy way of losing weight, many teens will follow the diet articles along with the exercise articles to an unhealthy extreme. Dohnt and Tiggeman (2006b) found that girls from five to eight years of age 
who looked at teen or women's magazines had increased knowledge of how to diet to lose weight.

The media not only has an effect on children's self-esteem, but it also affects how they view others. Dohnt and Tiggemann (2006b) found that girls who watched more television that focused on appearances had lower appearance satisfaction. The authors also acknowledged that girls who contemplated that their peers wanted a thinner body were also more likely to want a thinner body themselves. If the girls were to express the desire to have a thinner body to the peer could this in turn lead the peer to desiring a thinner body thus creating a cycle of desired thinness?

In turn, Harrison (2000) noted that viewing television shows that portrayed heavier women in a negative manner resulted in an increased frequency of males stereotyping overweight female characters. Contributing even more to the negative presentation of overweight people in the media, Greenberg, Eastin, Hofschire, Lachlan, and Brownell, (2003) found that the media may be sending a message that overweight people are of lesser value and importance because of their lack of representation and therefore significance in the mass media.

After reading the literature, one could argue that the media has a major impact on how children see themselves and also how children view others. The media may help children realize who they themselves or others are not what the media considers a normal size and weight. Since the media tends to show more underweight women, could this make children who are overweight feel more uncomfortable with their body shape and thus lower their self-esteem? Due to the media showing people who are overweight as 
being less desirable, are children more likely to feel less desirable if they are overweight or to feel that their overweight peers are less desirable?

Peers' influence. Peers themselves also have a direct effect upon the self-esteem of obese children. While Dohnt and Tiggemann (2005) proposed that children in Australia first develop body dissatisfaction and dieting awareness during the ages of five to seven years due to entering school, it would seem feasible that American children are exposed to this at a much earlier age due to the large number of children who attend preschools and daycares. This may explain why Cramer and Steinwert (1998) found that younger children already had a negative perception of obese people.

Children as young as 3 years have been found to demonstrate negative attitudes toward overweight children (Cramer \& Steinwert, 1998). In Cramer and Steinwert's study (1998) children were told of two characters: one who was thin and one who was overweight. The children were then told a story about two fictional characters in which one character performs a hateful act. The children were then asked to identify which character was the thin character and which one was the overweight character. Routinely the children attributed the hateful characteristics to the overweight child. One explanation for this may be another influence from the media. When portraying bullies on television, the bully is usually a large person. It may be that children are associating the overweight child with bullying.

Even though obesity has greatly increased since 1961, Latner and Stunkard (2003) discovered that children are more likely to rank obese children as the last choice for a friend when compared to a child who is of a healthy weight and other children with physical handicaps, more frequently now than in 1961. One may think that due to 
obesity being more frequently encountered in the public that this would have desensitized others as seeing obesity as making one different. The difference however, between liking the healthy and the obese pictured child almost doubled from the results of the 1961 study (Latner \& Stunkard, 2003).

It is difficult for children to separate the negative image of obesity as presented in the media from everyday people who happen to be obese. Bell and Morgan (2000) found that even with a medical explanation for the obesity, peers were less likely to choose obese children for a school project. Latner and Stunkard (2003) noted that when given the choice of ranking children with functional disabilities, appearance related disabilities, and obesity, the peers tended to rank children who were obese as the least likable children in the group. This may be attributed to the media showing obese people in a negative way and television shows for children that do not show people with disabilities in a negative manner. Another study found that while girls who were obese did not have a decreased general self-concept, they were still less likely to be chosen by peers as being popular (Phillips \& Hill, 1998). This lack of perceived social competence can decrease children's feeling of general self-worth (Harter, 2004).

Numerous studies have found children believing that becoming thin would increase their popularity and likeability (Cramer \& Steinwert, 1998; Dohnt \& Tiggemann, 2005; Harrison, 2000; Lowes \& Tiggemann, 2003). This may be children's way of compensating for the lack of popularity; they are not popular because they are not thin. Dohnt and Tiggemann (2005) found that children believed that if they chose to lose weight their number of friends and popularity may increase. 
Several studies have noted that obesity was a significant factor for bullying in elementary school-aged children (Griffiths, Wolke, Page, and Horwood, 2006; Fox \& Farrow, 2009; Lumeng et al. 2010). Brixval, Rayce, Rasmussen, Holstein, and Due (2011) reported that the risk of being bullied is greater for children who are obese when compared to their healthy weight peers. There is some debate as to whether children who are obese are being bullied because of their weight status or because of their lower selfesteem and increased body dissatisfaction (Brixval et al., 2011; Fox \& Farrow, 2009; Reulbach et al., 2013). Being bullied has been associated with increased depressive symptoms (Eisenberg, Neumark-Sztainer, \& Story, 2003). When the effects of bullying are compounded with the obesity it is not hard to conclude that children who are bullied because they are obese may develop substantial depression.

Parental and family influences. Families may affect obese children's selfesteem by constantly monitoring their diet (Jackson, Mannix, Faga, \& McDonald, 2005) or consistently commenting on their food choices (Davison \& Birch, 2001). This may actually have a back-fire effect where children eat large amounts of unhealthy foods in a binge attempt when the parent is not present to monitor the choices (Fisher \& Birch, 1999; Jackson et al. 2005). Parents may also affect children's perception of self if the parents are constantly discussing the need for weight loss with children (Davison \& Birch, 2004; Phares, Steinberg, \& Thompson, 2004) or if a parent is obsessed with themselves losing weight and diets constantly (Field et al., 2001). In a study by Jaballas, Clark-Ott, Clasen, Stolfi, and Urban (2011), 40\% of the parents surveyed felt that their child, who was overweight, would grow out this condition. Children are taught at a young age that thin is good and fat is bad (Flannery-Schroeder \& Chrisler, 1996). 
Ricciardelli and McCabe (2001) reported that numerous studies conducted with children between the ages of 7 and 11 years old found that the children believed obese children as having fewer friends, being less happy, being less liked by parents and being lazier. This leads one to wonder if children who feel that their parents are telling them that they are fat or that they need to lose weight and diet, will then see themselves as having fewer friends, being less happy, being less liked by parents and being lazier.

Another incident that routinely happens to obese children is weight-based teasing. Surprisingly the teasing may come from peers or family members (Eisenberg, NeumarkSztainer, \& Story, 2003). Thirty percent of adolescent girls reported being teased about their weight by their peers and $28.7 \%$ reported being teased by a member of their family (Eisenberg et al. 2003). Keery, Boutelle, van den Berg, and Thompson (2005) found that one-fourth of population in their study reported being teased by a parent about their appearance and one-third of the population in the study reported being teased by at least one sibling. Of the children in the Keery et al (2005) study, those who were teased by a father or older brother were more likely to have the highest negative outcomes. Although most children and teens see teasing as harmless, students who were teased regarding their weight reported a two to three time higher thought of suicide than teens who were not teased about their body weight (Eisenberg et al. 2003). Bang et al. (2012) reported that parental teasing may affect psycho-emotional health of the child as well as decrease their perceived view of their physical appearance and global self-worth.

Zeller, Saelens, Roehrig, Kirk, and Daniels (2004), reported that while one-third of the obese adolescents reported a form of psychological maladjustment, two-thirds of the mothers reported the adolescent having a form of psychological maladjustment. 
Zeller et al., (2004) could not tell whether this was due to the fact that one-third of the adolescents in their study did not recognize that they had a psychological maladjustment or because mothers tended to watch obese children more closely and assumed that they must have a psychological maladjustment such as depression.

Women's body dissatisfaction has become such a common occurrence that Rodin, Silberstein, \& Striegel-Moore (as cited in Lowes \& Tiggemann, 2003), refer to this as a 'normative discontent'. Because children mimic parental behaviors, children who were aware of their mother's body dissatisfaction had a positive correlation to their own level of body dissatisfaction (Lowes \& Tiggemann, 2003). Thus if a mother wanted to be thinner, her children also wanted to become thinner. Surprisingly there was no correlation between the father's body dissatisfaction and children's body dissatisfaction.

\section{Human Animal Interaction History}

Throughout history, animals have been a part of humans' lives. Animals have been used for hunting, as companions, and for health benefits. One of the earliest recordings of the use of animals for health benefits was by the Greeks, who used horses to rehabilitate wounded soldiers during the fifth century B.C. (Benda, Fredrickson, Flanagan, Zembreski-Ruple, \& McGibbon, 2000). Florence Nightingale suggested allowing patients to care for small animals such as birds, so that the patient would have a companion. Canaries were used in mines to detect poisonous gases and therefore protect the miners. Many people, including those with visual or mobility impairment, as well as seizures, may rely on an assistance animal for a more independent life.

In the recent literature, animals are being used for medical and psychological benefits. Human-animal relationships have been found to reduce blood pressure (Allen, 
Blascovich, \& Mendes, 2002; Anderson, Reid, \& Jennings, 1992; Baun, Bergstrom, Langston, \& Thoma, 1983; Friedmann, Katcher, Thomas, Lynch, \& Messent, 1983; Friedmann \& Thomas, 1995), improve the chance of survival one-year after an acute myocardial infarction (Friedmann \& Thomas, 1995), decrease minor health problems (Serpell, 1991), increase activity levels (Anderson et al., 1992; Dembicki \& Anderson, 1996; Johnson \& Meadows, 2010), correlate with lower plasma triglyceride levels (Anderson et al., Dembicki et al.), and facilitate weight loss (Johnson, 2010). Humananimal relationships have also been found to lessen feelings of loneliness (Staats, Sears, \& Pierfelice, 2006; Zasloff \& Kidd, 1994), decrease depression (Folse, Minder, Aycock, \& Santana, 1994), provide emotional support (Triebenbacher, 1998), have a positive effect on self affection (Bryant, 1990), enhance empathetic feelings (Vidovic, Stetic, \& Bratko, 1999), enhance pro-social behaviors (Vidovic et al.), facilitate less feelings of stress during stressful times, (Beetz et al., 2011; Havener et al., 2001), and improve feelings of independence (Valentine, Kiddoo, \& LaFleur, 1993).

As the literature demonstrates, human animal interaction has varied effects on people and their health. While it is known that the human animal interaction has the effects, the mechanism is still largely unknown. These results have been demonstrated in children and adults as well as across different ethnicities and disease processes, and findings have held in pet owners and people who are interacting with animals in which a long term relationship has not been formed.

Various animals have been utilized in researching the effects of the human animal interaction. Dogs have been most widely used (Johnson, Odendaal, \& Meadows, 2002). Cats have also been frequently used, while horses, rabbits, fish, and birds, as well as 
"pocket pets" such as guinea pigs and hamsters, have also been utilized (Roenke \& Mulligan, 1998). Snakes have also appeared in studies (Alonso, 1999; Ballouard et al., 2013; Eddy, 1996), as well as, dolphins (Humphries, 2003), elephants (R. Johnson, personal communication, April 18, 2011) and some 'exotic' pets which the researcher did not specifically name.

Many of these studies have been performed with animals that were unknown to the participants. From looking at the literature, it appears that the type of animal when used as an intervention does not have as large an impact as the feelings that the person has towards that particular animal. For instance, if someone is afraid of snakes then a snake would probably not be a good choice for an animal to be used as the intervention in a study monitoring anxiety. If the person feels secure with dogs, then a dog may be an appropriate choice for an animal to be used in a study monitoring anxiety.

\section{Obesity and Human Animal Interaction}

Human animal interaction may benefit children who are obese. Many of the areas that have been studied regarding the potential benefits of human animal interaction are areas in which children with obesity are suffering. These areas include mobility, blood pressure, and exercise, as well as, depression, self-esteem, and emotional support.

\section{Physiological Effects of Human Animal Interaction}

Cardiovascular Effects. A decrease in blood pressure in the presence of an animal has been well documented (Allen et al., 2002; Anderson et al., 1992; Baun et al., 1983; Friedmann et al., 1983; Friedmann et al., 1995). One of the first human animal interaction studies was conducted by Baun et al. (1983), in which the researchers found that adult participant's heart rate and blood pressure decreased, after an initial 'greeting 
increase' while the participants petted a familiar dog. The participants' heart rate and blood pressure did not change while they petted an unfamiliar dog or looked at a magazine.

Allen et al. (2002) found that participants, who owned a pet and were given a stressor both physical and mental, had lower resting heart rate and blood pressure and significantly smaller fluctuations in their heart rate and blood pressure when their pet was present during the stressor than compared with non-pet owners who had family or friends present. During the stressor the pets were present in the room with their owners to offer support, while the non-pet owners had their spouse or friend present during the stressor to offer support. Allen discovered that the fact that the pet owners had smaller changes in cardiac reactivity demonstrated that the pets were a form of social support for the owners.

In contrast, Friedmann et al. (1983) completed a similar project with children ages 9 to 16 years, where the participants were placed in a room with an unfamiliar dog but not allowed to pet the dog. The researchers found that, although the children did not physically touch the dog and did not previously know the dog, they did experience a decrease in blood pressure and heart rate when the dog was present.

Another study that was completed with children as subjects looked at the effect of a real dog, a toy dog, and an unknown human on a child's stress level while completing a difficult task (Beetz et al., 2011). The children used in the study were chosen because they had insecure or disorganized attachment to humans making it harder for these children to trust a human being. During the study the child was randomly assigned to one of three groups: real unknown dog, toy dog, or unfamiliar but friendly adult. Beetz et al., (2011) found that the children who were placed in the real dog group had significantly 
lower salivary cortisol levels. Another interesting finding that Beetz et al., (2011) noticed was the cortisol levels were inversely related to the amount that the child stroked the real $\operatorname{dog}$.

Allen et al. (2002), Anderson et al. (1992), Baun et al. (1983); and Friedmann et al. (1995) utilized the dogs owned by the participants, while Friedmann et al. (1983) and Beetz et al. (2011) used dogs that were unfamiliar to the participants. While all of these studies were completed in the presence of an animal, Allen et al. (2002) and Friedmann et al. (1983) did not allow participants to touch the animal during the study. In Allen et al.'s study, a bond had previously been formed between the adult pet owner and the pet; however, in Friedmann's study the dog was unknown to the children and the children were unable to touch the dog. The children in Friedmann et al.'s study may not have needed to touch the dog in order to reap the cardiovascular benefits because of children's feelings towards dogs. They may have felt secure and safe with the dog in the room (Melson, 2002). These feelings of security and safety may have acted like a social support system and a buffering effect may have been present in which they did not perceive the event to be as stressful because of the perceived social support of the dog.

The studies conducted by Allen et al. (2002) and Baun et al. (1983) may indicate that it takes more than the presence of a dog to have an effect on an adult's heart rate and blood pressure, that it may take a bond to be formed between the subject and the dog before changes in cardiovascular reactivity will occur. Conversely, the findings by Friedmann et al. (1983) may lend credence to the theory that the animal does not have to be an animal known to the participant nor be an animal in which a bond has formed with the participant in order to have an effect on the participant's heart rate and blood 
pressure. Another point that is as yet uninvestigated is whether the age of the participant has an effect on the cardiovascular benefits received from the presence of a dog. In Allen et al. (2002) and Baun et al. (1983) the participants were adults, while in Friedmann et al. (1983), the participants were children. Further research would need to be completed before this hypothesis could be tested, but it may be that the children's age and feelings towards dogs in general relieves them of the need to have an established bond formed with the dog while an adult may need to have that established bond with a dog in order to gain the same cardiovascular benefits.

A landmark study in the area of human animal interaction was completed by Friedmann et al., in 1995. This project studied pet owners and non-pet owners who suffered an acute myocardial infarction. The researchers found that participants who owned a pet, specifically a dog, were more likely to be alive, one year after suffering an acute myocardial infarction with asymptomatic arrhythmias. This study added credibility to the hypothesis that pets, specifically dogs, are beneficial to health. In previous studies, because the baseline health of dog owners had not been controlled for, it was unknown if people who chose to own dogs did so because they were already in better physical health. In Friedmann et al.'s study, all of the randomly selected participants had recently experienced an acute myocardial infarction; thus, the health status of the individual was somewhat controlled.

General health complaints. Serpell (1991) investigated effects of a newly acquired pet, cat or dog, on behavior and health status changes. During the first 10 months after acquiring the animal participants showed greater improvement in the scores on the General Health Questionnaire (GHQ), than the control group. During this same 
10-month period both dog- and cat-owners also reported a significant decrease in minor health problems. The authors attribute the change in the participant's GHQ scores to the increased walking time during the first six months. This decrease in minor health problems may be connected to a decrease in depressive symptoms when exposed to an animal, as was reported by Folse et al. (1994). Depression has been shown to cause numerous health complaints. If the participant had any depression that was improved through interacting with a pet, the participant may report less minor health problems.

Activity levels. Another health benefit that Serpell (1991) noted was that dog owners, but not cat owners, increased the frequency and duration of recreational walks. Dembicki and Anderson (1996) had similar results in a study that looked at elderly pet owners (majority of the participants were over 80 years of age). Dembicki and Anderson found that while there was not a statistically significant difference in the number of physical activities and duration of physical activity between pet owners and non-pet owners, there was a statistically significant increase in duration of walks that dog owners took. The inconsistency in findings between Serpell and Dembicki and Anderson may be due to the age of the participants (no ages were given for Serpell's study) or due to the age of the pet (no pet ages were reported for either study). Serpell's study was focused on people who were adopting pets, since younger animals are chosen for adoption at a higher rate than older animals; it would suggest that the animals in Serpell's study were younger in age. Dembicki and Anderson recruited elderly people who already had animals; however, there is no information given on age of the animal or how long the participant had owned the particular animal. 
Anderson et al. (1992) and Dembicki and Anderson (1996) also noted that the pet owners had significantly lower serum triglyceride levels than non-pet owners. Since exercise has a diminishing effect on serum triglycerides, the increase in duration of walks may be affecting the pet owner's serum triglyceride levels.

A more recent study conducted by Johnson and Meadows (2010) demonstrated that elderly clients were more likely to continue to exercise if they walked with a dog. Participants in the study made statements that suggested that they felt the dogs relied on them for exercise and social interaction which helped motivate the participants to continue walking the dog. These participants also reported a mean weight loss of 10 pounds during the study. Even though the participants in Johnson's study did not own the dog that they walked, they did walk the same dog in most cases, every week. The comments made by the participants suggest that a bond had formed between the participants and the dog.

One of the main contributing factors to childhood obesity has been shown to be decreased activity levels (Andersen, Crespo, Bartlett, Cheskin, \& Pratt, 1998; O’Loughlin, Gray-Donald, Paradis, and Meshefedjian, 2000; Stettler, Signer, \& Suter, 2004; Trost, Kerr, Ward, \& Pate, 2001; Vandewater, Shim, \& Caplovitz, 2004; Veugelers \& Fitzgerald, 2005). As in Johnson's study (2006) with adults, the use of a dog in the exercising of children may increase the their desire to continue exercising if they feel as if the dog is depending on them for the dog's exercise. This may be likely due to the human feelings that children assign to dogs. In Triebenbacher's study (1998) children who already owned a pet stated that their pet missed them and thought about them while they were at school. Triebenbacher also noted that children who did not own a dog had 
already envisioned what their dog would look like and what they would name the pet if given the opportunity to obtain a pet. This leads one to believe that children could easily assign human to feelings to a dog that was not previously known to them.

\section{Psychological Effects of Human Animal Interaction}

Loneliness. Zasloff and Kidd (1994) surveyed female students who were at least 21 years old. The investigators noted that, as expected women who lived alone were lonelier, than women who lived with people or a pet. The investigators also noted that there was no difference between dog and cat owners in mean loneliness or attachment, identifying that cats can also soothe an owner's feelings of loneliness. Staats, Sears, and Pierfelice (2006) also noted that women who lived alone were more likely to choose a pet for the social support that the pet offered.

Several studies reported that obese children were less likely to have friends or to not have as many friends as their healthy weight friends (Falkner et al. 2001; French, Perry, Leon, \& Fulkerson, 1996). As in the Zasloff and Kidd (1994) study, obese children may use their pet in order to curb their loneliness. Melson (1997) feels that children who do not receive the closeness and love that is needed from other people, may turn their attachment to pets in order to receive the needed love and closeness.

Depression. Folse et al. (1994) studied male and female students with a mean age of 21 years. The researchers found that participants who attended nondirective therapy groups who also utilized animal assisted therapy with a dog, had lower Beck Depression Inventory scores than participants who attended directed group therapy without the use of animal assisted therapy or participants who attended directed group therapy who utilized animal assisted therapy. 
Many obese children suffer from depression and low self-esteem (Cameron, 1999; Crocker \& Garcia, 2005; Dohnt \& Tiggemann, 2006a; French, Story, \& Perry, 1995; Hill, 2006; Israel \& Ivanova, 2002;O’Dea, 2006). If interacting with a dog helped improve symptoms of depression in older students, it may also help to improve symptoms of depression in younger children as well. This may be due to the perceived unconditional acceptance and love, or social support, that a dog may offer (Blouin, 2013; Melson, 1997; Triebenbacher, 1998a).

\section{Animals as Members of the Family}

While not everyone considers the family pet a member of their family, most children do consider their pet to be a part of the family (Beck \& Katcher, 1983). Animals are accepted members of the family among Americans (Bulcroft \& Albert, 1988; Cain, 1983; Triebenbacher, 1998b). According to the 2011-2012 American Pet Products Association (APPA) National Pet Owners Survey, "62\% of United States households own a pet, which equates to 72.9 million homes" (http://www.americanpetproducts.org/press_industrytrends.asp). Of the 72.9 million homes that own pets, 46.3 million of the pets were dogs (APPA website). Triebenbacher (1998b) reported that children love their pets and children feel that their pets love them. Children reported talking to their pets even though many of the children were not sure if the pet truly understood them (Triebenbacher, 1998b). These same children felt that their pets had feelings and that their pets had the capacity to think, giving the pets human qualities. Bryant (1985) also stated that pet owners were as likely to talk to their pets about emotional experiences as they were with their siblings. Melson, Schwarz, and Beck (1997) stated that "children who reported sharing private feelings and secrets with 
the pet during happy times also tended to turn to the pet in emotionally distressing situations when they were sad, afraid, or angry" (p. 1513). Melson (2003) believes that the children turn to their pets in times of stressful situations in order to gain social support. If children own a dog and the child is emotionally distressed due to feelings associated with being obese, the literature lends the belief that the child may talk with and interact with this dog in order to gain the social support that they are not receiving from humans.

Cohen (2002, p. 632) stated that for many people pets "are firmly inside the family circle." Cohen reported that while owners may assign their pets with human attributes, the owners do realize that the pets are not really human. This was evidenced by the participants stating that even though it would be hard they would choose to give a stranger over their pet a medication if it meant life or death to a human even if it meant that their pet would die.

If people realize animals are not really human then why do so many of them consider their pet in as a member of their family? This may also be answered by Cohen's research. Participants in Cohen's study (2002) reported that pets would not hurt or abandon a person as humans do. Some participants suggested that if told by a physician that they were allergic to their pet and their human partner they would try to find a way to continue living with their pet but they would either move or their partner would need to move if they were allergic to the human. This again leads credence to idea that children who have bonded with a dog may see that bond as strong as one that is created with a human friend or family member. 
Another study conducted by Blouin (2013) explains that whether people view their dog as a family member stems from how they view their relationship with their dog. Blouin feels that there are three different orientations that a person may have when viewing their relationship with their dog: dominionistic, humanistic, or protectionistic. People, who employ the humanistic view, generally see their dog as either a close friend or family member. People employing the humanistic view are also more likely to anthropomorphize their animals, meaning give the dog humanistic qualities and traits.

\section{Human-Pet Relationship}

Bryant (1990), found through studying children grades three through seven, that children saw the benefits of owning a pet but they also noted that there were some costs to owning a pet. The results of this study showed that the children felt that some areas of their relationship with their pet were beneficial. The children viewed their relationship with their pet as both a giving one, such as sharing secrets and enduring affection from the pet, and a taking relationship, such as caring for the pet and grief if the pet should die. The children felt that the pets made them feel good about themselves and made them feel important.

Triebenbacher (1998b) studied the relationship between a pet and children when she conducted a qualitative study to look at pets' role as a transitional object and the affect pets have on children's emotional development. In this study, children from preschool to fifth grade were interviewed regarding their views of relationships with pets. Ninety-eight percent of the children with pets felt that their pet was a member of the family. Children stated responses such as, "he loves me very much/ I love him very 
much/ we take care of each other" (Triebenbacher p. 194). Triebenbacher's study illustrates the ability of children to form a close bond with a pet.

Triebenbacher's study also demonstrated that children who did not own pets had formed a bond with their ideal pet. The children already knew what they wanted their pet to look like and also what they would name their pet. Triebenbacher's participants were not described as obese nor were they described as having fewer friends and yet had 'befriended' an imaginary pet. The question then arises would obese children who felt unaccepted by peers and family be more likely to form a bond with a real or imaginary pet? This pet may give them perceived social support by unconditionally accepting them.

\section{Empathy and Prosocial Behavior}

Vidovic et al. (1999) studied children's attachment to their pets as well as the children's prosocial behavior and ability to empathize. The children who were younger reported higher levels of attachment to their pet and higher frequencies of prosocial behavior than the older children. A more recent study conducted by O'Haire, McKenzie, McCune, and Slaughter (2013) found that the children did not have to own the animal in order to gain more social skills. Students who had a guinea pig in their class for 6 weeks were reported by teachers as demonstrating more socially skilled behaviors and having less problem behaviors than children who did not have a guinea pig in their classroom.

When the investigators looked at the children's level of empathy, they found that dog owners were more empathic than non-pet owners. The investigators propose that the level of empathy that children have correlates with the feelings of attachment to their pet. Non-dog owners scored significantly lower on empathetic feelings and prosocial behaviors than dog owners. This would make one pause after reading Triebenbacher's 
study (1998b), and ask oneself if the children who did not currently own a pet but could envision the pet that they wanted and had already named this pet would show similar levels of empathetic feelings and prosocial behaviors as the current dog owners.

The research regarding feelings of children who are obese show that children may have low self-esteem if few people accept or understand them. Due to children seeing their animals as members of the family and animals offering acceptance children who are obese may turn to the family dog for the social support that they are not receiving from parents, adults, and peers in their life.

\section{Animals and Social Support}

Animals can also show emotional and tangible or physical support. An example of a tangible showing of support would be licking the children to show the dog's approval, sitting by the children, or playing with the children. Emotional support could be demonstrated by sitting quietly and "listening" to children when they talk.

Bryant (1985) found that children listed their own pets and neighbor's pets when asked to list members of their social network. The children then described the pets as friends or confidants. Melson, Schwarz, and Beck (1997) also found that children mentioned their pets without prompting when asked about their general sources of support. These findings suggest that children value the support that is given to them by dogs.

In 2009, Friedmann and Son stated, "Pets and companion animals seem to reduce psychosocial distress by altering the owner's perceptions and making situations and people seem more benign" (p. 294). This may offer some explanation on how dogs and other animals can affect so many different age groups of people from so many different 
levels socially. Rew (2000) found that homeless adolescents felt that dogs were a big part of their social support by offering unconditional love. Juhasz (1985) stated that adolescence ranked a companion animal below parents but above other people that made them feel good about themselves. Taylor, Funk \& Craighill (2006) found that $94 \%$ of respondents felt close to their dog, $87 \%$ felt close to their mom, and $74 \%$ felt close to their dad. Kurdek (2008) completed a similar study and found that mothers, close friends, and significant others ranked higher in regards to closeness than dogs, dogs were equal in ranking of closeness to fathers and siblings.

Many of the health benefits that were previously discussed in this paper may be attributed to the social support that pets offer. For instance, the increased survival after a myocardial infarction (Friedmann \& Thomas, 1995) may be related to the social support that the participants received from their pets.

\section{Theoretical Framework}

The theoretical framework used to guide this study is derived from Susan Harter's theory on children's self-esteem (Harter, 1999). This theory explains why some children who are obese may have higher self-esteem scores and why other children who are obese may have lower self-esteem scores.

Harter (1999, 2008), used the phrases self-esteem and self-worth interchangeably because both terms are considered by Harter to be expressions of how people view themselves and how people feel others perceive them. Harter (1982) also stated that children do not just evaluate themselves in one domain but instead judge or evaluate themselves in separate domains. Initially Harter posited that there were four domains. These domains were: cognitive competence, social competence, physical competence, 
and general self-worth. In 1985, Harter released her revised Manual for the SelfPerception Profile for Children. With the revision of her model she added two new domains: physical appearance and behavioral conduct. The physical appearance domain was added after interviews with children revealed that their physical appearance became a prominent aspect of their self-worth in later elementary and middle school (1985). The behavioral conduct domain was added due to increasing interest in special populations where conduct may be an issue (1985). With the revision, Harter also renamed the original domains. Cognitive competence was altered to scholastic competence to reflect the fact that this domain was reflective of children's school work. In 2012, Harter renamed social acceptance as social competence and changed the wording on the questions in this domain to reflect "that the items should refer to characteristics of the self." Data collection for the current study had already began using the old format of questions. In order to preserve reliability of the information collected, the researcher in the current study chose to continue to collect data with the version released prior to 2012 . However, in order to prevent confusion of terms throughout the discussion, the term social competence has replaced social acceptance.

The physical competence domain was renamed as athletic competence to reflect the fact that this domain measures how children feel they rate in outdoor activities and sports. The word physical was also removed from the title after the new domain, physical appearance, was added so as to not confuse the information. The five domain subscales in Harter's revised instrument are: scholastic competence, athletic competence, social competence, physical appearance, and behavioral conduct (2012). Harter also 
posited that there is a sixth subscale of self-worth that needs to be directly measured in order to adequately assess children's feelings of general self-worth (1984).

Harter (1982) theorized that children's feelings of general self-worth are in addition to their feelings of self-competence in the five different domains. The general self-worth subscale is a component of children's overall feelings of self-competence. She feels that children over the age of seven years have the ability to view themselves as competent or not competent in each domain separately and does not add their feelings of competence in the different domains together to develop a total self-worth. Instead, the total self-worth is derived from the difference between one's perceptions of one's own competence and the perceived value of competence that society in turn children place on it (Harter, 1982).

Harter (1982) does not believe that children perceive themselves as competent in all of the domains but instead may perceive themselves to be incompetent in one or more domains. This may in part be explained by James' (1892) theory that children may make up for it by not placing feelings of importance on the domain that they feel they are less competent in. For instance, obese children may score lower on the physical appearance and athletic competence but not place importance on these domains so his or her global self-worth may still be intact. Other obese children may score lower on the physical appearance and athletic competence and have a lower global self-worth score because of the importance that they feel is placed on those domains by their family so they therefore place a large amount of importance on those domains.

Harter posits that the measurement of children's global self-worth is not accurate in children younger than seven years of age. The literature has shown that children 
younger than the age of seven years are not capable of separating their real talents and capabilities from what he or she would ideally like their talents and capabilities to be (Fischer, 1980; Harter, 1989; Higgins, 1991; Leahy \& Shirk, 1985). Harter (2006) goes on to state that "this overestimation, for some children, is not a reflection of socially desirable response tendencies..., but rather a genuine normative inability to distinguish between their actual abilities and their desired qualities" (p. 315). Developmentally, after the age of seven to eight years, children do have the capability to separate what their ideal self is from what their actual real self is.

\section{Summary}

The literature review demonstrates the three main factors that affect obese children's self-esteem. These are the media, peers, and parental / family. If obese children are not receiving support from their parents then they may look for support from another family member such as the family dog. This relationship that has been established between children and the dog may help to increase children's perceptions of themselves in the domains of social acceptance and global self-worth. This may be due to the fact that the dog offers unconditional love and acceptance to children which makes the children feel an increase in their self-worth. 


\section{Chapter III}

\section{Design and Methods}

Chapter III describes the research design and methods utilized in the study. The first section discusses research design, recruitment process, participants, setting, and procedures. The second section addresses data analysis, limitations of the study, and measures taken to protect human participants.

\section{Design, Setting, Participants}

Study design. The study used a non-experimental, descriptive, cross-sectional, four-group comparison design. As shown in Table 1, the four groups studied were: Obese children whose families owned a dog, healthy weight children whose families owned a dog, obese children whose families did not own a dog and healthy weight children whose families did not own a dog. A quota sampling format was used to recruit participants.

Table 1

Groups of Participants

\begin{tabular}{|c|c|}
\hline Healthy weight children with a dog & Obese children with a dog \\
\hline Healthy weight children without a dog & Obese children without a dog \\
\hline
\end{tabular}

Research questions. The study design and method enabled the investigator to address the following research questions and hypotheses:

1. What is the difference in self-esteem between obese children who have a family dog and obese children who do not? 
H1: Obese children who have a family dog will have higher self-esteem than obese children without a family dog.

2. To what extent are obese children more strongly bonded with their family dog than children of a healthy weight?

$\mathrm{H} 2$ : Children who are obese will have a significantly stronger bond with their dog than children who are of a healthy weight.

3. What is the difference in self-esteem levels between children who have a family dog and children who do not have a family dog?

H3: Children who have a family dog will have higher self-esteem than children who do not have a family dog.

4. To what extent do children anthropomorphize the family dog?

H4: Obese children will anthropomorphize the family dog more frequently than children who are of a healthy weight.

5. To what extent is the strength of the bond with their family dog associated with obese children's self-esteem?

H5: Obese children who have a stronger bond with their family dog will have higher self-esteem than obese children with a weaker bond with their family dog.

According to Polit and Beck (2004), when the independent variable is not manipulated, the design is non-experimental. The independent variables for this study were the strength of the relationship formed between children and their dog and the children's weight status. The investigator chose children of families in which a bond was already formed with a dog and did not manipulate this bond nor did the investigator 
manipulate the child's obesity status. Because the study was not prospective, assignment to dog ownership condition was not necessary and would have been impossible in any case. The dependent variable in this study was children's self-esteem.

Polit and Beck (2004) described correlational research as "research that explores the interrelationships among variables of interest without any active intervention by the investigator" (p. 715). The investigator chose this design due to a noticeable lack of research regarding the relationship between children and their dog. Missing specifically, were ways in which this relationship may impact children's lives as well as information concerning how children's relationship with their dog may influence their self-esteem. Thus, this design was chosen to develop a better understanding of the relationship between the variables of self-esteem, obesity and the human animal bond (Polit \& Beck, p. 189).

It was not possible to manipulate the child's weight for the purpose of the study. The investigator also studied the natural phenomenon of the bond that had already been established between children and their dogs given that little information is known about this relationship. It was also not possible to introduce dogs into families for the purpose of the study, making this independent variable nonmanipulable.

Setting. Participants were recruited from communities and schools in the Midwest via five defined avenues. A parochial school in a moderate sized Midwestern city was used to recruit participants. The school's student body was comprised of children ages five through 14 years. The school's approximate enrollment was 600 students and served children from Kindergarten through the eighth grade. It was 
comprised of $85 \%$ Caucasian, 10\% African-American, 2\% Hispanic, and 3\% Asian ethnicities. The average socio economic status of the parochial school was middle class.

Local recreational swim clubs and soccer clubs were also used to recruit participants. The clubs all consisted of children from surrounding public, private, and parochial schools, as well as some children who were home schooled. The average socioeconomic status was middle class and the majority of the children were of Caucasian ethnicity.

A bulletin was placed in an electronic newsletter that is regularly sent to all University of Missouri employees (MU INFO) as well as posted on a bulletin board in a local pediatrician's office. The bulletin stated, "Children between the ages of 8 and 11 years are being sought for a study that is about the relationship between children and how their weight and dog ownership may influence their self-esteem. The study will take approximately 30 to 45 minutes to complete and will involve your child being weighed and measured and then completing 1 or 2 surveys. As the parent you will be asked to sign a consent form and fill out a small questionnaire. All children that complete the survey will receive a 5.00 gift certificate. Please e-mail Pam Evans-Smith at EvansSmithP@missouri.edu or call (573) 864-5098 to enroll in the study or to find out more information regarding the study."

Network sampling was also utilized. Each participant's parent was asked if any of the child's friends were interested in participating in the study. A business card with the name of the research project as well as the name of the investigator and a contact phone number was on the card. If the parent was aware of anyone, contact information for the potential participant was gained from the parent. 
The investigator used a wide variety of mechanisms to enroll children in the study in an attempt to gain an acceptable number of participants. The public school systems did not allow the investigator to gain access to their students. Only one parochial school allowed the investigator access to their students; however, this school was smaller in size than the public schools and was limited in ethnic and socioeconomic diversity. Another challenge that the investigator faced in only using a parochial school was the need for half of the sample to be obese. Because this school was smaller there were not as many obese children in the school system. In an attempt to gain access to the students who attended public schools, the investigator tried to enroll children who attended public schools and children who were home schooled through community groups and recreational clubs.

The investigator was aware that there was selection bias present. The majority of the accessible population was of children who were Caucasian and of middle class socioeconomic status. According to Hernán, Hernández-Diaz, and Robins (2004), "the common consequence of selection bias is that the association between exposure and outcome among those selected for analysis differs from the association among those eligible." The socioeconomic status of the family may have impacted the participant's self-esteem. While this prevents generalizability of the results to the general school-age population, it represents a unique contribution to extant literature regarding the relationship between children and their dogs and to what extent this relationship is associated with obese children's self-esteem.

Participants. Pre-adolescent children aged eight to 11 years were recruited for the study. Younger children were not included because they lack the ability to form an overall concept of their worth (Harter, 1990, 1999, 2005; Higgins, 1991). Before the age 
of seven years, the children are incapable of separating their ideal self from their actual self (Higgins, 1991). Instead of being aware of their own successes and limitations, children younger than seven years tend to think of themselves as good at everything that they feel is a desirable characteristic and not having any characteristic viewed as undesirable. Because the preadolescent stage is when children first begin to be able to evaluate their own self-esteem and realize that other people also analyze their worth, human animal interactions may have the greatest impact on children's self-esteem at this age (Davis, 1987; Davis \& Juhasz, 1985; Levinson, 1978; and Van Houtte \& Jarvis, 1995). This may be due to the complete and unconditional acceptance that children may feel from a dog (Melson, 1997; Triebenbacher, 1998).

Once children reach the age of 12 , the way that they view themselves begins to change. According to Harter, Bresnick, Bouchey, and Whitesell (1997), adolescents viewed themselves as "multiple selves" in the different roles that they take: child, sibling, friend, student, romantic partner, and athlete. Harter (2008) posited that adolescents could see themselves as sarcastic and depressed with their parents, intelligent and creative as a student, and shy around potential romantic partners. Because of this change in perspective, there are more domains that should be measured when assessing an adolescent's self-esteem (Harter, 2008). With the addition of more domains, there would also be more factors needing to be considered when assessing the adolescents' global self-worth. Due to the adolescents' ability to have "multiple selves" it would not be possible to identify which self was affected by the relationship with the dog. This factor would make it impossible to determine exactly how the dog affected the adolescents' global self-worth. 
Another component that affected selection of this particular age range of participants in this study was how the children's age impacted the relationship between them and their dog. Melson and Fogel (1989) reported that parents stated that the length of time children spent with pets, included both playing and care of the animal, and increased steadily from the age of five years to twelve years. Melson, Peet, and Sparks (1991) found that among kindergarten children, perceived competence was positively and significantly affected by attachment to their pet. Among older children, attachment to their pet and perceived competence were found to be unrelated and by the fifth grade (1011 years) a negative correlation was beginning to form (Melson, Peet, \& Sparks, 1991). Taking the information related to the child's ability to view themselves and the relationship between attachment and perceived competence into consideration, the study did not include children older than the age of 11 years.

Inclusion criteria. Male and female children, age eight to 11 years were invited to participate in the study. Children who were obese, as well as children who were of a healthy weight, were invited to participate in the study. Children with any type of pet were invited to participate in the study; however, only children whose dog lived in the house at least $50 \%$ of the time were considered as having a dog. The limited research available regarding children and their relationship with pets, considered pet ownership as "the presence of companion animals within the home" (Melson, 1998, p. 221). Only children who spoke English as a first language were asked to participate in the study due to lack of established reliability and validity of the study instruments in other languages.

Exclusion criteria. Children with a terminal illness or an illness in which medications may have changed their appearance were not asked to participate in the 
study due to the effects that the illness or treatment may have had on their self-esteem. This included children who were receiving chemotherapy or high dose, long term steroids. Children with any type of developmental delay such as trisomy 21 or autism were also excluded because of the effect that the developmental delay may have had on the ability to measure self-esteem. Johnson, Johnson, and Rynders (1981), found that children with handicaps such as mental retardation, reported higher levels of self-esteem. This may be attributed to children not being able developmentally to separate their real self from their ideal self. Farley, Lopez, and Saunders (2010), found that children with autism were less likely to conceptualize themselves from another's perspective. Since other people's perspective may have an important impact on children's self-esteem, children with autism were not included in the study.

To prevent children from being enrolled in the study more than once, the investigator kept a list of the children's names. Before each child was enrolled in the study the investigator checked the list for duplication. Before enrolling in the study the child was also asked to sign a written assent form. If the child did not wish to sign the assent form, the investigator thanked the parent and child for their time and the interview ended.

\section{Recruitment}

Approval to recruit participants from the parochial school was obtained from the Principal of the school. Approval to recruit participants from the community clubs and organizations was obtained from the head office of each organization and the local group leaders working directly with the children. Approval to recruit from the pediatrics office was obtained from a health care provider in the practice. For the community clubs and 
organizations, the investigator prepared a brief, IRB-approved study description document which also contained contact information for the investigator via electronic mail or cellular phone. This was distributed to the children in each of the community clubs and organizations. The children were asked to take the document home and give it to their parents In the school, the investigator mailed, to the child's home, an IRB approved letter from the investigator which explained the study and gave contact information so the parent could contact the investigator via electronic mail or cellular phone, to enroll in the study. In the pediatrics office, a bulletin was placed on the wall with the investigator's contact information so the parent could contact the investigator via electronic mail or cellular phone, to enroll in the study.

Once the parent contacted the investigator, an appointment was made for one of the parents and the child to meet with the investigator and complete the study instruments. The parent and child were told by the investigator that she was studying the strength of the bond that existed between children and their dogs and the relationship that this bond had on children's self-esteem. It was explained that children's BMI may be a factor in their self-esteem level so the child's height and weight was also to be measured. The investigator ruled out children who had already participated in the study by checking the list of names of the children who had participated in the study. The investigator obtained written consent from (see Appendix A) the parent or guardian of each child before any data collection took place. The investigator also obtained written assent (see Appendix B) from the child who participated in the study. If the parent consented for the child to participate in the study but the child did not grant assent, the investigator thanked the child and parent for their consideration and the session ended. Each child who 
participated in the study was compensated for their time with a $\$ 5.00$ gift card from a local department store. The investigator also asked the parents of participants for contact information of any friends who may have had children interested in participating in the study.

The participant's data was categorized into a group dependent upon the status of dog ownership and the child's BMI. As stated previously the dog was required to live in the house at least $50 \%$ of the time in order for the child to be considered as owning a dog for this study. Children with a BMI of greater than $85 \%$ were categorized as obese for this study. The investigator utilized quota sampling to ensure that each of the four groups had the same number of participants. Once a group in the study had enrolled enough members the investigator no longer accepted participants into that group. The investigator continued recruiting until each group had 30 participants enrolled in the study.

The BMI for each child was calculated by hand by the investigator before completing the instruments and then double checked using the Center for Disease Control's website calculator (http://apps.nccd.cdc.gov/dnpabmi/Calculator.aspx) after the instruments were completed. Due to a calculating error in the field, the group of children who were of healthy weight without a dog had 31 participants and the group of children who were overweight without a dog had 29 participants. One child was calculated in the field as having a BMI in the 85th percentile which would have placed the child in the overweight group but when double checked, it was found the BMI for the child was in the 83rd percentile which placed the child in the healthy weight group. 
The sample was technically a "convenience sample" however, as described, extraordinary efforts were made to obtain participants. A power analysis was not done as results would yield low power. This means that while the study results are valid, one should exercise caution when generalizing them beyond the sample. The level of significance was chosen because the number of statistical tests to be completed was small and the number of dependent variables was also small thus a level of significance of 0.05 would be adequate to minimize the risk of making a Type I error (Cohen, 1992). This meant that the investigator was willing to reject a true null hypothesis five times out of 100. By rejecting a true null hypothesis in this study, no known detriments would occur to the participants or children similar to them.

The analysis was completed utilizing an univariate analysis of variance (ANOVA) with two main effects (one for obesity and one for dog ownership). Each main effect had two levels, and an interaction to see whether weight status interacted with dog ownership (S. Osterlind, personal communication, May 4, 2014). According to Kellar and Kelvin (2012), the ANOVA test examines the variation, and tests whether the between group variation is greater than the within group variation" (p. 178). A quota sampling was employed which will be discussed more in the data collection section.

\section{Measures}

Children's weight was measured using a medical digital Seca Clara 803 floor scale (http://www.seca.com/de_at/produkte/alle-produkte/produktdetails/seca803clara.html). The scale had a weight limit of 330 pounds and weight increments of 0.01 pounds. The scale was recalibrated according to manufacturer's recommendations each time the scale was moved. Children were measured for height on 
a Seca 213 portable free-standing stadiometer. The stadiometer had a height limit of 81 inches and had height increments of 1/8 inch (http://www.seca.com/de_at/produkte/alleprodukte/produkt-details/seca213.html).

All child participants completed the Self-Perception Profile for Children. Only children who owned a dog completed the Pet Bonding Scale.

Self-Perception Profile for Children (SPPC). The SPPC is a 36-item, fourpoint Likert-type instrument containing six subscales addressing five domains of selfcompetence as well as global self-worth (Harter, 1985, p. 5). The subscales are: scholastic competence, social competence, athletic competence, physical appearance, behavioral conduct, and global self-worth. In scholastic competence, the instrument measures the child's feelings of competence in academic performance. In social competence, the instrument measures the level to which the child feels accepted by peers or feels popular. In the athletic competence subscale, the instrument measures how capable the child feels with sports and outdoor games. In the behavioral conduct subscale, the instrument measures the degree to which the child feels that they act the way they are supposed to and do the right thing. In the global self-worth subscale, the instrument measures the extent to which the child likes oneself as a person and is generally happy with oneself. Global self-worth is not a measure of general competence but a way to examine the relationship between general self-worth and the separate domain specific subscales (Harter, 1985).

At the encouragement of Harter (1982), the investigator in the current study first explained to the children that this was a survey of how they feel and there was no right or wrong answer. Each subscale in the SPPC contains six items worded so that the child 
first has to decide which type of child they are more like. The child then has to decide if they are "really" like that child or "sort of" like that child. For example, the sample question is: "Some kids would rather play outdoors in their spare time BUT other kids would rather watch T.V." The child first must decide if they like to play outside or watch T.V. After the child decides which child they are most like, they then must choose either "Sort of true for me" or "Really true for me" (see Figure 3). The questions are formatted this way in an effort to decrease socially desirable answers (Harter, 1985).

\begin{tabular}{|c|c|c|c|c|c|}
\hline \multicolumn{6}{|c|}{ Figure 3} \\
\hline \multirow[t]{2}{*}{$\begin{array}{l}\text { Really } \\
\text { True } \\
\text { for me }\end{array}$} & $\begin{array}{l}\text { Sort of } \\
\text { True } \\
\text { for me }\end{array}$ & & & $\begin{array}{l}\text { Sort of } \\
\text { True } \\
\text { for me }\end{array}$ & $\begin{array}{l}\text { Really } \\
\text { True } \\
\text { for me }\end{array}$ \\
\hline & & $\begin{array}{l}\text { Some kids often forget } \\
\text { what they learn }\end{array}$ & $\begin{array}{l}\text { Other kids can } \\
\text { remember things } \\
\text { easily }\end{array}$ & & \\
\hline
\end{tabular}

Item order of the SPPC was randomized within the instrument to avoid response bias associated with several negative or several positive items occurring sequentially. The present study investigator read the first two questions to every child in the study. After the first two questions if the child was in the fifth grade or greater, the present study investigator asked the child if they would like to continue to be read the questions or if the child would rather read and complete the instrument by themselves. If the child chose to read the instrument to themselves, the investigator would then check to make sure that all items on the instrument had been answered with only one choice. If the child had left 
any unanswered or if the child had chosen more than one answer the investigator would clarify with the child what their final choice was.

At the recommendation of the author of the instrument, the investigator read each question to children who were in the fourth grade or younger. This insured that the child was only choosing one answer for each item and that all items were answered. The author of the SPPC, Harter (1985) recommended this approach due to the SPPC being different than most scales. Harter found that children who were in the fifth grade or older were able to easily complete the SPPC correctly, while children who were younger than the fifth grade became confused and would not complete the instrument correctly.

Each question was then scored from a one to four. A one indicated low perceived competence and a four indicated a high perceived competence. The Cronbach's alpha reliability coefficients for each item in the instrument ranged from $0.71-0.86$ when this instrument was utilized with American children in third through eighth grades $(N=1543$; girls=789; boys=754). Harter's Manual for the Self-Perception Profile for Children (SPPC) (Harter, 1985), had a range of scores from 4 to 24 for each subscale. The reported standard deviations for Harter's Manual (Harter) ranged from 0.5 to 0.9. Harter (1985) used a sample of 1,543 children from third to eighth grade when obtaining psychometrics for her SPPC. Ninety percent of the children surveyed by Harter were Caucasian, primarily from lower middle class to upper middle class neighborhoods. The majority of the population that was recruited for the present study were also Caucasian children from lower middle class to upper middle class.

The SPPC and instruction manual were purchased from Dr. Susan Harter, who granted the investigator permission to use the instrument. The manual contained a copy 
of the instrument along with a scoring key and data coding sheet. A copy of the instrument, along with a master list of items grouped according to subscale may be found in Appendix C.

Pet Bonding Scale (PBS). The PBS (see Appendix D) is a 25-item self-report, instrument that is designed to measure a child's self-reported feelings of attachment to their pet (Angle, Blumentritt, \& Swank, 1994). Angle (1994) tested the PBS on children ages 9 to 13 . The PBS is a three point Likert-type scale. The choices for responses are never, usually, and always. The instrument has a possible score range from $25-75$ points. The instrument was scored as a never (1), usually (2), and always (3). A higher score indicates a stronger feeling of attachment with the child's pet. Internal consistency was assessed utilizing Cronbach's alpha and Split-Half Technique with a Gutmann-Flanagan correction; the values were .98 for both procedures (Angle, Blumentritt, \& Swank, 1994). If the family had more than one dog, Angle (1994) asked the child to think of the dog that they have the strongest relationship with when they answered the Pet Bonding Scale.

The total score of all 25 items on the instrument was used to address Research Questions one and five and Hypothesis one and five. The investigator also selected six questions from the PBS that were analyzed separately. These six questions gave humanistic/anthropomorphic qualities to the pet such as friendship, telling the pet secrets, and the pet's ability to make the child feel important. The results from the statistical analysis of these six questions were utilized in an effort to study whether children who were obese anthropomorphized their pets more frequently in an effort to have a surrogate friend. The statistical analysis helped to identify the extent to which the dog was perceived as providing additional social support and friendship to the child. This will be 
the first time that these items have been grouped together, away from the PBS as a whole. This will pose a challenge to the validity of the items; however, may offer a starting point for future research.

Permission was gained from the authors to use the PBS in the present study. The PBS is available free of charge. When developing the PBS, Angle (1994) utilized the Fry Readability Scale to insure that the instrument was on a fourth-grade reading level. While some of the children in the present study were in a grade less than the fourth grade, the instrument was read to the child by the investigator in the present study. None of the children in the present study had any problems with understanding the statements in the PBS. Angle (1994) did not report the time that her participants needed to complete the PBS only, however; she did report that the participants were able to complete the PBS, a demographic questionnaire that contained seven items, and another instrument that was a five point Likert-type scale that consisted of 46 questions in 20-30 minutes.

The Pet Bonding Scale (PBS) (Angle, 1994) had a range of possible scores from 25 to 75 . Angle reported a mean score on the PBS as 62.97 with a range in scores from 34 to 75 and a SD of 7.9. When broken down by gender, Angle reported a mean score of 57.69 for males and 65.72 for females with SD of 9.24 and 5.63 respectively. Angle (1994) used a sample of 90 elementary students, aged 9- to 13- years of age, from a rural community in the southwest which was minutes from a major metropolitan area. Of the sample, 26 were males and 50 were females. Angle reported that the community itself was mainly lower to middle working class families. The majority of the population that was recruited for the present study were also children from lower middle class to upper middle class. 
Demographic Questionnaire (DQ). Participant demographic information included: age of child, grade level of child, gender of child, ethnicity of child, socio economic level of family, number of children in family, number of adults living in the household, proximity of nearest neighbor, other pets owned by the family, number of dogs in family, and length of time that family has owned dogs. See Appendix E for a copy of the DQ.

\section{Data Collection}

A non-probability quota sample was recruited. Due to the inclusion requirements of each quota group, the investigator was unable to utilize probability sampling.

After consent and assent were obtained, the investigator measured the child's height and weight, calculated the child's BMI and found out if the child owned a dog that lived inside at least $50 \%$ of the time. The investigator then ascertained which quota group the child belonged in. If the group that the child would fit in was already full, the investigator thanked the parent and the child for their time and the visit was terminated.

The DQ was completed by the parent directly after consent for the child to participate had been obtained and the group that the child would belong to was determined. If time permitted, the investigator immediately helped the child complete the instruments. If the instruments were completed at the child's home, the investigator asked for a quiet area such as the kitchen table or living room. At no time was the investigator alone in a room with the child with a door closed. In some instances, the investigator initially met with the parent and child at the school to gain consent and assent. If the instruments were completed at school, the investigator utilized a quiet classroom in which an adult or other children were present. If other children were 
present in the room, the child was weighed and measured in a corner of the room where no one except for the investigator and the child could see the scale. If the parent did not wish to wait for the child to complete the instruments, a meeting time and place that was mutually agreeable for the parent, child, and investigator was established.

Angle (1984) and Harter (1985) reported that their instruments may be used in a group setting with the researcher reading the questions to the participants and then taking time to allow the participants to select their answer to each question. Initially the investigator of the current study gathered data utilizing two groups containing six participants in each group. The investigator found that this method did not allow the children adequate time to think about the question before giving their answer nor did the children ask for clarifications until after the instruments were completed with this method. Before turning in the instruments to the researcher, the children were allowed to change their answers once clarification was sought. After these two groups, the researcher opted to collect data with participants in a one-on-one interview.

The 12 responses that were collected in a small group setting were compared to the one-on-one responses using a $t$-test. Mean scores for the PBS and the scores for Harter's six domains on the SPPC were compared. There were no significant differences $(p \leq 0.05)$ between the groups by dependent sample $t$-tests.

\section{Procedure}

Recruitment and data collection began once the dissertation committee and IRB approval was obtained. Children were enrolled in the study until each of the four quota groups (obese with dog, obese without dog, healthy weight with dog, healthy weight 
without dog) were reached or until no other participants were willing to enroll by the end of the data collection period.

\section{Human Participants Protection}

Expedited approval from the University of Missouri's Health Science Institutional Review Board was obtained. The project qualified for Expedited Review by the Health Science IRB because it presented no more than minimal risks to the participants and consisted of collection of body composition information and the completion of surveys (http://research.missouri.edu/hsirb/index). Potential participants and their parents were told that the purpose of the study was to describe the strength of the bond that existed between children and their dogs and the relationship that this bond had on the child's self-esteem. It was explained that a child's BMI may be a factor in their self-esteem level so the child's height and weight was measured. The Demographics Questionnaire, SPPC, and PBS were identified by a number that was not traceable to the participant. This identification number was assigned consecutively and recorded on all 3 instruments that the child and parent completed. The signed consent forms, assent forms, and the list of participants that the investigator utilized to insure that a child was not enrolled in the study more than once, were kept in alphabetical order so that there was no link between these forms and the numbers assigned to the completed instruments.

The investigator kept a list of participants' names separate from any data and consent forms. The list did not contain any information that could identify children's BMI information or their PBS scores or self-esteem scores. The list was only used to validate that the child had not previously participated in the study in an effort to prevent cross contamination of participants due to the multiple recruitment sites. The token 
reward (\$5 gift card) for participating represented an appreciation gift for the participants' time spent in completing the study. The investigator did not identify any attempts by participants to repeat participation in the study to gain more rewards.

Benefits to participation in the study were the contribution to a better understanding of the bond formed between children and their dog, as well as, during the completion of the PBS the children may have experienced positive feelings toward their dog. Risks to participating in the study were minimal. There was a small risk that while the children completed the Self-Perception Profile for Children, they may have begun to feel inadequate or feel negative about themselves. All parents were given the study information sheet before consent was obtained. This sheet contained the primary investigator's contact information. Parents were encouraged to contact the investigator if they were concerned about their child's wellbeing after completing the study. No parent contacted the investigator during the study due to concern for their child's wellbeing; however, if a parent had contacted the investigator, the number of a local psychologist who specialized in children would have been given.

The parents and the children were informed of their rights to withdraw from the study at any time until the instruments were completed and the meeting was terminated. Due to the instruments not containing any identifiable information once the investigator had placed the completed instruments in the file, it would be impossible to retrieve a specific child's instrument. All instruments were completed without incidence. Data collected from children were not made available to parents.

\section{Data Management}


Completed instruments were kept in a locked filing cabinet. Consent and assent forms were kept in a locked filing cabinet separate from the completed instruments. The locked filing cabinets were in a locked office in the MU Sinclair School of Nursing. The list of children's names was destroyed once all data had been collected. There was no information that could connect the consent or assent forms to the completed instruments. The completed instruments were numbered consecutively so that the PBS and SPPC were matched for the same child, however; no identifying data were on either instrument. The consent and assent forms were stored in alphabetical order to insure that they could not be associated with completed instruments.

Data were entered by the investigator into two separate Excel spreadsheets on two separate occasions. The Statistical Compare program was then utilized to check for accurate entry. The data were stored on an encrypted jump drive which was also stored in the locked filing cabinet. The data that were entered into the spread sheet included the identification number assigned to the instruments and the responses from the instrument but not the child's name.

The data will be stored for 7 years after the completion of the study. After 7 years the data will be destroyed by shredding hard copies of instruments and erasing the jump drive. The investigator, the investigator's committee chair, and the statistician will have access to the data during the 7 years after the completion of the study.

\section{Data Analysis}

Descriptive statistics were computed using the demographic questionnaire responses in order to describe and determine differences between the groups (Polit \& 
Beck, 2008). The data for the PBS and SPPC were entered into SPSS for analysis in order to answer the research questions and to test the study hypotheses.

Hypothesis 1- Obese children who have a family dog will have higher self-esteem than obese children without a family dog.

Hypothesis 2- Children who are obese will have a significantly stronger bond with their dog than children who are of a healthy weight.

Hypothesis 3- Children who have a family dog will have higher self-esteem than children who do not have a family dog.

Hypothesis 4- Obese children will anthropomorphize the family dog more frequently than children who are of a healthy weight.

Hypothesis 5- Obese children who have a stronger bond with their family dog will have higher self-esteem than obese children with a weaker bond with their family dog. 


\section{Chapter IV}

\section{Results}

This chapter is divided into four sections: demographic characteristics of the children, pet ownership characteristics, and findings from hypothesis testing for each dependent variable. The independent variables in the study were the child's weight status, dog ownership, and the child's pet bonding score. The key dependent variables in this study were the child's weight status, the child's self-esteem, and the strength of the bond formed with their dog.

The children were recruited from a local parochial school $(n=86)$, a soccer club $(n=11)$, a swim club $(n=11)$, or by word of mouth $(n=12)$. Many of the children who attended the parochial school were also members of one of the sporting clubs; however, they received the information through the school system versus through their sporting club. The children were divided into four groups. The factors that were used to determine which group the children belonged to were the child's weight status and whether the child owned a dog that lived inside the house at least $50 \%$ of the time. The four groups were: children who were of a healthy weight and owned a dog, children who were of a healthy weight and did not own a dog, children who were overweight and owned a dog, and children who were overweight and did not own a dog (See Figure 4). 
Figure 4 Groups of Participants

\begin{tabular}{|l|l|}
\hline Group 1 $(\mathrm{n}=29)$ & Group 2 $(\mathrm{n}=31)$ \\
Healthy weight with a dog & Healthy weight without a dog \\
\hline Group 3 $(\mathrm{n}=32)$ & Group 4 $(\mathrm{n}=28)$ \\
Overweight with a dog & Overweight without a dog \\
\hline
\end{tabular}

Figure 4. Participants were assigned to one of the above groups based on child's weight and dog ownership status.

The data were collected utilizing two instruments: Harter's Self-Perception Profile (SPPC) and the Pet Bonding Scale (PBS). The SPPC consists of 6 domains: Scholastic Competence, Athletic Competence, Social Competence, Physical Appearance, Behavioral Conduct, and Global Self-Worth (or self-esteem). The scale uses a Likert format with $1=$ low perceived competence and $4=$ a high perceived competence. The highest score possible in each domain is 24 while the lowest score possible in each domain is six. The higher the score in a domain the more confident the child feels in that domain and vice versa. Table 3 shows descriptive statistics on data derived from the SPPC.

The Pet Bonding Scale consists of 25 items. The scale uses a Likert format with 1 = weak bonding and $3=$ strong bonding. The lowest possible score for the PBS is a 25 , indicating no bond or a very weak bond formed between the child and their dog. The highest score possible for the PBS is a 75, which indicates a strong bond has formed between the child and their dog. Table 2 shows the descriptive statistics derived from the PBS. 
Table 2

Descriptive Statistics for $S P P C \& P B S$

\begin{tabular}{|c|c|c|c|c|c|c|c|c|c|c|c|c|}
\hline \multirow[b]{3}{*}{ Variable } & \multicolumn{6}{|c|}{ Dog } & \multicolumn{6}{|c|}{ No Dog } \\
\hline & \multicolumn{3}{|c|}{$\begin{array}{l}\text { Healthy Weight } \\
\text { (Group 1) }\end{array}$} & \multicolumn{3}{|c|}{$\begin{array}{l}\text { Overweight } \\
\text { (Group 3) }\end{array}$} & \multicolumn{3}{|c|}{$\begin{array}{l}\text { Healthy Weight } \\
\text { (Group 2) }\end{array}$} & \multicolumn{3}{|c|}{$\begin{array}{l}\text { Overweight } \\
\text { (Group 4) }\end{array}$} \\
\hline & Mean & SD & Range & Mean & SD & Range & Mean & $\mathrm{SD}$ & Range & Mean & SD & Range \\
\hline Age (years) & 10.1 & 1.415 & $8.0-11.9$ & 10.4 & 1.187 & $8.0-11.9$ & 10.07 & 1.436 & $8.0-11.9$ & 10.2 & 1.172 & $8.25-11.9$ \\
\hline $\begin{array}{l}\text { BMI } \\
\text { percentile }\end{array}$ & 56.3 & & $24-83$ & 93.2 & & $88-99$ & 58.8 & & $1-83$ & 87.3 & & $85-98$ \\
\hline $\begin{array}{l}\text { Scholastic } \\
\text { Competence }\end{array}$ & 17.63 & 4.335 & $11.0-24.0$ & 17.91 & 3.938 & $11.0-24.0$ & 18.1 & 4.206 & $10.0-24.0$ & 18.3 & 4.384 & $10.0-24.0$ \\
\hline $\begin{array}{l}\text { Physical } \\
\text { Appearance }\end{array}$ & 18.87 & 2.543 & $14.0-24.0$ & 16.66 & 3.642 & $10.0-24.0$ & 19.84 & 2.354 & $11.0-24.0$ & 17.81 & 2.543 & $13.0-23.0$ \\
\hline $\begin{array}{l}\text { Athletic } \\
\text { Competence }\end{array}$ & 17.77 & 4.305 & $8.0-24.0$ & 17.81 & 4.351 & $6.0-24.0$ & 17.87 & 3.713 & $13.0-23.0$ & 17.19 & 4.625 & $10.0-24.0$ \\
\hline $\begin{array}{l}\text { Behavioral } \\
\text { Conduct }\end{array}$ & 18.70 & 2.973 & $12.0-24.0$ & 18.63 & 2.826 & $11.0-24.0$ & 19.35 & 3.261 & $15.0-24.0$ & 20.22 & 2.455 & $13.0-24.0$ \\
\hline $\begin{array}{l}\text { Global } \\
\text { Self-Worth }\end{array}$ & 20.40 & 2.673 & $14.0-24.0$ & 18.81 & 2.571 & $14.0-24.0$ & 20.77 & 2.404 & $15.0-24.0$ & 19.67 & 2.304 & $16.0-24.0$ \\
\hline $\begin{array}{l}\text { Social } \\
\text { Competence }\end{array}$ & 18.33 & 3.717 & $8.0-22.0$ & 16.03 & 4.575 & $8.0-24.0$ & 18.32 & 2.903 & $8.0-22$ & 16.78 & 3.766 & $11.0-22.0$ \\
\hline $\begin{array}{l}\text { Pet Bonding } \\
\text { Scale }\end{array}$ & 58.03 & 9.814 & $37.0-73.0$ & 55.59 & 7.943 & $42.0-72.0$ & & & & & & \\
\hline
\end{tabular}




\section{Demographic Characteristics of the Sample}

There were slightly more male participants $(n=65)$ than female participants $(n=55)$ as shown in Table 3. Fifty-nine of the participants had a body mass index that was at the $85^{\text {th }}$ percentile or higher causing them to be considered in the overweight/obese group. Participants ranged in age from eight to eleven years, with age 11 being the most common. The mean age ranged from 10.0 to 10.5 in each of the four groupings of children according to their weight status and dog ownership status. The majority of the participants were Caucasian from upper middle to high socio-economic status co-residing in a home with both biological parents. Only $9.2 \%(\mathrm{n}=11)$ of the children did not have siblings. Additional information regarding the demographic characteristics of the participants can be found in Table 3.

For the purpose of this study, children whose BMI was on or above the $85^{\text {th }}$ percentile for their gender and age were considered to be obese. Z-scores of percentile curves can also be useful to evaluate the size and growth of children (Kuczmarski et al., 2000). Z-scores can "facilitate comparisons across ages and allow the mean and standard deviation to be calculated for a group of measures" (Kuczmarski et al., 2000). Z-scores, compare the measured size (BMI percentile) of the individual, to the standard deviation for other children of the same age and gender, the reference population (Kuczmarski et al., 2000, p. 15). Table 4 shows the mean scores for the BMI, BMI percentile, and zscores for each age group split by gender. 
Table 3

Demographic Characteristics of Participants $(N=120)$

\begin{tabular}{|c|c|c|c|c|}
\hline \multirow[b]{2}{*}{ Age } & \multirow[b]{2}{*}{$\begin{array}{l}\text { Healthy Weight } \\
\text { With a dog } \\
\quad(n=16)\end{array}$} & \multicolumn{2}{|c|}{ Girls } & \multirow[b]{2}{*}{$\begin{array}{l}\text { Overweight } \\
\text { Without a dog } \\
\quad(n=13)\end{array}$} \\
\hline & & $\begin{array}{l}\text { Healthy Weight } \\
\text { Without a dog } \\
\quad(n=14)\end{array}$ & $\begin{array}{l}\text { Overweight } \\
\text { With a dog } \\
\quad(n=12)\end{array}$ & \\
\hline 8 & $5.8 \%(7)$ & $4.2 \%(5)$ & $1.7 \%(2)$ & $1.7 \%(2)$ \\
\hline 9 & $1.7 \%(2)$ & $1.7 \%(2)$ & $3.3 \%(4)$ & $6.7 \%(8)$ \\
\hline 10 & $1.7 \%(2)$ & $2.5 \%(3)$ & $1.7 \%(2)$ & $1.7 \%(2)$ \\
\hline 11 & $4.2 \%(5)$ & $3.3 \%(4)$ & $3.3 \%(4)$ & $0.8 \%$ \\
\hline \multirow[b]{2}{*}{ Age } & & \multicolumn{2}{|c|}{ Boys } & \\
\hline & $\begin{array}{l}\text { Healthy Weight } \\
\text { With a dog } \\
\quad(n=14)\end{array}$ & $\begin{array}{l}\text { Healthy Weight } \\
\text { Without a dog } \\
\quad(n=17)\end{array}$ & $\begin{array}{l}\text { Overweight } \\
\text { With a dog } \\
\quad(n=20)\end{array}$ & $\begin{array}{l}\text { Overweight } \\
\text { Without a dog } \\
\quad(n=14)\end{array}$ \\
\hline 8 & $1.7 \%(2)$ & $4.2 \%(5)$ & $2.5 \%$ & $0.8 \%$ \\
\hline 9 & $2.5 \%(3)$ & $2.5 \%(3)$ & $2.5 \%(3)$ & $1.7 \%(2)$ \\
\hline 10 & $2.5 \%(3)$ & $1.7 \%(2)$ & $3.3 \%(4)$ & $2.5 \%$ \\
\hline 11 & $5 \%$ & $5.8 \%(7)$ & $8.3 \%(10)$ & $6.6 \%(8)$ \\
\hline
\end{tabular}




\begin{tabular}{|c|c|c|c|c|}
\hline $\begin{array}{l}\text { Racial/ Ethnic } \\
\text { Background }\end{array}$ & $\begin{array}{l}\text { Healthy Weight } \\
\text { With a dog } \\
(n=30)\end{array}$ & $\begin{array}{l}\text { Healthy Weight } \\
\text { Without a dog } \\
\quad(n=31)\end{array}$ & $\begin{array}{l}\text { Overweight } \\
\text { With a dog } \\
\quad(n=32)\end{array}$ & $\begin{array}{l}\text { Overweight } \\
\text { Without a dog } \\
\quad(n=27)\end{array}$ \\
\hline African American & $0 \%(0)$ & $0 \%(0)$ & $0 \%(0)$ & $7.4 \%(2)$ \\
\hline Caucasian & $100 \%(30)$ & $100 \%(31)$ & $93.8 \%(30)$ & $88.9 \%(24)$ \\
\hline Mixed Race & $0 \%(0)$ & $0 \%(0)$ & $6.2 \%(2)$ & $3.7 \%(1)$ \\
\hline \multicolumn{5}{|c|}{ Socio-Economic Status (dollars/year) } \\
\hline Less than 25,000 & $0 \%(0)$ & $6.5 \%(2)$ & $3.1 \%(1)$ & $0 \%(0)$ \\
\hline $25,001-74,999$ & $6.7 \%(2)$ & $12.9 \%(4)$ & $6.3 \%(2)$ & $40.7 \%(11)$ \\
\hline Greater than 75,000 & $93.3 \%(28)$ & $80.6 \%(25)$ & $90.6 \%(29)$ & $59.3 \%(16)$ \\
\hline \multicolumn{5}{|l|}{ Family Status } \\
\hline Parents Married & $90 \%(27)$ & $77.4 \%(24)$ & $81.3 \%(26)$ & $77.8 \%(21)$ \\
\hline Parents Divorced & $10 \%(3)$ & $19.4 \%(6)$ & $15.6 \%(5)$ & $22.2 \%(6)$ \\
\hline Parents Separated & $0 \%(0)$ & $3.2 \%(1)$ & $0 \%(0)$ & $0 \%(0)$ \\
\hline Parents Widowed & $0 \%(0)$ & $0 \%(0)$ & $3.1 \%(1)$ & $0 \%(0)$ \\
\hline
\end{tabular}


Table 4

Means of BM I, BMI Percentiles and z scores for participants (Age in years)

\begin{tabular}{|c|c|c|c|c|c|c|c|c|}
\hline \multirow[t]{2}{*}{ Age } & \multicolumn{4}{|c|}{ Male } & \multicolumn{4}{|c|}{ Female } \\
\hline & $n$ & BMI & BMICentile & z score & $n$ & BMI & BMICentile & z score \\
\hline 8 yrs & 11 & 17.8 & 70.3 & -0.659 & 16 & 17.5 & 65.1 & -0.752 \\
\hline 9 yrs & 11 & 19.4 & 72.5 & -1.31 & 16 & 19.7 & 78.0 & -1.31 \\
\hline $10 \mathrm{yrs}$ & 12 & 20.7 & 76.7 & +0.235 & 9 & 18.0 & 77.2 & -0.23 \\
\hline $11 \mathrm{yrs}$ & 31 & 21.8 & 80.8 & +0.57 & 14 & 20.4 & 69.6 & +0.14 \\
\hline
\end{tabular}

\section{Pet Ownership Characteristics}

Twenty-six percent of the children $(\mathrm{n}=31)$ who did not have a dog that lived in the house reported owning some other type of indoor pet. Other animals reported by the children to be living inside the house were birds, guinea pigs, hamsters, rats, fish, turtles, hermit crabs, a ferret, frogs, and chickens. Of the children who owned dogs living inside their homes, the majority owned one dog; however 26 of the children owned more than one dog that lived inside the home. In these instances, the child was told "Answer these questions only about the dog you named as closest to being your friend" (Angle, Blumentritt, \& Swank, 2007).

Several of the participants had owned their dogs for longer than five years $(\mathrm{n}=$ 19). Only four reported that their dog had lived with them for less than a year. Over half of the parents of children who owned inside dogs reported that the child spent at least one hour per day interacting with the dog. Dog owners were also described by their parents based on the type of care that they provided their dogs each week. This included feeding, walking, grooming, playing with, and cleaning up after the dog. Additional information regarding pet ownership characteristics may be found in Table 5 . 
Table 5

Characteristics of Pet Ownership

\begin{tabular}{|c|c|c|c|c|}
\hline & $\begin{array}{l}\text { Healthy Weight } \\
\text { With a dog } \\
(n=30)\end{array}$ & $\begin{array}{l}\text { HealthyWeight } \\
\text { Without a dog } \\
\quad(n=31)\end{array}$ & $\begin{array}{l}\text { Overweight } \\
\text { With a dog } \\
\quad(n=32)\end{array}$ & $\begin{array}{l}\text { Overweight } \\
\text { Without a dog } \\
\quad(n=27)\end{array}$ \\
\hline $\begin{array}{l}\text { Indoor Dog Only } \\
\text { Indoor Dog \& Other } \\
\text { Pet }\end{array}$ & $\begin{array}{l}53.3 \%(16) \\
46.6 \%(14)\end{array}$ & & $\begin{array}{l}28.1 \%(9) \\
71.9 \%(23)\end{array}$ & \\
\hline $\begin{array}{l}\text { No Dog but Other Pet } \\
\text { No Pet }\end{array}$ & & $\begin{array}{l}54.8 \%(17) \\
45.2 \%(14)\end{array}$ & & $\begin{array}{l}51.9 \%(14) \\
48.1 \%(13)\end{array}$ \\
\hline Number of Inside Dogs & $\begin{array}{l}\text { Healthy Weight } \\
\quad(n=30)\end{array}$ & & $\begin{array}{l}\text { Overweight } \\
\quad(n=32)\end{array}$ & \\
\hline $\begin{array}{l}1 \\
2 \\
3\end{array}$ & $\begin{array}{l}66.7 \%(20) \\
16.7 \%(5) \\
16.7 \%(5)\end{array}$ & & $\begin{array}{l}50.0 \%(16) \\
34.4 \%(11) \\
15.6 \%(5)\end{array}$ & \\
\hline
\end{tabular}


Healthy Weight $\quad$ Overweight

$(n=30) \quad(n=32)$

\begin{tabular}{lll}
\hline Years Owned Dog & $3.3 \%(1)$ & \\
$<$ 1 Year & $6.7 \%(2)$ & $9.4 \%(3)$ \\
One Year & $23.3 \%(7)$ & $6.3 \%(2)$ \\
Two Years & $30.0 \%(9)$ & $12.5 \%(4)$ \\
Three Years & $3.3 \%(1)$ & $12.5 \%(4)$ \\
Four Years & $3.3 \%(1)$ & $12.5 \%(4)$ \\
Five Years & $30.0 \%(9)$ & $9.4 \%(3)$ \\
> Five Years & & $37.5 \%(12)$ \\
& & \\
Hours/day interacting with dog & $30.0 \%(9)$ & $21.9 \%(7)$ \\
< 1 Hour & $50.0 \%(15)$ & $59.4 \%(19)$ \\
1 Hour & $23.3 \%(7)$ & $18.9 \%(6)$ \\
2 Hours & & \\
\end{tabular}

$\stackrel{\infty}{\omega}$ 
Table 6 presents the coefficients for inter-correlations among study variables. Examination of the table shows that there was a significant negative correlation between weight status and social competence. Children who were overweight were more likely to have a lower score in social competence. A significant correlation was also found between athletic competence and social competence. Children who had higher athletic competence scores also reported to have higher social competence scores. Negative correlations were noted between physical appearance and dog ownership and behavioral conduct and dog ownership. Children who owned a dog, regardless of weight status, reported lower scores for physical appearance and behavioral conduct. Another negative correlation was also noted between physical appearance and weight status. Children who had lower physical appearance scores, regardless of dog ownership, reported lower scores for physical appearance. Positive correlations were noted between physical appearance and social competence and physical appearance and athletic competence. Children who reported higher physical appearance scores also had higher social competence scores and higher athletic competence scores. Correlations between general self-worth and scholastic competence, social competence, athletic competence, and physical appearance were also noted. Children who reported higher scores for general self-worth also reported higher scores for scholastic competence, social competence, athletic competence, and physical appearance. A positive correlation was noted between behavioral conduct and general self-worth. Children who reported higher behavioral conduct scores also reported higher scores for general self-worth. 
Table 6

Correlation Coefficients

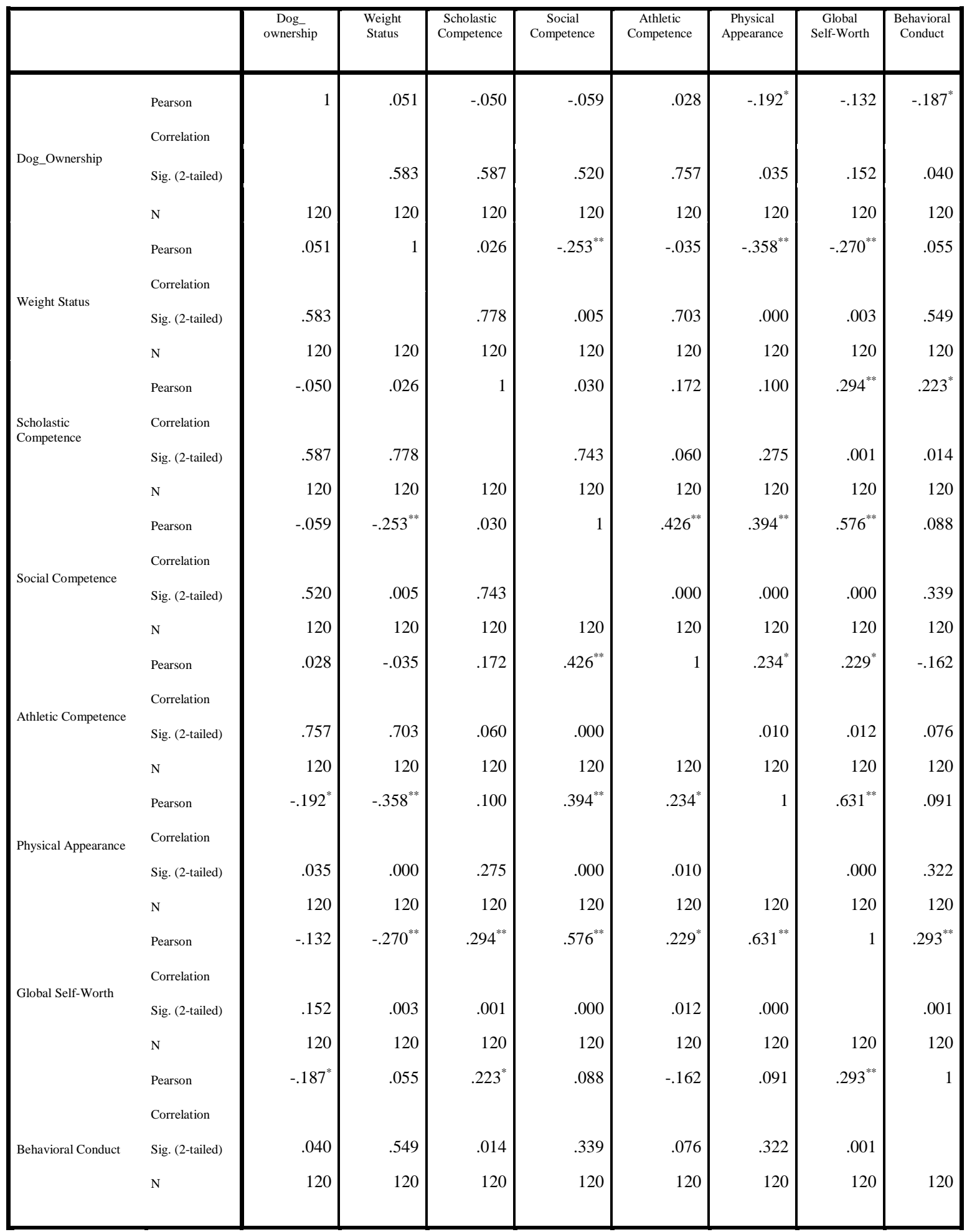

* Correlation is significant at the 0.05 level (2-tailed).

** Correlation is significant at the 0.01 level (2-tailed). 


\section{Hypotheses testing}

Hypotheses were tested using a One-way Analysis of Variance (ANOVA) with two main effects (obesity and dog ownership) each with two levels, and an interaction to see whether obesity interacted with dog ownership. The level for determining statistical significance for all hypothesis testing was $p \leq 0.05$.

Hypothesis 1- Obese children who have a family dog will have better self-esteem scores than obese children without a family dog. Weight of the child and dog ownership acted as independent variables. The dependent variable for this hypothesis was self-esteem of the child. A one-way ANOVA was conducted to identify any association between owning a dog and selfesteem in healthy and over-weight children. As shown in Table 7, obese children had significantly lower self-esteem than children of healthy weight $[\mathrm{F}(3,1)=8.698, p=0.004]$.

However, there was no relationship between obesity and self-esteem among children who owned a $\operatorname{dog}[F(3,1)=0.276, p=0.600]$. Therefore, hypothesis 1 was rejected. While obese children did have lower self-esteem, owning a family dog was not associated with better self-esteem.

Table 7

Test of Between-Subjects Effects with Self-Esteem as the Main Effect

Dependent Variable: Self-Esteem

\begin{tabular}{|l|r|r|r|r|r|r|}
\hline Source & $\begin{array}{r}\text { Type III Sum } \\
\text { of Squares }\end{array}$ & df & \multicolumn{1}{c|}{$\begin{array}{c}\text { Mean } \\
\text { Square }\end{array}$} & \multicolumn{1}{c|}{ F } & Sig. & $\begin{array}{r}\text { Partial Eta } \\
\text { Squared }\end{array}$ \\
\hline Corrected Model & $70.497^{\mathrm{a}}$ & 3 & 23.499 & 3.768 & .013 & .089 \\
Intercept & 47391.186 & 1 & 47391.186 & 7598.370 & .000 & .985 \\
Weight Status & 54.252 & 1 & 54.252 & 8.698 & .004 & .070 \\
Dog-ownership & 11.270 & 1 & 11.270 & 1.807 & .181 & .015 \\
Weight Status & 1.721 & 1 & 1.721 & .276 & .600 & .002 \\
Dog-ownership & & & & & & \\
Error & 723.494 & 116 & 6.237 & & & \\
Total & 48355.000 & 120 & & & & \\
Corrected Total & 793.992 & 119 & & & & \\
\hline
\end{tabular}

a. $\mathrm{R}^{2}=.089$ (Adjusted R Squared $=.065$ ) 
Hypothesis 2- Children who are obese will have a significantly stronger bond with their dog than children who are of a healthy weight. The independent variables were weight and dog ownership. The strength of bonding with the dog was the dependent variable. Mean PBS scores were 55.59 for the obese children who owned a dog and 58.03 for the children of a healthy weight who owned a dog. A one-way ANOVA was conducted to compare the association between weight and pet bonding scores in healthy and over-weight children. As shown in Table 8, there was not a significant effect of weight on pet bonding at the $p \leq .05$ level for the conditions $[\mathrm{F}(3,1)=1.086, p=0.300]$. Therefore, hypothesis 2 was rejected. Children who were obese did not have a significantly stronger bond with their dog than children who were of a healthy weight.

Table 8

Test of Between-Subjects Effects with Pet Bonding Scale Score as the Main Effect

Dependent Variable: Pet Bonding Scale-Total Score

\begin{tabular}{|l|r|r|r|r|r|r|}
\hline Source & $\begin{array}{r}\text { Type III Sum } \\
\text { of Squares }\end{array}$ & df & \multicolumn{1}{c|}{$\begin{array}{c}\text { Mean } \\
\text { Square }\end{array}$} & \multicolumn{1}{c|}{ F } & Sig. & \multicolumn{1}{c|}{$\begin{array}{c}\text { Partial Eta } \\
\text { Squared }\end{array}$} \\
\hline Corrected Model & $96683.981^{\mathrm{a}}$ & 3 & 32227.994 & 787.259 & .000 & .953 \\
Intercept & 96439.087 & 1 & 96439.087 & 2355.796 & .000 & .953 \\
Weight Status & 44.455 & 1 & 44.455 & 1.086 & .300 & .009 \\
Dog ownership & 96439.087 & 1 & 96439.087 & 2355.796 & .000 & .953 \\
Weight Status* & 44.455 & 1 & 44.455 & 1.086 & .300 & .009 \\
Dog ownership & & & & & & \\
Error & 4748.685 & 116 & 40.937 & & & \\
Total & 204686.000 & 120 & & & & \\
Corrected Total & 101432.667 & 119 & & & & \\
\hline
\end{tabular}

a. $\mathrm{R}^{2}=.953$ (Adjusted R Squared $=.952$ )

Hypothesis 3- Children who have a family dog will have a better level of self-esteem than children who do not have a family dog. The independent variable was dog ownership. The dependent variable was self-esteem (as measured by general self-worth scores on the SPPC). A 
one-way ANOVA was conducted to compare the effect of having a family dog on self-esteem. As previously shown in Table 7, there was no significant relationship between owning a dog and self-esteem $[\mathrm{F}(3,1)=1.807, p=0.181]$. Therefore, hypothesis 3 was rejected. Children who had a family dog did not have better self-esteem than children who did not own a family dog.

Hypothesis 4 - Obese children will anthropomorphize the family dog more frequently than children who are of a healthy weight. The independent variables for hypothesis four were weight status and dog ownership. The dependent variable was anthropomorphizing the family dog. Anthropomorphizing was measured by summing six items on the Pet Bonding Scale. These items suggested that the child assigned the dog human qualities. A subscale was created using these items and data were analyzed via a one-way ANOVA to describe the association between obesity and the childrens' anthromorphizing the family dog. As shown in Table 9, there was no significant relationship between weight status and a child's tendency to anthropomorphize the family $\operatorname{dog}[\mathrm{F}(3,1)=0.326, p=0.569]$. Therefore, hypothesis 4 was rejected. Obese children did not anthropomorphize the family dog more frequently than did children who were of a healthy weight.

Table 9

Test of Between-Subjects Effects with Scores from Selected Items on the PBS as the Main Effect Dependent Variable: Pet Bonding Scale-subscore

\begin{tabular}{|l|r|r|r|r|r|r|}
\hline Source & $\begin{array}{c}\text { Type III Sum of } \\
\text { Squares }\end{array}$ & \multicolumn{1}{c|}{ df } & \multicolumn{1}{c|}{$\begin{array}{c}\text { Mean } \\
\text { Square }\end{array}$} & \multicolumn{1}{c|}{ F } & \multicolumn{1}{c|}{ Sig. } & \multicolumn{1}{c|}{$\begin{array}{c}\text { Partial Eta } \\
\text { Squared }\end{array}$} \\
\hline Corrected & $7022.556^{\mathrm{a}}$ & 3 & 2340.852 & 906.836 & .000 & .959 \\
Model & 6995.059 & 1 & 6995.059 & 2709.856 & .000 & .959 \\
Intercept & .840 & 1 & .840 & .326 & .569 & .003 \\
Weight Status & 6995.059 & 1 & 6995.059 & 2709.856 & .000 & .959 \\
Dog ownership & .840 & 1 & .840 & .326 & .569 & .003 \\
Weight Status * & & & & & & \\
Dog ownership & 299.435 & 116 & 2.581 & & & \\
Error & 14827.000 & 120 & & & & \\
Total & 7321.992 & 119 & & & & \\
Corrected Total & & &
\end{tabular}


a. $\mathrm{R}^{2}=.959$ (Adjusted $\mathrm{R}$ Squared $=.958$ )

Hypothesis 5- Obese children who have a stronger bond with their family dog will have a better level of self-esteem (as evidenced by global self-worth scores) than obese children with a weaker bond with their family dog. The independent variables for hypothesis 5 were weight status and dog ownership. The dependent variables were strength of bond and selfesteem. A one-way ANOVA was conducted to identify the relationship between the strength of the bond formed between obese children and the family dog and the children's self-worth scores. As previously shown in Table 8, bonding scores were not significantly related to self-esteem [F $(3,1)=1.086, p=0.300]$. The PBS and BMI show evidence of a low correlational relationship at 0.23 ; however, statistically this was not significant. Therefore, hypothesis 5 was rejected. Obese children who had a stronger bond with their family dog did not have better self-esteem than obese children who had a weaker bond with the family dog.

\section{Other Findings}

In this study, (32\%) of the obese children reported that they felt that they did not have very many friends, while only $(11 \%)$ of the participants who were of a healthy weight felt that they did not have very many friends. When the variable of weight was controlled for, children who owned a $\operatorname{dog}(n=16)$ were more likely to report not having as many friends as children who did not own a dog $(n=10)$.

The data were then analyzed to see if general self-worth of the children who owned a dog and reported not having as many friends, would have been less if the children did not own a dog. This was to determine if the child's self-esteem would have possibly been lower without the support of the dog but was within the mean score because of the support of the dog. However, all subjects who owned a dog reported a strong bond with their dog and there was no difference in the general self-worth scores on 
the SPPC between those children who were obese and those children who were of a healthy weight. As presented in Table 10, the hypothesis that self-esteem would be lower if the obese child did not own a dog was not supported by the data.

Table 10

Test of Between-Subjects Effects with Self-Esteem as the Main Effect and Dog Ownership and BMI Percentile as Interactive Effects

Main Effect: General Self-Worth

\begin{tabular}{|rl|r|r|r|}
\hline BMI_centile_2groups Dog_numeric & Mean & Std. Deviation & N \\
\hline \multirow{3}{*}{1} & No & 20.77 & 2.404 & 31 \\
& Yes & 20.40 & 2.673 & 30 \\
& Total & 20.59 & 2.526 & 61 \\
& No & 19.67 & 2.304 & 27 \\
& Yes & 18.81 & 2.571 & 32 \\
& Total & 19.20 & 2.469 & 59 \\
& No & 20.26 & 2.403 & 58 \\
\multirow{3}{*}{ Total } & Yes & 19.58 & 2.719 & 62 \\
& Total & 19.91 & 2.583 & 120 \\
\hline
\end{tabular}

Statistically significant between-group differences were found between obese children and healthy weight children on the SPPC in the domains of Social Competence $[\mathrm{F}(3,1)=7.673, p=0.007]$, Behavioral Conduct $[\mathrm{F}(3,1)=4.486, p=0.036]$, and Physical Appearance $[\mathrm{F}(3,1)=4.216, p=0.042]$. Mean Physical Appearance, Behavioral Conduct, and Social Competence Scores are located in Table 11. Children who did not own a dog in both obese and healthy weight groups had higher scores in all three domains than children who did own a dog. This was a counter-intuitive finding.

Behavior was then used as a moderating variable in a statistical analysis with dog ownership as an independent variable and the strength of the bond as the dependent variable. There was no statistical difference between the groups so this also was statistically not supported by the data.

\section{Performance of the Study Instruments}


In the current study, the Cronbach's Alpha for the PBS was a $0.989(\mathrm{~N}=120)$. In the current study, the Cronbach's Alpha for the SPPC was a $0.882(\mathrm{~N}=120)$. 
Table 11

Univariate ANOVA Physical Appearance and Social Acceptance Scores with Dog Ownership $(N=120)$

\section{Mean Physical Appearance Mean Social Competence Mean Behavioral Conduct}

\begin{tabular}{lccc}
\hline Overweight without a $\operatorname{dog}(\mathrm{N}=27)$ & $17.81 \pm 2.543$ & $16.78 \pm 3.766$ & $20.22 \pm 2.455$ \\
Overweight with a $\operatorname{dog}(\mathrm{N}=32)$ & $16.66 \pm 3.642$ & $16.03 \pm 4.575$ & $18.63 \pm 2.826$ \\
Healthy weight without a $\operatorname{dog}(\mathrm{N}=31)$ & $19.84 \pm 2.354$ & $18.32 \pm 2.903$ & $19.35 \pm 3.261$ \\
Healthy weight with a $\operatorname{dog}(\mathrm{N}=30)$ & $18.87 \pm 2.543$ & $18.33 \pm 3.717$ & $18.70 \pm 2.973$
\end{tabular}




\section{CHAPTER V}

\section{Discussion}

In this chapter, study findings are discussed relative to current literature. Study strengths and limitations are acknowledged. Implications of the findings of this research are identified. Future research areas are recommended. Numerous studies have been conducted regarding childhood obesity and self-esteem. Human animal interaction however, is a newer field of study and a limited number of studies have been conducted with children. There is no known research published in which all three variables in the present study (self-esteem, obesity, and human animal interaction) have been investigated together.

\section{Discussion of Dependent Variables in Current Literature}

Self-esteem in children. The group of children studied in the present research is comparable to the group studied by Harter (2012) when further validating the SelfPerception Profile for Children (SPPC) as shown in Table 12. Harter's sample was drawn from Colorado. Ninety percent of Harter's participants were Caucasian and were from lower middle class to upper middle class families. The sample in the current study was also mainly Caucasian; however, the majority was from upper middle class families residing in mid-Missouri. When comparing the current sample's subscale means of the SPPC with Harter's sample there is very little difference. Harter's mean subscale score for general self-worth ranged from 2.86 to 3.33; however, Harter's lowest mean subscale score (2.86) appeared to be an outlier. When this subscale score was removed from Harter's results, her subscale range for General Self-Worth increased to 3.00-3.33. This is comparable to the mean subscale scores of 3.14-3.46 found in the current study. 
Table 12

Comparison of Harter's Sample With the Sample From the Current Study

Measures Harter's Sample Current Study Sample

Grade Level 3-8

2-7

Geographical location

Colorado

Mid-Missouri

Ethnicity $90 \%$ Caucasian

96\% Caucasian

Socio-Economic Status

Lower middle to

Upper middle class

upper middle class

The slight difference in scores may be explained by geographical location or group make-up. All of the participants in the current study were from mid-Missouri while the children in Harter's study were from Colorado. Harter does not report whether her sample was urban, rural, or a mixture while the majority of the children in the current study were from rural areas. Due to differing aims of the studies, the participants in the current study were placed in groups based on dog ownership and weight of child. Harter grouped children by gender and grade level.

As discussed in Chapter 2, numerous studies have shown a correlation between obesity and lower self-esteem in children. These studies varied in the instruments used to measure self-esteem as well as the populations studied. Several of these studies, (Burrows \& Cooper, 2002; Davison \& Birch, 2001; Franklin, Denyer, Steinbeck, Caterson, \& Hill, 2006; Kimm et al., 1997) however, were more closely related to the current study in methods and population.

For example, Davison and Birch (2001) conducted a longitudinal study sampling girls (both obese and non-obese) from Pennsylvania at age five and seven-years. The authors used The Pictorial Scale of Perceived Competence and Social Acceptance for Young Children (PCSA) as well as the Body Esteem Scale (BES). The BES was developed by Mendelson and White (1982) and assesses overall, nonspecific body 
esteem. The PCSA was also developed by Harter (Harter \& Pike, 1984) but accounts for fewer domains and is written at a level for younger children.

Davison and Birch (2001) reported lower body esteem in the obese girls. In the current study the scores for obese children in the domain of physical appearance were lower than children who were not obese. In addition, the girls in Davison and Birch's (2001) study also reported a decrease in perceived athletic ability. In the current study, there was no significant difference in the domain of Athletic Competence. The difference in findings may be due to the sample in the current study containing boys as wells as girls (Gabelko, Roth, D.A., \& Worrell, 1997; Ridgers, Fazey, \& Fairclough, 2007). Harter (2012), reported that boys consistently have higher athletic competence scores. It may also be due to the current study recruiting some of the participants from competitive sporting clubs or from a school where no child is prohibited from team membership based on athletic ability (Miller \& Levy, 1996).

Davison and Birch (2001) also reported obese girls feeling less perceived peer acceptance. In the current study, significantly lower scores in the domain of social competence was noted in the obese sample. While not exactly the same, the domain of social competence is similar to the domain of peer acceptance on the PCSA. Similar findings between Davison and Birch (2001) and the current study include decreased scores in social competence and physical appearance. The difference in the findings regarding athletic competence may be attributed to the demographic differences of samples as described above.

Burrows and Cooper (2002) found that in girls ages 11 to 12 years, there was a statistically significant inverse relationship between the girl's BMI and self-esteem. This 
means that when the girl's BMI was high, the self-esteem score was low. In the current study, a relationship was also noted between high BMI scores and low self-esteem scores. Burrows and Cooper (2002) also found significant relationships between obesity and the domains of physical appearance and athletic competence scores. As was noted in the Davison and Birch (2002) discussion above, the current study found a similar relationship between obesity and physical appearance scores, while no significant relationship was found between BMI scores and athletic competence scores. Burrows and Cooper (2002) recruited only girls from state schools (the equivalent of public schools in the United States) in England. There was no mention as to whether any of the participants were involved in sporting clubs or team sports through school.

Franklin, Denyer, Steinbeck, Caterson, and Hill (2006) also reported that obese Australian children aged 9.2 to 13.7 years, had significantly lower scores in the domains of athletic competence, physical appearance, and global self-worth. The current study sampled children from eight to 11 years and found lower scores in the domains of physical appearance and global self-worth in obese children. While Franklin et al. (2006) did not find lower scores in the domain of social competence within their whole sample, they did report that obese girls were twice as likely to have low perceived social competence scores when compared with the other participants. The current study also found lower social competence scores in obese children when compared with non-obese children. Franklin et al. (2006) did not discuss whether the children in their study were involved in sporting clubs or team sports.

Kimm et al. (1997) used the SPPC in their study of obese girls ages nine to 10 years. The researchers reported lower scores in the domains of social competence, 
physical appearance, and global self-worth. The current study also found lower scores in the domains of social competence, physical appearance and global self-worth in obese participants. The main difference in the current study was these findings occurred with both males and female obese participants.

Several studies have found socioeconomic status and ethnicity to be possible mediators of the association between obesity and self-esteem; however, the current study did not have a diverse enough sample to isolate these variables as possible mediators (Kimm et al., 1997; Strauss, 2000). Of the total sample in the current study ( $\mathrm{N}=120)$, only $18 \%$ of the participants were from lower socioeconomic status and $4 \%$ of the participants were not Caucasian. While not statistically significant, when analyzed separately the children who were obese and from lower socioeconomic status $(n=14)$ had higher mean subscale scores in the domains of scholastic competence, athletic competence, physical appearance, behavioral conduct, and global self-worth when compared with the overall group mean scores $(\mathrm{N}=120)$. This may be due to the fact that the majority of the participants attend the parochial school which requires uniforms without name brands. This helps to prevent children from lower socioeconomic status from feeling that the socioeconomic differences are as noticeable (Firmin, Smith \& Perry, 2006). While there were several studies in the obesity literature with findings similar to the current study, there were also several studies in the human animal interaction literature with findings similar to the current study.

Pet bonding. Triebenbacher (1998a) found that “children's attachment to a companion animal was positively related to their sense of self-esteem"(p. 143). In the current study, it was determined that general self-esteem as evidenced by global self- 
worth scores, was not significantly associated with owning a dog. However, the majority of children who reported having fewer friends also owned a dog. One of the questions on the PBS did ask the child if they felt like their dog was their only friend. None of the children answered yes to this question; however, several of them made a comment that they considered the dog a friend but not their only friend. The SPPC asks questions about the number of friends but does not assess the quality of these friendships or what these friendships mean to the child. The children that report fewer friends may actually count the dog as a friend in order to protect their self-esteem. The child may feel that other children may judge them on physical appearance or behavioral conduct, where the dog does not judge them. Neither instrument used in the current study was developed to measure strength of friendship or to investigate if the children view this friendship with the dog as equal to the friendship with human friends. A study which investigated this friendship between children and their dog may identify the depth of this relationship between children and their dog. It would be especially beneficial to further investigate the friendship between children with fewer human friends, and their dog.

Owning a dog was significantly related to physical appearance and behavioral conduct. Children, who owned a dog in both the healthy weight group and the obese group, had lower mean physical appearance and behavioral conduct scores than their counterparts who did not own a dog. These findings are counter intuitive and this study does not provide an explanation for these results. A key factor is that these are only the child's perceptions of their behavior and appearance. No data were collected regarding how the child's teacher or parent ranked the child's behavior in comparison with other children's behavior or appearance. There are no published articles in the literature that 
can offer an explanation for these results. More research needs to be done to identify a possible explanation for this finding.

Triebenbacher (1998b) also found that both pet owning and non-pet owning children like to talk about animals. Pet owners relayed stories about their pets to Triebenbacher, while children who did not actually own a pet also relayed stories regarding what their pet would be like if they were to own one. Albert and Bulcroft (1988) also found that pet owners like to talk about their pets. An interview that was designed to take approximately 25 minutes took 40 to 50 minutes to complete because participants wanted to talk about their pets. While Albert and Bulcroft's interview was a quantitative study, the participants offered such rich qualitative data that the investigators subjected it to qualitative analysis. This same phenomenon was found to occur with the children who owned pets in the current study. The Pet Bonding Scale should have taken the children 10-15 minutes to complete. On the average, children in the current study took approximately 40-45 minutes in order to complete the PBS because they offered so much conversation about their pets. In contrast, 30 minutes was allotted for the children to complete the SPPC. The majority of the children completed the SPPC in approximately 15-20 minutes and offered little anecdotal information about themselves.

A major difference between the collected data from this study and the data collected in Angle's study (1994) is the range of scores on the PBS. Angle administered the instrument to her participants in the classroom with all participants at one time. The questions were read aloud and then the students were asked to choose the answer that best represented their feelings for their pet. This may have led children to make decisions without giving thought to the question, answering questions without receiving 
clarification, or answering in a socially desirable manner since they were able to see how others were answering the questions. As previously discussed, when the data were collected during the current study, the PBS was administered in either a small group (less than seven children) or one on one. The difference between the scores from the current study when compared with the scores from Angle's study may be related to the fact that the children were allowed to discuss their dog in the context of the question in the current study and were then able to better apply their thoughts into an answer on the PBS.

Anthropomorphizing. Many studies have discussed the fact that some adults anthropomorphize their pets (Albert \& Bulcroft, 1988; Blouin, 2013) so it is not surprising that children may also anthropomorphize their pets. Blouin (2013) reported that pet owners usually leaned toward one of three orientations regarding pets. The three groups that Blouin utilized were dominionistic, humanistic, or protectionistic. According to Blouin (2013) people who have a domionistic orientation toward pets, see pets as lower in importance than humans but useful in some capacity such as for protection. People who have a protectionistic orientation toward animals, see pets as equivalent or superior to some humans and have a deep respect and concern for all animals. People who have a humanistic orientation towards pets, have an intense emotional attachment to their pet. People who have a humanistic orientation towards pets often think of their dogs as either family or a very close friend.

Children, in the current study, tended to be humanistic in their view of the dog as either a close friend or equal to a sibling or by assigning human characteristics to the dog. In many instances, children in the current study insisted that their dog was a member of their family. Several of the children listed their dog as one of their best friends. Many 
of the children ascribed human emotions to their pet such as anger, loneliness, and happiness. A majority of the children felt that their dog understood what the child was saying to them as well as understood any feelings that the child experienced. Almost all of the children felt that their pet had a favorite family member.

During the data collection for the current study, only one child did not anthropomorphize his dog as much as the other children. This child lived in the country on a farm. Engaging in conversation with this child's father led to the realization that the father had a dominionistic attitude regarding dogs. The father felt that dogs were below humans, that he was the dog's boss, and that the role of the dog was to protect the family and livestock from predators. The dog was allowed in the house at least $50 \%$ of the time, but only in the kitchen on the tile floor. The dog was not allowed in the child's room. This particular child may have been influenced by his father's view; however, it was notable that the child still felt highly of the dog as being part of his family and that the dog had feelings. The fact that the dog was not allowed out of the kitchen or in the child's room may have been an obstacle in this child's ability to bond with his dog; however, the child was adamant that this dog was part of his family.

\section{Strengths and Limitations}

A strength of this study was the method of data collection. The children were either interviewed in a small group or one-on-one with the investigator. This allowed the children more time to process their answers as well as to clarify any questions with the investigator. The investigator was the sole data collector insuring that all of the children, with the exception of the two small groups previously discussed in chapter three, were interviewed and measured in the same manner. 
In the past, some researchers have used self-report to gather anthropometric data. Sherry, Jefferds, and Grummer-Strawn (2007), found that adolescents underestimated their weight when self-reporting. This was especially true for overweight individuals. Goodman, Hinden, and Khandelwal (2000) reported that parents of teens were more accurate than the teenager with reporting their teen's weight but were not always correct. In the current study several parents were surprised by their child's height or weight. All children were measured with the same equipment by the same researcher thus decreasing the risk for error.

The study had several limitations. One limitation was the lack of diversity in the sample. The majority of this sample was Caucasian children from middle income neighborhoods living with both biological parents. The majority of the sample was also derived from the same Parochial school. The small sample may have been another reason that many differences between groups were not noted.

Many of the children who were non dog owners did own other pets that resided in the house and some pets that resided outside of the house. Some of the current non-pet owners had previously owned a dog. The bonds with these animals may have affected the child's self-esteem. If children who did not own a dog were able to think about the dog in a very positive way (Triebenbacher, 1998a), then it is not farfetched to believe that children who had previously owned a dog could think about the bond formed with that dog if they were feeling lonely or sad. In the present study, children were not asked about bonds that were established with other pets. Triebenbacher (1998a) reported that children who owned a cat or dog were more bonded to their pet than other types of pets, however, the children in this study may have felt love and acceptance from non-dog pets. 
In order to obtain an adequate sample size in the present study, children who were overweight or greater than the $85^{\text {th }}$ percentile $(n=43)$ were considered in the same group as children who were obese or greater than the $95^{\text {th }}$ percentile $(n=16)$. Daniels (2005) found that some adolescents who were overweight by guidelines established by the Center for Disease Control (Cole, 2000), reported that their weight was "okay." Allen, Byrne, Blair, and Davis (2006) found that children, who had concerns about their weight and shapes regardless of their actual size, had higher levels of depression when compared with children who had little to no concerns about their weight or shape.

The sample was a convenience sample. Numerous methods were utilized to recruit the 120 participants for the current study. While gender, socioeconomic status, age, and ethnicity have all been implicated as mediators for depression and decreased body satisfaction as related to obesity, when broken down into smaller groups, the number of participants was not large enough to reach statistical significance.

It is a possibility that some of the children in the current study did not consider themselves to be overweight or obese so therefore did not have a lower self-esteem. Along with the Harter SPPC, the study may have been strengthened by also asking the children about their body shape perception. In this model, children are shown nine drawings of body shapes ranging from very thin to very fat (Tiggemann \& Pennington, 1990). These shapes are more like silhouettes, so the child is not choosing a picture based on hair color or facial features. The child then selects what they feel is their current body type as well as what they would like their body type to be.

By using the figure rating method, researchers would be able to distinguish children who are considered obese by their BMI but who did not feel that they are obese 
from children who are considered obese by their BMI and also feel that they are obese. The children who did not feel that they were obese would select figures that were thinner than children who had similar BMI scores and also felt that they were obese. While the domain of Physical Appearance in Harter's SPPC asks questions about the child's physical appearance, it does not tell us if the child wishes they weighed less or more. The SPPC also factors in responses on the child's perception of their face and hair along with questions about their body size (see Appendix C for copy of the SPPC). The figure ratings method "offer a concrete visual representation" (Tiggemann \& Wilson-Barrett, 1998, p. 84). The figure rating method allows for children who are visual processors to relay their feelings of body size without having to process verbal questions.

Another limitation of the current study was the lack of data collection in regard to other potential mediators. Teasing and bullying by both peers and family have been shown in several studies to have a negative effect on the child's self-esteem (Brixval et al., 2011; Fox \& Farrow, 2009; Griffiths et al., 2006; Porter, Stern, Mazzeo, Evans, \& Laver, 2013; Reulbach et al., 2013). Low self-esteem for physical appearance and body dissatisfaction have been discussed in some literature as being a mediating variable between a child's weight status and being a victim of bullying (Brixval, Rayce, Rasmussen, Holstein, \& Due, 2011; Fox \& Farrow, 2009; Lumeng et al., 2010; Reulbach et al., 2013.) Fox and Farrow (2009) stated, "global self-worth, self-esteem for physical appearance and body dissatisfaction all acted as mediators" between weight status and becoming the victim of bullying (p. 1298). Fox and Farrow (2009) went on to say, "Thus, it is not simply being overweight or obese that appears to put children at risk of being victimized by their peers, but these other factors" (p. 1298). Being the victim of 
bullying has also been shown to lead to depression and low self-esteem (Hawker \& Boulton, 2000).

The majority of the children in this study were recruited from a Parochial school which has a zero bullying tolerance. If a child is found to be bullying another child action by the administration will be taken. According to the school's handbook:

Harassment is defined as any unwanted and unwelcome behavior that interferes with the student's performance or creates an intimidating, hostile, or offensive learning environment. Harassment includes physical, visual, verbal, and sexual forms of behavior....If a student believes he/she is being harassed, the student is encouraged to speak with any teacher, the assistant principal, the principal, or any member of the OLLIS staff. The disciplinary action, if warranted, will relate to the nature, context, and seriousness of the harassment, and can include all disciplinary actions up to and including immediate dismissal from OLLIS." The results of this study may have been different if the obese children in this study were subjected to bullying in their school setting. (Our Lady of Lourdes Interparish School, 2014 p. 42)

The researcher in the current study did not ask the children about being bullied, however; when discussing bullying with the teachers at the Parochial school, the teachers reported that bullying is not tolerated. As one teacher stated, "There are times when hurtful comments are made, however, these are usually isolated incidents and are dealt with immediately by the school counselors or the teachers themselves. The ongoing process of bullying is not tolerated" (E. Whaley, personal communication, March 30, 2012). 
A supportive family environment has also been discussed as a potential mediating variable between obesity and low self-esteem in children (Franklin et al., 2006). The participants in the current study who owned a dog already had an established bond with this dog. It could be that this bond did have an effect on the child's self-esteem; however, since the child already owned the dog, a change in self-esteem would not necessarily have been detected. The sample is too small and does not have enough variation to detect subtle changes.

One of the premises for this study was that children who did not receive support from their family may turn to the dog for the social support that they do not garner from their families. The children in this study were mainly from upper middle class socioeconomic status and lived in the same household with both biological parents. It could be that these children have a strong family support to begin with and their selfesteem scores reflect this familial social support. The family members and income for each child was identified but no information was obtained about the perceived social support that the family offered the child nor about possible teasing that the child has received from their family regarding their weight status.

It could also be that owning a dog does not increase self-esteem but may actually effect another construct such as comfort to the child. It could also be that the bond with the dog acts as a moderating variable with some unknown factor. Without the other factor, the bond does not influence the child.

\section{Implications}


The current study suggested that a relationship may exist between owning a dog and how a child feels about their behavioral conduct and physical appearance. Other relationships that were suggested in the current study were between a child's weight and their feelings of self-esteem in the domains of physical appearance, social competence, and general self-worth.

The current study also demonstrated that children formed strong bonds with their dogs and in many instances considered the dog to be a part of their immediate family. Children who owned an inside-residing dog tended to anthropomorphize their dog and discuss the dog as if it were a member of their family. A few of the children compared their dog to that of a sibling expressing a close relationship with their dog.

Caution should be taken, however, when using these results because of the small, homogenous sample utilized. The results can be generalized to Caucasian children, from upper middle class households.

Another implication resulting from this study is the fact that the majority of the obese participants in this study were from upper middle class households. Shrewsbury and Wardle (2008) reported that research that had been presented over the previous 15 years to their study, demonstrated an inverse relationship between socioeconomic status and adiposity. In the current study however; only $24 \%$ of the participants were in lower socioeconomic classes. This demonstrates that children from higher socioeconomic classes also experience obesity. The same healthcare concerns that face obese children from lower socioeconomic classes will also face the obese children from higher socioeconomic classes.

\section{Future Research}


Future research should be conducted using a more diverse and larger sample. An intervention study in which a dog is introduced into the household with a control group and pre-test/post-test design for self-esteem to identify a potential cause and effect relationship would also be beneficial. Including questions regarding children's experiences of being bullied and teased would also strengthen this area of research.

As discussed previously, a research project which focused on studying the quality of the friendship formed with dogs when the child reported fewer human friends. This study may investigate the quality of the friendship that children have with their dog as well as how children view their friendship with the dog when compared to friendships with other children. This study would offer a different construct, such as friendship, to measure versus bonding.

In addition to further research already mentioned, future studies should also be completed in which information is gathered to evaluate the relationship between pet ownership and a child's feelings of self-esteem in the domain of Behavioral Conduct. By using a mixed method study and gathering information from the child, their parents, and a teacher more information may be obtained in order to evaluate the relationship between dog ownership and the child's Behavioral Conduct. A mixed methods study in which children would complete the SPPC, as well as specifically asking children to elaborate on their answers to the SPPC may offer more information on the child's perception of their behaviors. While having parents and teachers of the child, complete the Teacher's Rating Scale of Child's Actual Behavior. This is a companion scale developed by Harter to be administered to teachers or parents as a companion to the SPPC. This study can serve as 
the basis for future studies of relationships between dog ownership of obese children and effects on self-esteem. 


\section{References}

Albert, A. \& Bulcroft, K. (1988). Pets, families, and the life course. Journal of Marriage and the Family, 50(2), 543-552.

Allen, K., Blasovich, J., \& Mendes, W. (2002). Cardiovascular reactivity and the presence of pets, friends, and spouses: The truth about cats and dogs. Psychosomatic Medicine, 64, 727-739.

Allen, K. L., Byrne, S. M., Blair, E. M., \& Davis, E. A., (2006). Why do some overweight children experience psychological problems? The role of weight and shape concern. International Journal of Pediatric Obesity, 1, 239-247. doi: $10.1080 / 17477160600913552$

Alonso, Y. (1999). Cardiovascular responses to a pet snake. The Journal of Nervous and Mental Disease, 187(5), 311-313.

Andersen, R. E., Crespo, C. J., Bartlett, S. J., Cheskin, L. J., \& Pratt, M. (1998). Relationship of physical activity and tv watching with body weight and level of fatness. JAMA, 279(12), 938-942.

Anderson, W. P., Reid, C. M., and Jennings, G. L. (1992). Pet ownership and risk factors for cardiovascular disease. The Medical Journal of Australia, 157, 298-301.

Angle, R. L. (1994). Utilization of the pet bonding scale to examine the relation between the human/companion animal bond and self-esteem in preadolescence (Doctoral dissertation). Retrieved from The University of Houston.

Angle, R. L., Blumentritt, T. \& Swank, P. (1994). The pet bonding scale: Internal reliability and factorial validity. In Annual Meeting of the Southwestern Psychological Association, Tulsa OK.

Arend, R., Gove, F. L., \& Sroufe, A. (1979). Continuity of individual adaptation from infancy to kindergarten: A predictive study of ego-resiliency and curiosity in preschoolers. Child Development, 50(4), 950-959.

Ball, J., Bindler, R., \& Cowen, K. (2014). Principles of pediatric nursing: Caring for children. Upper Saddle River, NJ: Prentice Hall.

Ballouard, J. M., Ajtic, R., Balint, H.,Cmobmja-Isailovic, J., Desmonts, D.., ElMouden, E. H., ...Bonnet, X. (2013). Schoolchildren and one of the most unpopular animals: Are they ready to protect snakes? Anthrozoos, 26(1), 93-109. 
Bang, K., Chae, S., Hyn, M., Nam, H. K., Kim, J., \& Park, K. (2012). The mediating effects of perceived parental teasing on relations on body mass index to depression and self-perception of physical appearance and global self-worth in children. Journal of Advanced Nursing, 68(12), 2646-2653. doi:10.1111/j.13652648.2012.05963.x

Battle, J. (1978). Relationship between self-esteem and depression. Psychological Reports, 42, 745-746.

Baun, M. M., Bergstrom, N., Langston, N. F., \& Thoma, L. (1983). Physiological effects of human/companion animal bonding. Nursing Research, 33(3), 126-129.

Beck, A. M. \& Katcher, A. H. (1983). Between pets and people: The importance of animal companionship. New York: G. P. Putnam's Sons.

Beetz, A., Kotrschal, K., Turner, D. C., Hediger, K., Uvnas-Moberg, K., \& Julius, H. (2011). The effect of a real dog, toy dog, and friendly person on insecurely attached children during a stressful task: An exploratory study. Anthrozoos, 24(4), 349-368.

Bell, S. K. \& Morgan, S. B. (2000). Children's attitudes and behavioral intentions toward a peer presented as obese: Does a medical explanation for the obesity make a difference? Journal of Pe diatric Psychology, 25(3), 137-145.

Blouin, D. D. (2013). Are dogs children, companions, or just animals? Understanding variations in people's orientations to animals. Anthrozoos, 26(2), 279-284.

Borzekowski, D. L. G., Robinson, T. N., \& Killen, J. D. (2000). Does the camera add 10 pounds? Media use, perceived importance of appearance, and weight concerns among teenage girls. Journal of Adolescent Health, 26, 36-41.

Brixval, C. S., Rayce, S. L. B., Rasmussen, M., Holstein, B. E., \& Due, P. (2011). Overweight, body image and bullying- an epidemiological study of 11- to 15-year olds. European Journal of Public Health, 22(1), 126-130. doi:10.1093/eurpub/ckr010

Brown, K. M. \& Marshall, M. A. (2006). The three faces of self-esteem. In M. H. Kernis (Ed.), Self-Esteem Issues and Answers (pp. 4-9).

Brown, K. M., McMahon, R. P., Biro, F. M., Crawford, P., Schreiber, G. B., Similo, S. L., ...Striegel-Moore, R. (1998). Changes in self-esteem in black and white girls between the ages of 9 and 14 years: The NHLBI growth and health study. Journal of Adolescent Health, 23(1), 1-19. doi: 10.1016/S1054-139X(97)00238-3

Brownell, K. D., Puhl, R. M., Schwartz, M. B., \& Rudd, L. (2005). Weight bias. New York: The Guilford Press. 
Bryant, B. K. (1985). The neighborhood walk: A study of sources of support in middle childhood from the child's perspective. Monographs of the Society for Research in Child Development, 50(3), 1-114.

Bryant, B. K. (1990). The richness of the child-pet relationship: A consideration of both benefits and costs of pets to children. Anthrozoos, 3(4), 253-261.

Burns, C. E., Barber, N., Brady, M. A., \& Dunn, A. M. (Eds.). (1996). Vegetarian diets, pediatric primary care: A handbook for nurse practitioners.(pp. 54-67). Philadelphia, PA : W.B. Saunders.

Burrows, A. \& Cooper, M. (2002). Possible risk factors in the development of eating disorders in overweight pre-adolescent girls. International Journal of Obesity, 26, 1268-1273. doi: 10.1038/sj.ijo.0802033

Butler, R. J. \& Gasson, S. L. (2005). Self esteem/self concept scales for children and adolescents: A review. Child and Adolescent Mental Health, 10(4), 190-201.

Cain, A. O. (1983). A study of pets in the family system. In A. H. Katcher \& A. M. Beck (Eds), New perspectives on our lives with companion animals (pp. 351-359), Philadelphia: University of Pennsylvania Press.

Cameron, J. W. (1999). Self-esteem changes in children enrolled in weight management programs. Issues in Comprehensive Pediatric Nursing, 22, 75-85.

Cameron, N., Jones, L. L., Griffiths, P. L., Norris, S. A., \& Pettifor, J. M. (2009). How well do waist circumference and body mass index reflect body composition in pre-pubertal children? European Journal of Clinical Nutrition, 63, 1065-1070. doi: $10.1038 /$ ejen.2009.26

Carless, D. \& Fox, K. (2003). The physical self. In T. Everett, M. Donaghy, \& S. Feaver (Eds.), Interventions for Mental Health: An evidence-based approach for physiotherapists and occupational therapists, St. Louis: Elsevier.

Centers for Disease Control and Prevention. (2009). Growth charts. [z-score data files]. Retrieved from http://www.cdc.gov/growthcharts/zscore.htm

Centers for Disease Control and Prevention. (2010). Economic consequences [Fact sheet]. Retrieved from http://www.cdc.gov/obesity/causes/economics.html

Cohen, J. (1992). A power primer. Psychological Bulletin, 112(1), 155-159.

Cohen, S. P. (2002). Can pets function as family members? Western Journal of Nursing Research, 24(6), 621-638. 
Cole, T. J. (2000). Secular trends in growth. Proceedings of the Nutrition Society, 59(02), 317-324.

Cole, T. J. (2006). Childhood obesity: Assessment and Prevalence. In N. Cameron, N. G. Norgan, \& G. T. H. Ellison (Eds.). Childhood obesity: Contemporary issues. (pp.3-12). New York: Taylor \& Francis.

Cole, T. J., Bellizzi, M. C., Flegal, K. M., \& Dietz, W. H. (2000). Establishing a standard definition for child overweight and obesity worldwide: International survey. $B M J$, $320,1-6$.

Cooley, C. H. (1902). Human nature and the social order. Retrieved from https://archive.org/details/humannaturesocia00cooluoft

Coopersmith, S. (1967). The antecedents of self esteem. San Francisco: W H Freeman.

Copeland, K. C., Silverstein, J., Moore, K. R., Prazar, G. E., Raymer, T., Shiffman, R. N., ....Flinn, S. K. (2013). Management of newly diagnosed type 2 diabetes mellitus (T2DM) in children and adolescents. Pediatrics, 131(2), 364-382.

Cornette, R. (2008). The emotional impact of obesity on children. Worldviews on Evidence-Based Nursing, 5(3), 136-141.

Cramer, P. \& Steinwert, T. (1998). Thin is good, fat is bad: How early does it begin? Journal of Applied Developmental Psychology, 19(3), 429-451.

Crandall, C. S. (1991). Prejudice against fat people: ideology and self-interest. Journal of Personality and Social Psychology, 66(5), 882-894.

Crandall, C. S. (1995). Do parents discriminate against their heavyweight daughters? Personality and Social Psychology Bulletin, 21(7), 724-735. doi:10.1177/0146167295217007

Crocker, J. \& Garcia, J. A. (2006). Stigma and the social basis of the self: A synthesis. In S. Levin \& van Laar, C. (Eds.), Stigma and group equality: Social psychological perspectives (pp. 287-309). Mahwah, New Jersey: Lawrence Erlbaum Associates.

Crocker, J. \& Park, L. E. (2004). The costly pursuit of self-esteem. Psychological Bulletin, 130(3), 392-414.

Cunningham, S. A., Kramer, M. R., \& Narayan, K. M. (2014). Incidence of childhood obesity in the United States. The New England Journal of Medicine, 370(5), 403411. 
Cusumano, D. L. \& Thompson, K. J. (2001). Media influence and body image in 8-11year-old boys and girls: A preliminary report on the multidimensional media influence scale. International Journal of Eating Disorder, 29(1), 37-44.

Daniels, S. R. (2005). Complications of obesity in children and adolescents. International Journal of Obesity, 33, S60-S65.

Davis, J. H. (1987). Preadolescent self-concept development and pet ownership. Anthrozoos, 1(2), 90-94.

Davis, J. H. \& Juhasz, A. M. (1985). The preadolescent/pet bond and psychosocial development. Marriage and Family Review, 8(3), 79-94.

Davison, K. K. \& Birch, L. L. (2001). Weight status, parent reaction, and self-concept in five-year-old girls. Pediatrics, 107(1), 46-53. doi: 10.1542/peds.107.1.46

Davison, K. K. \& Birch, L. L. (2002). Processes linking weight status and self-concept among girls from ages 5 to 7 years. Developmental Psychology, 38(5), 735-748. doi: $10.1037 / / 0012-1649.38 .5 .735$

Davison, K. K. \& Birch, L. L. (2004). Predictors of fat stereo-types among 9-year-old girls and their parents. Obesity Research, 12(1), 86-94.

Dembicki, D. \& Anderson, J. (1996). Pet ownership may be a factor in improved health of the elderly. Journal of Nutrition for the Elderly, 15(3), 15-31.

Dietz, W. H. (1998). Health consequences of obesity in youth: Childhood predictors of adult disease. Pediatrics, 101(S2), 518-525.

Dietz, W. H. \& Bellizzi, M. C. (1999). Introduction: The use of body mass index to assess obesity in children. The American Journal of Clinical Nutrition, 70(1), $123 \mathrm{~s}-125 \mathrm{~s}$.

Dohnt, H. K. \& Tiggemann, M. (2005). Peer influences on body dissatisfaction and dieting awareness in young girls. British Journal of Developmental Psychology, 23, 103-116.

Dohnt, H. K. \& Tiggemann, M. (2006a). Body image concerns in young girls: The role of peers and media prior to adolescence. Journal of Youth and Adolescence, 35(2), 141-151. doi:10.1007/s10964-005-9020-7

Dohnt, H. K. \& Tiggemann, M. (2006b). The contribution of peer and media influences to the development of body satisfaction and self-esteem in young girls: A prospective study. Developmental Psychology, 42(5), 929-936. doi:10.1037/00121649.42.5.929 
Eddy, T. J. (1996). RM and Beaux: Reductions in cardiac activity in response to a pet snake. The Journal of Nervous and Mental Disease, 184(9), 573-575.

Eisenberg, M. E., Neumark-Sztainer, D., \& Story, M. (2003). Associations of weightbased teasing and emotional well-being among adolescents. Archives of Pediatric Adolescent Medicine, 157, 733-738.

Fabricatore, A. N. \& Wadden, T. A. (2004). Psychological aspects of obesity. Clinics in Dermatology, 22, 332-337.

Farley, A. J., Lopez, B., \& Saunders, G. (2010). Self-conceptualisation in autism: Knowing oneself versus knowing self-through-other. Autism. doi: $10.1177 / 1362361310368536$

Felker, D. A. (1968). Relationship between self-concept, body build, and perception of father's interest in sports in boys. Research Quarterly, 39(3), 513-517. doi: 10.1080/10671188.1968.10616573

Fikkan, J. \& Rothblum, E. (2005). Weight bias in employment. In K. D. Brownell, R. M. Puhl, M. B. Schwartz, \& L. Rudd (Eds.), Weight Bias (pp. 15-28). New York, NY: The Guilford Press.

Firmin, M., Smith, S, \& Perry, L. (2006). School uniforms: A qualitative analysis of aims and accomplishments at two Christian schools. Journal of Research on Christian Education, 15(2), 143-168.

Fischer, K. W. (1980). A theory of cognitive development: The control and construction of hierarchies of self. Psychological Review, 87(6), 477.

Fisher, J. O. \& Birch, L. L. (1999). Restricting access to foods and children's eating. Appetite, 32(3), 405-419.

Flannery-Schroeder, E. C., \& Chrisler, J. C. (1996). Body esteem, eating attitudes, and gender-role orientation in three age groups of children. Current Psychology, 15(3), 235-248.

Folse, E. B., Minder, C. C., Aycock, M. J., \& Santana, R. T. (1994). Animal-assisted therapy and depression in adult college students. Anthrozoos, 7(3), 188-194.

Foster, L. \& Page, A. (2006). Self-perceptions and physical activity behavior of obese young people. In N. Cameron, N. G. Norgan, \& G. T. H. Ellison (Eds.). Childhood obesity: Contemporary issue.(pp 51-64). New York: Taylor \& Francis.

Fouts, G. \& Burggraf, K. (1999). Television situations comedies: Female body images and verbal reinforcements. Sex Roles, 40(5), 473-481. 
Fouts, G. \& Burggraf, K. (2000). Television situation comedies: Female weight, male negative comments, and audience reactions. Sex Roles, 42(9), 925-932.

Fox, C. L. \& Farrow, C. V. (2009). Global and physical self-esteem and body dissatisfaction as mediators of the relationship between weight status and being a victim of bullying. Journal of Adolescence, 32, 1287-1301. doi: 10.1016/j.adolescence.2008.12.006

Franklin, J., Denyer, G., Steinbeck, K. S., Caterson, I. D., \& Hill, A. J. (2006). Obesity and risk of low self-esteem: A statewide survey of Australian children. Pediatrics, 118, 2481-2487. doi:10.1542/peds.2006-0511

French, S. A., Perry, C. L., Leon, G. R., \& Fulkerson, J. A. (1996). Self-esteem and change in body mass index over 3 years in a cohort of adolescents. Obesity Research, 4(1), 27-33.

French, S. A., Story, M., \& Perry, C. L. (1995). Self-esteem and obesity in children and adolescents: A literature review. Obesity Research 3(5), 479-490.

Friedmann, E., Katcher, A. H., Lynch, J. J., \& Thomas, S. A. (1980). Animal companions and one-year survival of patients after discharge from a coronary care unit. Public Health Reports, 95(4), 307-312.

Friedmann, E., Katcher, A. H., Thomas, S. A., Lynch, J. J., \& Messent, P. R. (1983). Social interaction and blood pressure influence of animal companions. The Journal of Nervous and Mental Disease, 171(8), 461-465.

Friedmann, E. \& Son, H. (2009). The human-companion animal bond: How humans benefit. Veterinary Clinics of North America, 39, 293-326.

Friedmann, E. \& Thomas, S. A. (1995). Pet ownership, social support, and one-year survival after acute myocardial infarction in the cardiac arrhythmia suppression troll. The American Journal of Cardiology, 76(17), 1213-1217.

Gabelko, N.H., Roth, D.A., \& Worrell, F.C. (1997, March). Age and gender differences in global, academic, social, and athletic self-concepts in academically talented students. Paper presented at the annual meeting of the American Educational Research Association, Chicago, IL.

Gable, S., Krull, J. L., \& Srikanta, A. (2008). Childhood overweight and academic achievement. In H. E. Fitzgerald \& V. Mousouli (Eds.), Obesity in childhood and adolescence (pp. 49-72). Westport, Connecticut: Praeger Perspectives.

Gapinski, K. D., Brownell, K. D., \& LaFrance, M. (2003). Body objectification and "fat talk": Effects on emotion, motivation, and cognitive performance. Sex Roles, 48(9), 377-388. 
Gapinski, K. D., Schwartz, M. B., \& Brownell, K. D. (2006). Can television change antifat attitudes and behavior? Journal of Applied Biobehavioral Research, 11(1), 128.

Garner, D. M., Garfinkel, P. M., Schwartz, D., \& Thompson, M. (1980). Cultural expectations of thinness in women. Psychological Reports, 47(2), 483-491. doi:10.2466/pr0.1980.47.2.483

Goodman, E., Hinden, B. R., \& Khandelwal, S. (2000). Accuracy of teen and parental reports of obesity and body mass index. Pediatrics, 106(1), 52-58.

Gortmaker, S. L., Must, A., Perrin, J. M., Sobol, A. M., \& Dietz, W. H. (1993). Social and economic consequences of overweight in adolescence and young adulthood. The New England Journal of Medicine, 329(14), 1008-1012. Retrieved from http://content.nejm.org/cgi/content/full/329/14/1008

Granleese, J. \& Joseph, S. (1994). Reliability of the Harter self-perception profile for children and predictors of global self-worth. The Journal of Genetic Psychology, 155(4), 487-492.

Greenberg, B. S., Eastin, M., Hofschire, L., Lachlan, K., \& Brownell, K. D. (2003). Portrayals of overweight and obese individuals on commercial television. American Journal of Public Health, 93(8), 1342-1348.

Greenberg, B. S. \& Worrell, T. R. (2005). The portrayal of weight in the media and its social impact. In K. D. Brownell, R. M. Puhl, M. B. Schwartz, \& Rudd, L. (Eds.), Weight bias: Nature, consequences, and remedies (pp. 42-53). New York: Guilford Press.

Griffiths, L. J., Wolke, D., Page, A. S., \& Horwood, J. P. (2006). Obesity and bullying: Different effects for boys and girls. Archives of disease in Childhood, 91, 121125. doi: 10.1136/adc.2005.072314

Hansen, K. M., Messinger, C. J., Baun, M. M., \& Megel, M. (1999). Companion animals alleviating distress in children. Anthrozoos, 12(3), 142-148.

Harrison, K. (2000). Television viewing, fat stereotyping, body shape standards, and eating disorder symptomatology in grade school children. Communication Research, 27(5), 617-640.

Harter, S. (1982). The perceived competence scale for children. Child Development, 53, 87-97.

Harter, S. (1985). Manual for the Self-Perception Profile for Children. University of Denver. 
Harter, S. (1990). Self and identity development. Cambridge, MA: Harvard University Press.

Harter, S. (1999). The construction of the self. New York: Guilford Press.

Harter, S. (2004). The developmental emergence of self-esteem: Individual differences in change and stability. In D. Mrozek \& T. Little (Eds.), The handbook of personality development. Hillside, New Jersey: Lawrence Erlbaum Associates, Inc.

Harter, S. (2006). The self. Handbook of child psychology. doi:10.1002/9780470147658.chpsy0309

Harter, S. (2008). The developing self. In W. Damon \& R. M. Lerner (Eds.), Child anda adolescent development: An advanced course (pp. 216-262). Hoboken, New Jersey: John Wiley \& Sons.

Harter, S. (2012). Self-perception profile for children: Manual and questionnaires. Denver CO: University of Denver.

Harter, S., Bresnick, S., Bouchey, H., \& Whitesell, N. R. (1997). The development of multiple role-related selves during adolescence. Development and Psychopathology, 9(4), 835-853.

Harter, S. \& Pike, R. (1984). The pictorial scale of perceived competence and social acceptance for young children. Child Development, 55(6), 1969-1982. doi: $10.2307 / 1129772$

Havener, L., Gentes, L., Thaler, B., Megel, M. E., Baun, M. M., Driscoll, F. A.,... Agrawal, S. (2001). The effects of a companion animal on distress in children undergoing dental procedures. Issues in Comprehensive Pediatric Nursing, 24, 137-152.

Hawker, D. S. J. \& Boulton, M. J. (2000). Twenty years' research on peer victimization and psychosocial maladjustment: A meta-analytic review of cross sectional studies. The Journal of Child Psychology and Psychiatry. 41(4), 441-455. doi:10.1111/1469-7610.00629

Hernán, M. A., Hernández-Diaz, S., \& Robins, J. M. (2004). A structural approach to selection bias. Epidemiology, 15(5), 615-625. doi:10.1097/01.ede.0000135174.63482.43

Higgins, E. T. (1991). Development of self-regulatory and self-evaluative processes: Costs, benefits, and tradeoffs. In M. R. Gunnar \& A. L. Sroufe. The Minnesota symposia on child psychology. 
Hill, A. (2006). Social and self-perception of obese children and adolescents. In N. Cameron, N. G. Norgan, \& G. T. H. Ellison (Eds.), Childhood obesity: Contemporary issues (pp. 39-50). Boca Raton, FL: Taylor \& Francis Group.

Humphries, T. L. (2003). Effectiveness of dolphin assisted therapy as a behavioral intervention for children with disabilities. Bridges, 1(6), 1-9.

Israel, A. C. \& Ivanova, M. Y. (2002). Global and dimensional self-esteem in preadolescent and early adolescent children who are overweight: Age and gender differences. International Journal of Eating Disorders, 31(4), 424-429.

Jaballas, E., Clark-Ott, D., Clasen, C., Stolfi, A., \& Urban, M. (2011). Parent's perceptions of their children's weight, eating habits, and physical activities at home and at school. Journal of Pediatric Health, 25(5), 294-301.

Jackson, D., Mannix, J., Faga, P., McDonald, G. (2005). Overweight and obese children: mother's strategies. Journal of Advanced Nursing Practice. 52(1), 6-13.

James, W. (1890). The principles of psychology. Retrieved from http://psychclassics.yorku.ca/James/Principles/index.htm

Jeynes, W. H. (2007). The relationship between parental involvement and urban secondary school student academic achievement: A meta-analysis. Urban Education, 42(1), 82-110. doi: 10.1177/004208590629381

Johnson, D. W., Johnson, R. T., \& Rynders, J. (1981). Effect of cooperative, competitive, and individualistic experiences on self-esteem of handicapped and nonhandicapped students. The Journal of Psychology: Interdisciplinary and Applied, 108(1), 31-34.

Johnson, R. A. \& Meadows, R. L. (2010). Dog walking: Motivation for adherence to a walking program. Clinical Nursing Research, 19(4), 387-402. doi: $10.1177 / 1054773810373122$

Johnson, R. A., Odendaal, J. S., \& Meadows, R. Animal-assisted interventions research. Western Journal of Nursing Research, 24(4), 422-439.

Juhasz, A. M. (1985). Measuring self-esteem in early adolescents. Adolescence 20(80), 877-887.

Kagan, A. (2010). Type 2 Diabetes: Social and Scientific Origins, Medical Complications, and Implications for Patients and Others. Jefferson, NC: McFarland.

Kaplan, K. M. \& Wadden, T. A. (1986). Childhood obesity and self-esteem. The Journal of Pediatrics, 109(2), 367-370. 
Keery, H., Boutelle, K., van den Berg, P., \& Thompson, J. K. (2005). The impact of appearance-related teasing by family members. Journal of Adolescent Health, 37, $120-127$.

Kellar, S. P. \& Kelvin, E. A. (2012). Munro's statistical methods for health care research $\left(6^{\text {th }}\right.$ ed.). Philadelphia, PA: Lippincott.

Kernis, M. H. (1993). The roles of stability and level of self-esteem in psychological functioning. Self esteem: The puzzle of low self-regard (pp. 167-182). doi:10.1007/978-1-4684-8956-9_9

Kimm, S. Y. S., Barton, B. A., Berhane, K., Ross, J. W., Payne, G. H., \& Schreiber, G. B. (1997). Self-esteem and adiposity in black and white girls: The NHLBI growth and health study. Annals of Epidemiology, 7(8), 550-560. Doi:10.1016/S10472797(97)00124-5

Klein, D., Najman, J., Kohrman, A. F., \& Munro, C. (1982). Patient characteristics that elicit negative responses from family physicians. The Journal of Family Practice, 14(5), 881-888.

Klesges, R. C., Haddock, C. K., Stein, R. J., Klesges, L. M., Eck, L. H., \& Hanson, C. L. (1992). Relationship between psychosocial functioning and body fat in preschool children: A longitudinal investigation. Journal of Consulting and Clinical Psychology, 60(5), 793-796. doi.org/10.1037/0022-006X.60.5.793

Kurdek, L. A. (2008). Pet dogs as attachment figures. Journal of Social and Personal Relationships 25(2), 247-266.

Latner, J. D. \& Schwartz, M. B. (2005). Weight bias in a child's world. In K. D. Brownell, R. M. Puhl, M. B. Schwartz, \& L. Rudd (Eds.), Weight Bias (pp. 5467). New York, NY: The Guilford Press.

Latner, J. D. \& Stunkard, A. J. (2003). Getting worse: The stigmatization of obese children. Obesity Research, 11(3), 452-456.

Leahy, R. L. \& Shirk, S. R. (1985). Social cognition and the development of the self. The development of the self, Academic Press.

Leary, M. R. (1999). Making sense of self-esteem. Current Directions in Psychological Science, 8(1), 32-35.

Levinson, B. M. (1978). Pets and personality development. Psychological Reports, 42, 1031-1038. 
Lowes, J. \& Tiggemann, M. (2003). Body dissatisfaction, dieting awareness and the impact of parental influence in young children. British Journal of Health Psychology. 8(2), 135-147.

Lowes, J. \& Tiggemann, M. (2010). Body dissatisfaction, dieting awareness, and the impact of parenteral influence in young children. British Journal of Health Psychology, 8(2), 135-147. doi:10.1348/135910703321649123

Lumeng, J. C., Forrest, P., Appugliese, D. P., Kaciroti, N., Corwyn, N. K., Bradley, R. H. (2010). Weight status as predictor of being bullied in third through sixth grades. Pediatrics, 125(6), e1301-e1307.

Mei, Z., Grummer-Strawn, L. M., Pietrobelli, A., Goulding, A., Goran, M. I., \& Dietz, W. H. (2002). Validity of body mass index compared with other body composition screening indexes for the assessment of body fatness in children and adolescents. American Journal of Clinical Nutrition, 75, 978-985.

Melson, G. F. (1998). The role of companion animals in human development. Companion Animals in Human Health, 219-236.

Melson, G. F. (2002). Psychology and the study of human-animal relationships. Society \& Animals, 10(4), 347-352.

Melson, G. F. (2003). Child development and the human-companion animal bond. The American Behavioral Scientist, 47(1), 31-39.

Melson, G. F. \& Fogel, A. (1989). Children's ideas about animal young and their care: A reassessment of gender differences in the development of nurturance. Anthrozoos, 2(4), 265-273.

Melson, G. F., Kahn, Jr. P. H., Beck, A. M., Friedman, B., Roberts, T., \& Garrett, E. (2005). Robots as dogs? Children's interactions with the robotic dog AIBO and a live Australian shepherd. In CHI '05 extended abstracts on Human factors in computing systems (pp. 1649-1652). doi: 10.1145/1056808.1056988

Melson, G. F., Peet, S., \& Sparks, C. (1991). Children's attachment to their pets: Links to socio-emotional development. Children's Environments Quarterly, 55-65.

Melson, G. F., Schwarz, R. L., \& Beck, A. M. (1997). Importance of companion animals in children's lives- implications for veterinary practice. JAVMA, 211(12), 15121518 .

Mendelson, B. K. \& White, D. R. (1982). Development of self-body-esteem in overweight youngsters. Developmental Psychology, 21, 90-96. 
Mendelson, B. K., White, D. R., \& Mendelson, M. J. (1996). Self-esteem and body esteem: Effects of gender, age, and weight. Journal of Applied Developmental Psychology, 17, 321-346.

Miller, J. L. \& Levy, G. D. (1996). Gender role conflict, gender-typed characteristics, self-concepts, and sport socialization in female athletes and nonathletes. Sex Roles, 35(12), 111-122.

Moran, R. (1999). Evaluation and treatment of childhood obesity. American Family Physician, 59(4), 861-868.

Mruk, C. J. (2006). Defining self-esteem: An often overlooked issue with crucial implications. In M. H. Kernis (Ed.), Self-esteem Issues and Answers (pp. 10-15).

Nagasawa, M., Kikusui, T., Onaka, T., \& Ohta, M. (2009). Dog's gaze at its owner increases owner's urinary oxytocin during social interaction. Hormones and Behavior, 55, doi: 10.1016/j.yhbeh.2008.12.002

Narayan, K. M. V., Boyle, J. P., Thompson, T. J., Sorenson, S. W., \& Williamson, D. F. (2003). Lifetime risks for diabetes mellitus in the United States. JAMA, 290(14), 1884-1890.

Neiss, M. B., Sedikids, C., \& Stevenson, J. (2002). Self-esteem: A behavioural genetic perspective. European Journal of Personality, 16(5), 351-367. doi:0.1002/per.456

Neumark-Sztainer, D. \& Eisenberg, M. (2005). Weight bias in a teen's world. In K. D. Brownell, R. M. Puhl, M. B. Schwartz, \& L. Rudd (Eds.), Weight bias: Nature, consequences, and remedies (pp. 68-82). New York: The Guilford Press.

Neumark-Sztainer, D., Story, M., \& Harris, T. (1999). Beliefs and attitudes about obesity among teachers and school health care providers working with adolescents. Journal of Nutrition Education, 31(1), 3-9, doi:10.1016S0022-3182(99)70378-X

Nolan, C. J., Damm, P., \& Prentki, M. (2011). Type 2 diabetes across generations: From pathophysiology to prevention and management. The Lancet, 378(9786), 169-181.

O'Dea, J. A. (2006). Self-concept, self-esteem and body weight in adolescent females: A three-year longitudinal study. Journal of Health Psychology, 11, 599-611. doi: $10.1177 / 1359105306065020$

Odendaal, J. S. J. \& Meintjes, R. A. (2003). Neurophysical correlates of affiliative behaviour between humans and dogs. The Veterinary Journal, 165(3), 296-301.

Ogden, C. L., Carroll, M. D., Kit, B. K., \& Flegal, K. M. (2014). Prevalence of childhood and adult obesity in the United States, 2011-2012. Journal of American Medical Association, 311(8), 806-814. 
Ogden, C. L. \& Carroll, M. D. (2010). Prevalence of obesity among children and adolescents: United States, trends 1963-1965 through 2007-2008. Retrieved from http://www.cdc.gov/nchs/data/hestat/obesity_child_07_08/obesity_child_07_08.ht $\mathrm{m}$

O’Haire, M. E., McKenzie, S. J., McCune, S., \& Slaughter, V . (2013). Effects of animalassisted activities with guinea pigs in the primary school classroom. Anthrozoos, 26(3), 445-458.

O’Loughlin, J., Gray-Donald, K., Paradis, G., \& Meshefedjian, G. (2000). One- and twoyear predictors of excess weight gain among elementary schoolchildren in multiethnic, low income, inner-city neighborhoods. American Journal of Epidemiology, 152(8), 739-746.

Phares, V., Steinberg, A. R., Thompson, J. K. (2004). Gender differences in peer and parental influences: Body image disturbance, self-worth, and psychological functioning in preadolescent children. Journal of Youth and Adolescence, 33(5), 421-429.

Phillips, R. G. \& Hill, A. J. (1998). Fat, plain, but not friendless: Self-esteem and peer acceptance of obese pre-adolescent girls. International Journal of Obesity, 22, 287-293.

Piers, E. V. \& Harris, D. B. (1964). Age and other correlates of self-concept in children. Journal of Educational Psychology, 55(2), 91-95.

Pierce, J. W. \& Wardle, J. (1997). Cause and effects beliefs and self-esteem of overweight children. The Journal of Child Psychiatry and Psychology, 38(6), 645-650.

Polit, D. F. \& Beck, C. T. (2008). Nursing Research. Philadelphia, PA: Lippincott.

Porter, J. S., Stern, M., Mazzeo, S. E., Evans, R. K., \& Laver, J. (2013). Relations among teasing, body satisfaction, self-estee, and depression in treatment-seeking obese African-American adolescents. Journal of Black Psychology, 39(4), 375-395. doi: $10.1177 / 0095798412454680$

Puhl, R. M. \& Latner, J. D. (2007). Stigma, obesity, and the health of the nation's children. Psychological Bulletin, 133(4), 557-580. doi: 10.1037/00332909.133.4.557

Reilly, J. J. (2002). Assessment of childhood obesity: National reference data or international approach? Obesity, 10(8), 838-840. doi: 10.1038/oby.2002.113

Roenke, L. \& Mulligan, S. (1998). The therapeutic value of the human-animal connection. Occupational Therapy in Health Care, 11(2), 27-43. 
Reulbach, U., Ladewig, E. L., Nixon, E., O’Moore, M., Williams, J., \& O’Dowd, T. (2013). Weight, body image and bullying in 9-year old children. Journal of Paediatrics and Child Health, 49, E288-E293. doi: 10.1111/jpc.12159

Rew, L. (2000). Friends and pets as companions: Strategies for coping with loneliness among homeless youth. Journal of Child \& Adolescent Psychiatric Nursing, 13(3), 125-132.

Ricciardelli, L. A., \& McCabe, M. P. (2001). Children's body image concerns and eating disturbance: A review of the literature. Clinical psychology review, 21(3), 325344.

Ridgers, N. D., Fazey, D. M. A., \& Fairclough, S. J. (2007). Perceptions of athletic competence and fear of negative evaluations during physical activity. British Journal of Educational Psychology, 77(2), 339-349.

Russell-Mayhew, S., McVey, G., Bardick, A., \& Ireland, A. (2012). Mental health, wellness and childhood overweight/obesity. Journal of Obesity. doi:10.1155/2012/281801

Sardinha, L. B., Going. S. B., Teixeira, P. J., \& Lohman, T. G. (1999). Receiver operating characteristic analysis of body mass index, triceps skinfold thickness, and arm girth for obesity screening in children and adolescents. The American Journal of Clinical Nutrition, 70(6), 1090-1095.

Serpell, J. (1991). Beneficial effects of pet ownership on some aspects of human health and behavior. The Journal of the Royal Society of Medicine, 84(12), 717-720. doi: 10.1177/014107689108401209

Shavelson, R. J., Hubner, J. J., \& Stanton, G. C. (1976). Self-concept: Validation of construct interpretation. Review of Educational Research, 46(3), 407-441.

Sherry, B., Jefferds, M. E., \& Grummer-Strawn, L. M. (2007). Accuracy of adolescent self-report of height and weight in assessing overweight status: A literature review. JAMA Pediatrics, 161(12), 1154-1161. doi:10.1001/archpedi.161.12.1154

Shrewsbury, V. \& Wardle, J. (2008). Socioeconomic status and adiposity in childhood: A systemic review of cross-sectional studies 1990-2005. Obesity a Research Journal, 16(2), 275-284. doi:10.1038/oby.2007.35

Sjoberg, R. L., Nilsson, K. W., \& Leppert, J. (2005). Obesity, shame, and depression in school-aged children: A population based study. Pediatrics, 116(3), 389-392. doi: 10.1542/peds.2005-0170

Sobal, J. (2005). Social consequences of weight bias by partners, friends, and strangers. In K. D. Brownell, R. M. Puhl, M. B. Schwartz, \& L. Rudd (Eds.), Weight Bias (pp. 150-164). New York, NY: The Guilford Press. 
Speiser, P. W., Rudolf, M. C. J., Anhalt, H., Camacho-Hubner, C., Chiarelli, F.,...Hochberg, Z. (2005). Childhood obesity. Journal of Clinical Endocrinology, 90(3), 1871-1887.

Staats, S., Sears, K., \& Pierfelice, L. (2006). Teachers' pets and why they have them: An investigation of the human animal bond. Journal of Applied Social Psychology, 36(8), 1881-1891.

Stettler, N., Signer, T. M., \& Suter, P. M. (2004). Electronic games and environmental factors associated with childhood obesity in Switzerland. Obesity Research, 12(6), 896-903.

Stradmeijer, M., Bosch, J., Koops, W., \& Seidell, J. (2000). Family functioning and psychosocial adjustment in overweight youngsters. International Journal of Eating Disorders, 27(1), 110-114.

Strauss, R. S. (2000). Childhood obesity and self-esteem. Pediatrics, 105(1) doi:10.1542/peds.105.1.e.15

Strauss, R. S. \& Pollack, H. A. (2003). Social marginalization of overweight children. Archives of Pediatrics and Adolescent Medicine, 157(8), 746-752. Retrieved from http://gateway.ut.ovid.com/gw2/ovidweb.cgi

Swann, W. \& Seyle, D. (2006). The antecedents of self-esteem. In: M. H. Kernis (Ed.), Self-Esteem Issues and Answers (pp. 201-207). New York: Psychology Press.

Taylor, P., Funk, C., \& Craighill, P. (2006). Dogs edge cats (dads trail both). Retrieved from http://www.pewsocialtrends.org/2006/03/07/gauging-family-intimacy/

Teachman, B. A. \& Brownell, K. D. (2001). Implicit anti-fat bias among healthcare professions: Is anyone immune? International Journal of Obesity, 25(10), 15251531.

Tiggemann, M. \& Anesbury, T. (2000). Negative stereotyping of obesity in children: The role of controllability beliefs. Journal of Applied Social Psychology, 30(9), 19771993.

Tiggemann, M. \& Pennington, B. (1990). The development of gender differences in body-size dissatisfaction. Australian Psychologist, 25(3), 306-313.

Tiggeemann, M. \& Wilson-Barrett, E. (1998). Children's figure ratings: relationship to self-esteem and negative stereotyping. International Journal of Eating Disorders, 23(1), 83-88. 
Triebenbacher, S. L. (1998a). The relationship between attachment to companion animals and self-esteem. In: C. C. Wilson \& D. C. Turner (Eds.). Companion Animals in Human Health, (pp. 135-148). California: Sage.

Triebenbacher, S. L. (1998b). Pets as transitional objects: Their role in children's emotional development. Psychological Reports, 82, 191-200.

Trost, S. G., Kerr, L. M., \& Pate, R. R. (2001). Physical activity and determinants of physical activity in obese and nonobese children. Obesity Research, 12(10), 1537-1538.

Valentine, D. Kiddoo, M., \& LaFleur, B. (1993). Psychosocial implications of service dog ownership for people who have mobility or hearing impairments. Social Work in Health Care, 19(1), 109-125.

Vandewater, E. A., Shim, M. S., \& Caplovitz, A. G. (2004). Linking obesity and activity level with children's television and video game use. Journal of Adolescence, 27(1), 71-85.

Van Houtte, B. A. \& Jarvis, P. A. (1985). The role of pets in preadolescent psychosocial development. Journal of Applied Developmental Psychology, 16(3), 463-479.

Veevers, J. E. (1985). The social meanings of pets: Alternative roles for companion animals. In: M. B. Sussman (Ed.). (1985). Pets and the family, (pp. 11-30). Philadelphia: Haworth Press.

Vegeulers, P. J. \& Fitzgerald, A. L. (2005). Prevalence of and risk factors for childhood overweight and obesity. Canadian Medical Association Journal, 173(6), 607-613.

Vidovic, V. V., Stetic, V. V., \& Bratko, D. (1999). Pet ownership, type of pet and socioemotional development of school children. Anthrozoos, 12(4), 211-217.

Wang, F. \& Veugelers, P. J. (2008). Self-esteem and cognitive development in the era of the childhood obesity epidemic. Obesity Reviews, 9, 615-623.

Wang, F., Wild, T. C., Kipp, S., Kuhle, S., \& Veugelers, P. J. (2009). The influence of childhood obesity on the development of self-esteem. Health Reports, 20(2), 2127.

Warschburger, P. (2005). The unhappy obese child. International Journal of Obesity, 29, S127-S129.

Wiseman, C., Gray, J., Mosimann, J. E., \& Ahrens, A. H. (1992). Cultural expectations of thinness in women: An update. International Journal of Eating Disorders, 11(1), 85-89. 
Zasloff, R. L. \& Kidd, A. H. (1994). Loneliness and pet ownership among single women. Psychological Reports, 75, 747-752. doi: 10.2466/pr0.1994.75.2.747

Zeller, M. H., Saelens, B. E., Roehrig, H., Kirk, S., Daniels, S. R. (2004). Psychological adjustment of obese youth presenting for weight management treatment. Obesity Research, 12(10), 1576-1586.

Zimmermann, M. B., Gubeli, C., Puntener, C., \& Molinari, L. (2004). Detection of overweight and obesity in a national sample of 6-12-y-old Swiss children: Accuracy and validity of reference values for body mass index from the US Centers for Disease Control and Prevention and the International Obesity Task Force. The American Journal of Clinical Nutrition, 79(5), 838-843.

Appendix A

CONSENT Form to PARTICIPATE IN A RESEARCH StUdY

Investigator's Name: Pam Evans-Smith

ProjeCT \#

Study Title: AN Evaluation Of THE RELATIONSHIPS BETWEen SELF-ESTEEM AND PeT

BONDING IN CHILDREN

INTRODUCTION

This consent may contain words that you do not understand. Please ask the investigator or the study staff to explain any words or information that you do not clearly understand. 
This is a research study. Research studies include only people who choose to participate. As a study participant you have the right to know about the procedures that will be used in this research study so that you can make the decision whether or not to participate. The information presented here is simply an effort to make you better informed so that you may give or withhold your consent to participate in this research study.

Please take your time to make your decision and discuss it with your family and friends.

Your child is being asked to take part in this study because they are between the ages of 8 and 11 years.

In order to participate in this study, it will be necessary to give your written consent.

\section{WHY IS THIS STUDY BEING DONE?}

The purpose of this study is to study the relationship between self-esteem and pet bonding in children especially those children who are overweight.

This research is being done because there is no information available about this possible relationship.

\section{How Many People Will Take Part In The Study?}

About 120 people will take part in this study in the Mid-Missouri region.

\section{WHAT IS INVOLVED IN THE STUDY?}

If you agree to allow your child to take part in this study, you will be asked to complete a questionnaire and sign a consent form allowing your child to participate in the study. Your child will be weighed and measured and will then be asked to complete a survey about their self-esteem. If your family owns a dog, your child will also be asked to complete a survey about their relationship with the dog.

\section{HOW LONG WILL I BE IN THE STUDY?}

It will take you about 10 minutes to fill out the questionnaire and sign the consent form. It will take your child approximately 30-45 minutes to complete the other questionnaires.

You or your child can stop participating at any time. You or your child's decision to withdraw from the study will not affect you or your child in any way including medical care.

\section{WHAT ARE THE RISKS OF THE STUDY?}


It is possible that the items on the survey may trigger painful or disturbing thoughts for your child. Your child will be told that they can stop at any time if they begin to feel stressed. There may be other risks that have not been identified. You may contact the investigator at 573-864-5098.

\section{Are There Benefits to Taking Part in the Study?}

If you agree to take part in this study, there may or may not be direct benefits to you or your child. Your child may expect to benefit from taking part in this research to the extent that they are contributing to a better understanding of the relationship between children and their dogs. We hope the information learned from this study will benefit other children in the future.

\section{What Other Options Are There?}

An alternative is to not allow your child to participate in the study.

\section{What ABOUt CONFIDENTIALITY?}

Information produced by this study will be stored in the investigator's file and identified by a code number only. The code key connecting your child's name to specific information about them will be kept in a separate, secure location. Information contained in your child's records may not be given to anyone unaffiliated with the study in a form that could identify your child without your written consent, except as required by law.

The results of this study may be published in a medical book or journal or used for teaching purposes. However, your child's name or other identifying information will not be used in any publication or teaching materials without your specific permission.

\section{What Are The COSTS?}

There is no cost to you or your child to participate in this study.

\section{Will I be PAid for Participating in The Study?}

Your child will receive no direct payment for taking part in this study. Your child will receive a gift card for a local department store worth a nominal amount upon completion of the questionnaire.

\section{WhAt ARE My Rights as A PARTiCiPANT?}

Participation in this study is voluntary. Your child does not have to participate in this study. Your child's present or future care will not be affected should you choose not to participate. If you decide to participate, you can change your mind and drop out of the study at any time without affecting your present or future care.

\section{Whom do I Call if I Have Questions or Problems?}


If you have any questions regarding your rights as a participant in this research and/or concerns about the study, or if you feel under any pressure to enroll or to continue to participate in this study, you may contact the University of Missouri Health Sciences Institutional Review Board (which is a group of people who review the research studies to protect participants' rights) at (573) 882-3181.

You may ask more questions about the study at any time. For questions about the study or a research-related injury, contact Pam Evans-Smith at 573 864-5098.

A copy of this consent form will be given to you to keep.

\section{Signature}

I confirm that the purpose of the research, the study procedures, the possible risks and discomforts as well as potential benefits that my child may experience have been explained to me. Alternatives to my child's participation in the study also have been discussed. I have read this consent form and my questions have been answered. My signature below indicates my willingness to allow my child to participate in this study.

Child's name

Parent's signature

Date

\section{Signature of Study Representative}

I have explained the purpose of the research, the study procedures, identifying those that are investigational, the possible risks and discomforts as well as potential benefits and have answered questions regarding the study to the best of my ability.

Study Representative

Date

Appendix B

\section{ASSENT Form To ParticiPate in a ReSEARCh StUdy}

Investigator's Name: Pam Evans-Smith

\section{ProjeCT \#}

Study Title: An Evaluation of THE RelationshiPs BetweEn SELF-Esteem AND Pet BONDING IN CHILDREN

This is a study about kid's and how they feel about themselves.

\section{Why YOU are invited}

You are invited to be in this study because you are between 8 and 11 years old. 


\section{What will happen?}

You will sit down with a member of the research team and answer some questions. Each question will be read to you and any words that you do not understand will be explained to you.

\section{Can anything bad happen to me?}

Some of the questions may make you remember things that are painful but you can quit answering questions at any time.

\section{Can anything good happen to me?}

This study won't cause anything good to happen to you but it may help us understand how kids feel about themselves.

\section{What if I don't want to do this?}

If you say you do not want to be in the study, you just have to tell us. No one will be mad at you. You can also say yes, and later if you change your mind, you can quit the study. The choice is up to you and your parents.

\section{Who will know my answers?}

The only people that will see your answers are members of the research team. Your parents will not see your answers.

Who can I talk to about the study?

You can ask questions any time. You can ask now. You can ask later.

\section{Do you have any questions about the study?}

YES

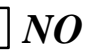

Do you want to be in the study?

YES 


\section{Appendix C}

What I Am Like

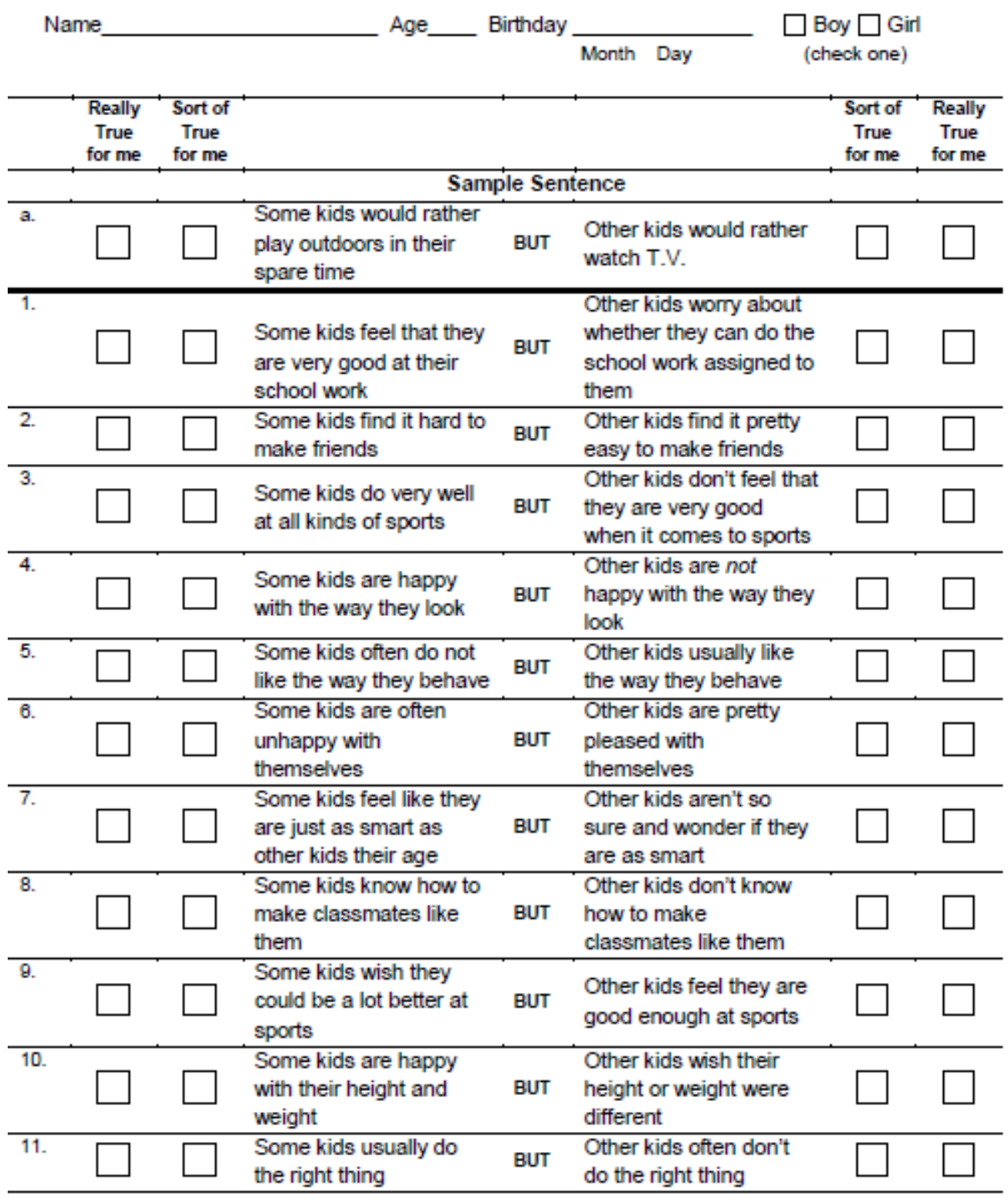




\begin{tabular}{|c|c|c|c|c|c|c|c|}
\hline & $\begin{array}{l}\text { Really } \\
\text { True } \\
\text { for me }\end{array}$ & $\begin{array}{l}\text { Sort of } \\
\text { True } \\
\text { for me }\end{array}$ & & & & $\begin{array}{l}\text { Sort of } \\
\text { True } \\
\text { for me }\end{array}$ & $\begin{array}{c}\text { Really } \\
\text { True } \\
\text { for me }\end{array}$ \\
\hline 12. & & & $\begin{array}{l}\text { Some kids don't like the } \\
\text { way they are leading } \\
\text { their life }\end{array}$ & BUT & $\begin{array}{l}\text { Other kids do like the } \\
\text { way they are leading } \\
\text { their life }\end{array}$ & & \\
\hline 13. & & & $\begin{array}{l}\text { Some kids are pretty } \\
\text { slow in finishing their } \\
\text { school work }\end{array}$ & BUT & $\begin{array}{l}\text { Other kids can do their } \\
\text { school work quickly }\end{array}$ & & \\
\hline 14. & & & $\begin{array}{l}\text { Some kids don't have } \\
\text { the social skills to make } \\
\text { friends }\end{array}$ & BUT & $\begin{array}{l}\text { Other kids do have the } \\
\text { social skills to make } \\
\text { friends }\end{array}$ & & \\
\hline 15. & & & $\begin{array}{l}\text { Some kids think they } \\
\text { could do well at just } \\
\text { about any new sports } \\
\text { activity they haven't tried } \\
\text { before }\end{array}$ & BUT & $\begin{array}{l}\text { Other kids are afraid } \\
\text { they might not do well at } \\
\text { sports they haven't ever } \\
\text { tried }\end{array}$ & & \\
\hline 16. & & & $\begin{array}{l}\text { Some kids wish their } \\
\text { body was different }\end{array}$ & BUT & $\begin{array}{l}\text { Other kids like their } \\
\text { body the way it is }\end{array}$ & & \\
\hline 17. & & & $\begin{array}{l}\text { Some kids usually act } \\
\text { the way they know they } \\
\text { are supposed to }\end{array}$ & BUT & $\begin{array}{l}\text { Other kids often don't } \\
\text { act the way they are } \\
\text { supposed to }\end{array}$ & & \\
\hline 18. & & & $\begin{array}{l}\text { Some kids are happy } \\
\text { with themselves as a } \\
\text { person }\end{array}$ & BUT & $\begin{array}{l}\text { Other kids are often not } \\
\text { happy with themselves }\end{array}$ & & \\
\hline 19. & & & $\begin{array}{l}\text { Some kids often forget } \\
\text { what they learn }\end{array}$ & BUT & $\begin{array}{l}\text { Other kids can } \\
\text { remember things easily }\end{array}$ & & \\
\hline 20. & & & $\begin{array}{l}\text { Some kids understand } \\
\text { how to get peers to } \\
\text { accept them }\end{array}$ & BUT & $\begin{array}{l}\text { Other kids don't } \\
\text { understand how to get } \\
\text { peers to accept them }\end{array}$ & & \\
\hline 21. & & & $\begin{array}{l}\text { Some kids feel that they } \\
\text { are better than others } \\
\text { their age at sports }\end{array}$ & BUT & $\begin{array}{l}\text { Other kids don't feel } \\
\text { they can play as well }\end{array}$ & & \\
\hline 22. & & & $\begin{array}{l}\text { Some kids wish their } \\
\text { physical appearance } \\
\text { (how they look) was } \\
\text { different }\end{array}$ & BUT & $\begin{array}{l}\text { Other kids like their } \\
\text { physical appearance the } \\
\text { way it is }\end{array}$ & & \\
\hline 23. & & & $\begin{array}{l}\text { Some kids usually get in } \\
\text { trouble because of } \\
\text { things they do }\end{array}$ & BUT & $\begin{array}{l}\text { Other kids usually don't } \\
\text { do things that get them } \\
\text { in trouble }\end{array}$ & & \\
\hline 24. & & & $\begin{array}{l}\text { Some kids like the kind } \\
\text { of person they are }\end{array}$ & BUT & $\begin{array}{l}\text { Other kids often wish } \\
\text { they were someone else }\end{array}$ & & \\
\hline
\end{tabular}




\begin{tabular}{|c|c|c|c|c|c|c|c|}
\hline & $\begin{array}{l}\text { Really } \\
\text { True } \\
\text { for me }\end{array}$ & $\begin{array}{l}\text { Sort of } \\
\text { True } \\
\text { for me }\end{array}$ & & & & $\begin{array}{l}\text { Sort of } \\
\text { True } \\
\text { for me }\end{array}$ & $\begin{array}{l}\text { Really } \\
\text { True } \\
\text { for me }\end{array}$ \\
\hline 25. & & & $\begin{array}{l}\text { Some kids do very well } \\
\text { at their classwork }\end{array}$ & BUT & $\begin{array}{l}\text { Other kids don't do very } \\
\text { well at their classwork }\end{array}$ & & \\
\hline 26. & & & $\begin{array}{l}\text { Some kids wish they } \\
\text { knew how to make more } \\
\text { friends }\end{array}$ & BUT & $\begin{array}{l}\text { Other kids know how to } \\
\text { make as many friends } \\
\text { as they want }\end{array}$ & & \\
\hline 27. & & & $\begin{array}{l}\text { In games and sports } \\
\text { some kids usually watch } \\
\text { instead of play }\end{array}$ & BUT & $\begin{array}{l}\text { Other kids usually play } \\
\text { rather than just watch }\end{array}$ & & \\
\hline 28. & & & $\begin{array}{l}\text { Some kids wish } \\
\text { something about their } \\
\text { face or hair looked } \\
\text { different }\end{array}$ & BUT & $\begin{array}{l}\text { Other kids like their face } \\
\text { and hair the way they } \\
\text { are }\end{array}$ & & \\
\hline 29. & & & $\begin{array}{l}\text { Some kids do things } \\
\text { they know they shouldn't } \\
\text { do }\end{array}$ & BUT & $\begin{array}{l}\text { Other kids hardly ever } \\
\text { do things they know } \\
\text { they shouldn't do }\end{array}$ & & \\
\hline 30. & & & $\begin{array}{l}\text { Some kids are very } \\
\text { happy being the way } \\
\text { they are }\end{array}$ & BUT & $\begin{array}{l}\text { Other kids wish they } \\
\text { were different }\end{array}$ & & \\
\hline 31. & & & $\begin{array}{l}\text { Some kids have trouble } \\
\text { figuring out the answers } \\
\text { in school }\end{array}$ & BUT & $\begin{array}{l}\text { Other kids almost } \\
\text { always can figure out } \\
\text { the answers }\end{array}$ & & \\
\hline 32. & & & $\begin{array}{l}\text { Some kids know how to } \\
\text { become popular }\end{array}$ & BUT & $\begin{array}{l}\text { Other kids do not know } \\
\text { how to become popular }\end{array}$ & & \\
\hline 33. & & & $\begin{array}{l}\text { Some kids don't do well } \\
\text { at new outdoor games }\end{array}$ & BUT & $\begin{array}{l}\text { Other kids are good at } \\
\text { new games right away }\end{array}$ & & \\
\hline 34. & & & $\begin{array}{l}\text { Some kids think that } \\
\text { they are good looking }\end{array}$ & BUT & $\begin{array}{l}\text { Other kids think that } \\
\text { they are not very good } \\
\text { looking }\end{array}$ & & \\
\hline 35. & & & $\begin{array}{l}\text { Some kids behave } \\
\text { themselves very well }\end{array}$ & BUT & $\begin{array}{l}\text { Other kids often find it } \\
\text { hard to behave } \\
\text { themselves }\end{array}$ & & \\
\hline 36. & & & $\begin{array}{l}\text { Some kids are not very } \\
\text { happy with the way they } \\
\text { do a lot of things }\end{array}$ & BUT & $\begin{array}{l}\text { Other kids think the way } \\
\text { they do things is fine }\end{array}$ & & \\
\hline
\end{tabular}

Susan Harter, Ph.D., University of Denver, 2012 


\section{Appendix D}

\section{Pet Bonding Scale}

Do you have a dog that lives in the house with you? Yes or No

What is this dog's name?

(Which dog is closest to being your friend?)

Answer these questions only about the dog that you named as closest to being your friend.

1. My pet can make me laugh.

2. I have a lot of fun with my pet.

3. My pet makes me feel important.

4. I have warm feelings when I think about my pet.

5. I like to spend a lot of time with my pet.

6. My pet loves me.

7. My pet misses me when I am gone.

8. I like to talk to my pet about things that are important to me.

9 I like to talk to my pet.

10 My pet understands my feelings.

11 I can tell secrets to my pets.

12 Sometimes my only friend is my pet.

13 My pet loves me no matter what.

14 One of my favorite things to do is spend time with my pet.

15 My pet is an important part of my family.

16 My pet understands what I say.

17 I would be very upset if something happened to my pet.

18 I try to protect my pet.

19 I keep pictures of my pet.

20 My pet stays close to me.

21 My pet has feelings.

22 I think about my pet when we are not together.

23 I miss my pet when I am gone.

24 My pet is important to me.

25 I am proud of my pet.

\begin{tabular}{|c|c|c|}
\hline Never & Usually ___ & Always \\
\hline Never & Usually __ & Always \\
\hline Never & Usually & Always \\
\hline Never & Usually & Always \\
\hline Never & Usually & Always \\
\hline Never & Usually & Always \\
\hline Never & Usually & Always \\
\hline Never & Usually & Always \\
\hline Never & Usually & Always \\
\hline Never & Usually & Always \\
\hline Never & Usually & Always \\
\hline Never & Usually & Always \\
\hline Never & Usually & Always \\
\hline Never & Usually & Always \\
\hline Never & Usually & Always \\
\hline Never & Usually & Always \\
\hline Never & Usually & Always \\
\hline Never & Usually & Always \\
\hline Never & Usually & Always \\
\hline Never & Usually & Always \\
\hline Never & Usually & Always \\
\hline Never & Usually & Always \\
\hline Never & Usually & Always \\
\hline Never & Usually & Always \\
\hline Never & Usually & Always \\
\hline
\end{tabular}


26 Do you help take care of your dog? Yes or No

\begin{tabular}{|c|c|c|c|c|}
\hline \multicolumn{5}{|c|}{$\begin{array}{l}\text { If you help take care of your dog which of the following are you responsible for and how often do } \\
\text { you complete the job? (Circle one choice for each line) }\end{array}$} \\
\hline 27 & Feed the dog & Everyday & Most days & Once or twice per week \\
\hline 28 & Walk the dog & Everyday & Most days & Once or twice per week \\
\hline 29 & Groom the dog & Everyday & Most days & Once or twice per week \\
\hline 30 & $\begin{array}{l}\text { Play outside } \\
\text { with the dog }\end{array}$ & Everyday & Most days & Once or twice per week \\
\hline 31 & $\begin{array}{l}\text { Play inside } \\
\text { with the dog }\end{array}$ & Everyday & Most days & Once or twice per week \\
\hline 32 & Clean up after the dog & Everyday & Most days & Once or twice per week \\
\hline
\end{tabular}

33 Who else helps take care of the

$\operatorname{dog}$ ?

34 Does your dog have a favorite family member? Yes or No

Who?

35 Do you have any other animals that you feel close to? Yes or No

If so what type of animal is it? 
Appendix E

ID\#

Demographics Questionnaire

Date:

What is the child's date of birth?:

1. What is the child's gender? (please circle): Male or Female

2. What grade is the child in? (please circle) $1^{\text {st }} 2^{\text {nd }} \quad 3^{\text {rd }} 4^{\text {th }} 5^{\text {th }} 6^{\text {th }}$

3. What is the household income prior to taxes? Include all sources of income (please circle):

Less than $25,0000 \quad 25,000-74,9999 \quad 75,000$ or more

4. What is your marital status? (please circle): Married Separated Divorced Widowed Single

5. How many people living in the house with the child are older than 18 years ?:

6. How many people living in the house with the child are younger than 18 years ?:

7. Who lives in the home with the child (circle all that apply):

Father Mother Step-father Step-mother Siblings (specify how many)

Grandparent Other:

8. What is the distance to the nearest neighbor? (please circle one):

25 feet $\quad 1$ block $\quad 1$ mile greater than 1 mile

9. What is the child's Ethnicity? (please circle one): Non Hispanic/ Latino Hispanic Latino

10. What is the child's Race (please circle all that apply):

White American Indian Alaskan Native Asian 
Black or African American Native Hawaiian or other Pacific Islander

11. Do you own a pet? Yes or No

If you answered no to the above question you are done with the questionnaire, if you answered yes to number 12 please continue.

Please continue on the back of this page.

12. Please circle all of the following pets that you own that live in the house.

Dog Cat Bird Guinea pig Hamster

Rat Fish Lizard Snake Turtle

Other:

If any of the above listed pets live in the child's bedroom please place an X over the name of the pet.

The rest of the survey should only be completed if you own a dog. If you do not own a dog you are finished with the survey.

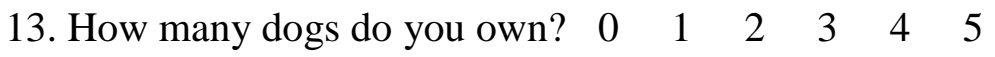

14. How many dogs live inside the house at least $50 \%$ of the time?

15. How long has the dog lived in the house? (if more than one dog in the house, choose the one that you have had the longest):

Less than 1 year 1 year 2 years 3 years 4 years 5 years greater than 5 years

16. If you have a dog that lives inside the house at least $50 \%$ of the time, how many hours a day does your child spends interacting with this dog?:

Less than $1 \quad 1 \quad 2 \quad 3 \quad 4 \quad$ greater than 5 
VITA

Pamela L. Evans-Smith was born May 16, 1968 in St. Louis, Missouri to Jack and Mary Lynn Evans. She graduated from Scott City High School, Scott City, Missouri in 1986. In 1991, she graduated from Moberly Area Community College, Moberly, Missouri. In 1998, she graduated from Central Methodist College, now known as Central Methodist University, Fayette, Missouri. In 2001, she graduated from University of Missouri, with a Master's degree in Nursing, Family Nurse Practitioner. She started the doctoral program in August of 2003 and completed the program in May of 2014.

During the course of her career, Pamela has worked in intensive care units, including both adults and pediatrics. She began teaching at the University of Missouri Sinclair School of Nursing in August of 2001. Pamela is the Alberty Richardson Fellow for Medical Surgical Nursing. She is the coordinator of the Accelerated Nursing option. Pamela plans to continue to teach in the undergraduate program at the Sinclair School of Nursing. 